UNIVERSIDADE DE SÃO PAULO

INSTITUTO DE GEOCIÊNCIAS

\title{
PROPOSTA PARA USO DO ERRO DE SUAVIZAÇÃO NA CLASSIFICAÇÃO DE
} RECURSOS MINERAIS

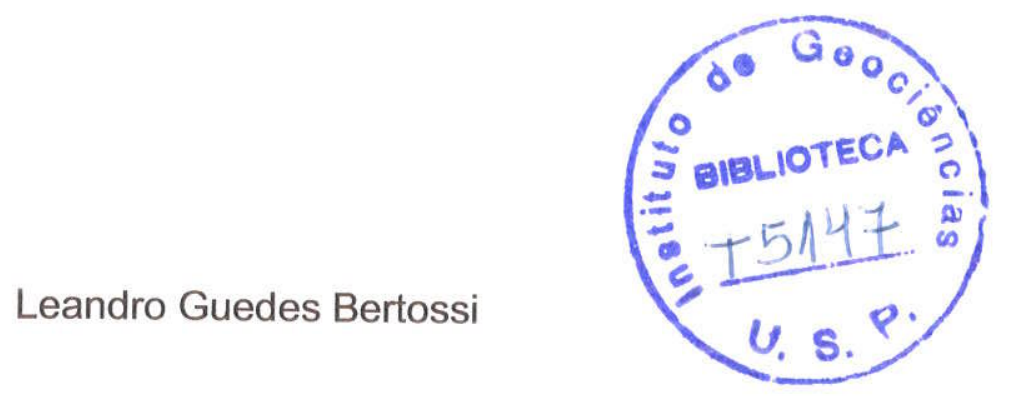

Orientador: Prof. Dr. Jorge Kazuo Yamamoto

\section{DISSERTAÇÃO DE MESTRADO}

Programa de Pós-Graduação em Recursos Minerais e Hidrogeologia

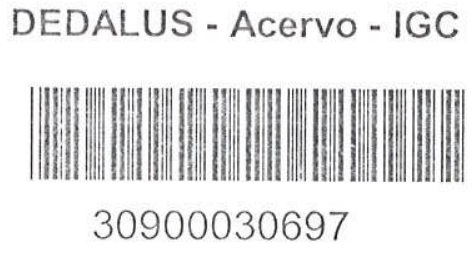

SÃO PAULO 


\section{AGRADECIMENTOS}

Ao Prof. Dr. Jorge Kazuo Yamamoto pela orientação nesse trabalho, pelas discussões sobre os temas aqui abordados, pelo auxilio nos momentos necessários e pela elaboração dos programas computacionais que permitiram o processamento dos cálculos aqui abordados.

Ao Prof. Dr. Marcelo Monteiro Rocha pelas discussões e auxilio prestado em determinados momentos durante a elaboração dessa dissertação.

Agradeço à Unimin do Brasil S/A e principalmente ao Cesar Castro pelo apoio prestado durante o periodo em que trabalhei nessa empresa, concedendo o tempo necessário para os estudos e incentivo. À Holcim (Brasil) S/A e principalmente ao Luiz Cláudio Bicalho Nepomuceno pelo apoio e compreensão nos momentos finais para a elaboração desse trabalho onde necessitei de mais tempo para executá-lo.

Agradeço ao irmão, amigo e geólogo Laércio Guedes Bertossi pelo inestimável apoio, pelas diversas discussões, ajuda e recomendações sobre o tema aqui apresentado. Ao amigo Fernando Machado Alves pelo incentivo e dicas que me auxiliaram na conclusão dessa dissertação.

À Ana Paula Abujamra Ferrari pelo carinho, incentivo, auxilio e também pela compreensão e paciência nos momentos de ausência.

E sempre à minha família pelo constante incentivo, carinho e apoio. 


\section{RESUMO}

BERTOSSI, L. B. Proposta para uso do erro de suavização na classificação de recursos minerais. 2011. 105 f. Dissertação (Mestrado) - Instituto de Geociências, Universidade de São Paulo, São Paulo, 2011.

A classificação de recursos minerais depende do conhecimento do depósito mineral. Tal conhecimento envolve volume, teores, densidade e mediçōes de outras variáveis para ter uma melhor descrição do corpo mineralizado como sua geometria e variação espacial de teores. Como podemos ver, existem diversos dados quantitativos que devem ser apropriadamente analisados para estimar os recursos minerais. A geoestatística é um ramo da estatística que vem sendo utilizado desde a década de 1960 para a avaliação de recursos minerais. A krigagem ordinária se tornou a técnica mais popular na indústria mineral para esse tipo de avaliação porque as estimativas apresentam boa relação com os dados da vizinhança. Além disso, a geoestatística foi a primeira técnica a fornecer uma medida de incerteza associada à estimativa. Essa incerteza nos dá uma idéia sobre o quanto conhecemos do depósito mineral e, portanto, temos que utilizá-la para fins de classificação dos recursos. Durante muitos anos a variância de krigagem foi utilizada para a classificação de recursos minerais. Entretanto, a variância de krigagem não poderia ser utilizada devido à sua natureza homoscedástica, pois depende apenas da configuração espacial entre as amostras. Assim, uma alternativa para o cálculo da incerteza de uma estimativa realizada por krigagem foi proposta e chamada de variância de interpolação. A variância de interpolação depende não só da configuração espacial, mas também dos valores das amostras utilizadas na estimativa. Nesse sentido, essa medida de incerieza fó considerada mais confível do que a variância de krigagem. Além disso, foi demonstrado que a variância de interpolação poderia ser combinada com o erro real, derivado do processo de validação cruzada para corrigir o efeito de suavização das estimativas realizadas pela krigagem. Essa dissertação examina o uso do erro de suavização para a classificação de recursos minerais. Uma aproximação clássica em geoestatística para a classificação dos recursos minerais é baseada no erro derivado do intervalo de confiança em torno das estimativas da krigagem ordinária. Esses dois métodos foram comparados e verificados com dados exaustivos. O erro de suavização provou ser superior à aproximação clássica para a classificação dos recursos minerais. 


\section{ABSTRACT}

BERTOSSI, L. B. Proposta para uso do erro de suavização na classificação de recursos minerais. 2011. 105 f. Dissertação (Mestrado) - Instituto de Geociências, Universidade de São Paulo, São Paulo, 2011.

Classification of mineral resources depends on the knowledge about the mineral deposit under study. Such knowledge involves volume, grades, density and other measurements made in order to have a better description of the ore body, including its geometry and spatial distribution of ore grades. As we can see there are a lot of quantitative data that has to be analyzed conveniently to estimate the mineral resources. Geostatistics is a branch of statistics that has been used since 60's for mineral resource evaluation. Ordinary kriging is the most popular technique used in the mineral industry for mineral resource estimation because estimates present a good correlation with neighbor data points. Besides, geostatistics was the first procedure concerned to give the associated uncertainty with the estimate. The uncertainty gives an idea about the knowledge about the mineral deposit and therefore we have to consider this variable for the purpose of mineral resource classification. For many years, the kriging variance was used for mineral resource classification. However, the kriging variance could not be used because its homoscedastic nature, that is it only depends on the spatial configuration of neighbor data points. Thus, an alternative uncertainty associated with the kriging estimate was proposed and named as interpolation variance. The interpolation variance depends on both spatial distribution and values of neighbor data points. In this sense, this measure of uncertainty was considered more reliable than the kriging variance. Moreover, it was shown that the interpolation variance could be combined with actual errors derived from the cross-validation procedure to correct the smoothing in kriging. This dissertation examines the use of the smoothing error for mineral resource classification. The classical approach for geostatistical mineral resource classification is based on the error derived from the confidence interval around the ordinary kriging estimate. These two approaches are compared and checked against exhaustive data. The smoothing error proved to be superior to the classical approach for mineral resource classification. 


\section{LISTA DE FIGURAS}

Figura 2.1 - Classificação de depósitos minerais adotada nos Estados Unidos em (Froidevaux, 1982).

Figura 2.2 - Sistema de classificação de depósitos minerais adotado no Canadá na década de 1970 (CIM, 2000)

Figura 2.3 - Sistema de classificação de depósitos minerais adotado após o Acordo de Genebra (CRIRSCO, 2006).

Figura 2.4 - Sistema de classificação de depósitos minerais adotado na Rússia e alguns países do Leste europeu e Ásia. (Henley, 2000).

Figura 2.5 - Sistema de classificação de depósitos minerais adotado pelo Brasil (DNPM, 1992).

Figura 3.1 - Exemplos de interpretação do limite do corpo mineralizado por extrapolação a partir do último furo de sonda com intervalo mineralizado. A) Interpretação otimista com o limite a $3 / 4$ de distância entre os furos. B) Interpretação conservadora com 0 limite a $1 / 4$ de distância entre os furos. C) Interpretação padrão com o limite na distância média entre os furos. Considerando a área do corpo entre o ultimo furo mineralizado e o limite (área hachurada). A) corresponde a uma área $31 \%$ maior que a interpretação padrão (C). B) representa apenas $56 \%$ da área mineralizada da interpretação padrão (C).

Figura 3.2 - Exemplo de um furo de sonda com desvio de $1^{\circ}$ a cada 50 metros interpretado como furo sem desvio. Após 500 metros de perfuração a diferença entre a real locação e a interpretação è de aproximadamente 41 metros.

Figura 5.1 - Representação esquemática dos resultados da distribuição da incerteza para uma localização $u$. Linhas contínuas e tracejadas representam incertezas locais obtido por duas abordagens diferentes (ex. krigagem ordinária e inverso da distância). A área vermelha é a sobreposição. (Babak; Deutsch, 2008).

Figura 5.2 - Estimativa de blocos a partir da mesma configuração de dados. (Armstrong, 1994). Em (A), a variância do erro deveria ser menor que em (B) por causa de dados mais consistentes.

Figura 6.1 - Mapas imagens das bases de dados exaustivas: A: LOG5; B: LOG10; C:

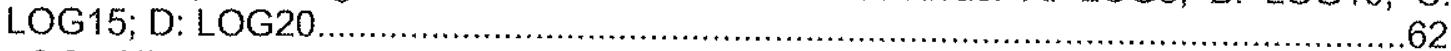

Figura 6.2 -- Histograma das bases de dados exaustiva: A: LOG5; B: LOG10; C: LOG15; D: LOG20.

Figura 6.3 - Mapas de localização das amostras aleatónias estratificadas. A: amostra da base LOG5; B: amostra da base LOG10; C: amostra da base LOG15 e D: amostra da base LOG20.

Figura 6.4 - Histograma das amostras aleatórias estratificadas: A: LOG5; B: LOG10; C:

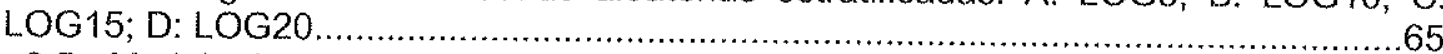

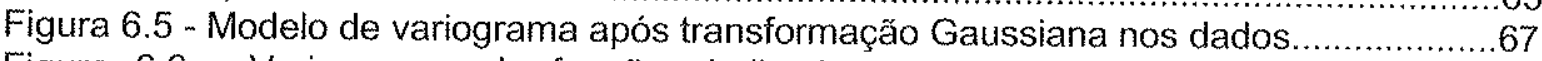

Figura 6.6 - Variogramas de funções indicadoras para 9 decis comparados com os

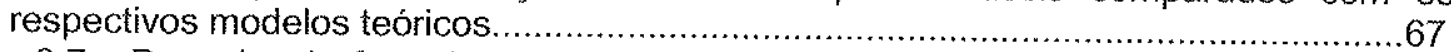

Figura 6.7 - Desenho da fronteira convexa e indicação dos blocos a serem estimados na

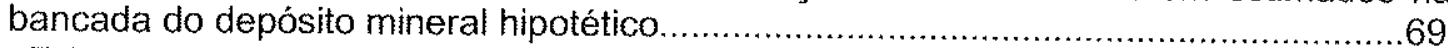

Figura 7.1 - Mapas imagens dos processamentos para LOG5 (A: krigagem ordinária; B: pósprocessada), para LOG10 (C: krigagem ordinária; D: pós-processada), para LOG15 (E: krigagem ordinária; F: pós-processada) e para LOG20 (G: krigagem ordinária; H: pósprocessada)

Figura 7.2 - Distribuições de freqüências acumulativas e diagramas P-P: A: LOG5; B: LOG10; C: LOG15; D: LOG20. (Legenda: cruz vermelha - ponto amostral; círculo verde - krigagem ordinária; quadrado azul - krigagem ordinária corrigida.). 
Figura 7.3 - Classificação dos recursos minerais dos blocos para os dados LOG5. A: erro relativo real; $\mathrm{B}$ : conforme erro de suavização e $\mathrm{C}$ : conforme o intervalo de confiança da média

Figura 7.4 - Gráfico comparativo da definição das classes de recursos para os métodos aplicados no conjunto LOG5

Figura 7.5 - Classificação dos recursos minerais dos blocos para os dados LOG10. A; erro relativo real; B: conforme erro de suavização e C: conforme o intervalo de confiança da média

Figura 7.6 - Gráfico comparativo da definição das classes de recursos para os métodos aplicados no conjunto LOG10

Figura 7.7 - Classificação dos recursos minerais dos blocos para os dados LOG15. A: erro relativo real; $\mathrm{B}$ : conforme erro de suavizaçăo e C: conforme o intervalo de confiança da média.

Figura 7.8 - Gráfico comparativo da definição das classes de recursos para os métodos aplicados no conjunto LOG15

Figura 7.9 - Classificação dos recursos minerais dos blocos para os dados LOG20. A: erro relativo real; $\mathrm{B}$ : conforme erro de suavização e $\mathrm{C}$ : conforme o intervalo de confiança da média

Figura 7.10 - Gráfico comparativo da definição das classes de recursos para os métodos aplicados no conjunto LOG20.

Figura 7.11 - Configuração espacial das amostras utilizadas para a estimativa do bloco. A escala de cores representa o teor da variável para a base de dados LOG10. (Bloco com centro em x: 25,5 e y: 22,5)

Figura 7.12 - Configuração espacial das amostras utilizadas para a estimativa do bloco. A escala de cores representa o teor da variável para a base de dados LOG10. (Bloco com centro em $x: 17,5$ e $y: 36,5$ ).

Figura 7.13 - Configuração espacial das amostras utilizadas para a estimativa do bloco. A escala de cores representa o teor da variável para a base de dados LOG10. (Bloco com centro em $x: 3,5$ e y: 14,5)

Figura 7.14 - Configuração espacial das amostras utilizadas para a estimativa do bloco. A escala de cores representa o teor da variável para a base de dados LOG10. (Bloco com centro em $x: 16,5$ e y: 4,5). 


\section{LISTA DE TABELAS}

Tabela 2.1 - Sistema de classificação de depósitos minerais adotado na Alemanha em 1959 (Wellmer, 1983).

Tabela 2.2 - Histórico da evolução dos códigos de classificação de depósitos minerais .................. 22

Tabela 2.3 - Comparação entre os sistemas de classificação de recursos e reservas minerais (Henley , 2000).

Tabela 3.1 - Critério geral de continuidade para as diferentes classes de recursos/reservas minerais (Dominy; Annels; Noppé, 2002b).

Tabela 5.1 - Classificação de recursos baseada na quantificação do erro a partir do desvio padrão de krigagem

Tabela 5.2 - Classificação de recursos baseada na quantificação do erro a partir a variância de interpolação (Yamamoto, 2000)

Tabela 6.1 - Parâmetros populacionais das bases de dados utilizadas...............................63

Tabela 6.2 - Estatísticas das amostras aleatórias estratificadas...........................................65

Tabela 6.3 - Niveis de erros para classificação de recursos minerais................................71

Tabela 7.1 - Estatísticas das estimativas da krigagem ordinária e das estimativas pós-. processadas.

Tabela 7.2 - Comparação dos blocos classificados com os erros experimentais em relação aos blocos reais para o conjunto LOG5.

Tabela 7.3 - Comparação dos blocos classificados com os erros experimentais em relação aos blocos reais para o conjunto LOG10.

Tabela 7.4 - Comparação dos blocos classificados com os erros experimentais em relação aos blocos reais para o conjunto LOG15.

Tabela 7.5 - Comparação dos blocos classificados com os erros experimentais em relaçäo aos blocos reais para o conjunto LOG20.

Tabela 7.6 - Diferença entre a quantidade de blocos definidos segundo a classificação de recursos minerais dos diferentes métodos utilizados nesse trabalho (Erro da suavização e Intervalo de confiança) pela classificação a partir do erro real.

Tabela 7.7 - Parâmetros utilizados no cálculo dos erros e valores obtidos para as diferentes bases de dados. Bloco com centro em x: 25,5 e y: 22,5. (Legenda de classificação dos recursos em função do cálculo do erro: Verde - medido; amarelo -indicado e vermelho -inferido).

Tabela 7.8 - Parâmetros utilizados no cálculo dos erros e valores obtidos para as diferentes bases de dados. Bloco com centro em x: 17,5 e y: 36,5. (Legenda de classificação dos recursos em função do cálculo do erro: Verde -- medido; amarelo -indicado e vermelho -inferido)....

Tabela 7.9 - Parâmetros utilizados no cálculo dos erros e valores obtidos para as diferentes bases de dados. Bloco com centro em x: 3,5 e y: 14,5. (Legenda de classificação dos recursos em função do cálculo do erro: Verde - medido; amarelo -indicado e vermetho -inferido)....

Tabela 7.10 - Parâmetros utilizados no cálculo dos erros e valores obtidos para as diferentes bases de dados. Bloco com centro em $x: 16,5$ e y: 4,5. (Legenda de classificação dos recursos em função do cálculo do erro: Verde - medido; amarelo -indicado e vermelho -inferido). 


\section{SUMÁRIO}

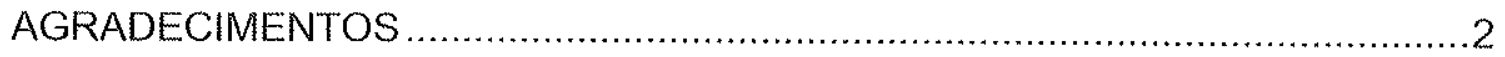

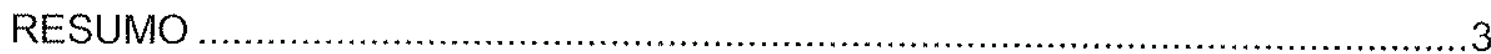

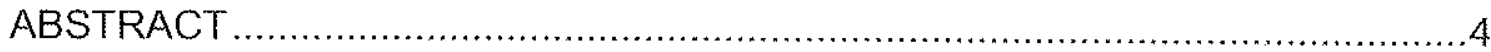

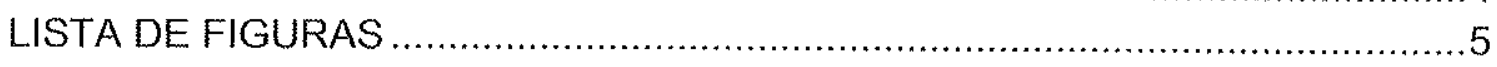

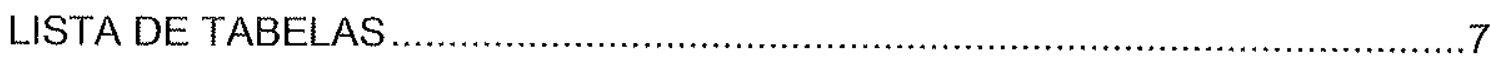

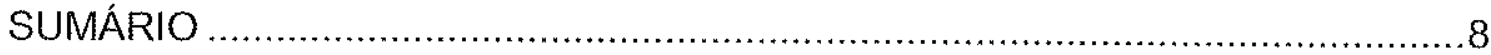

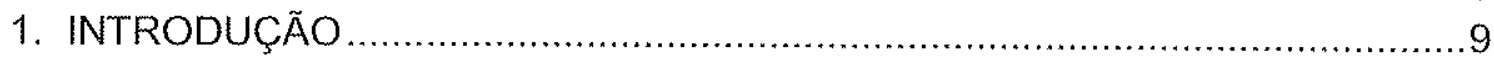

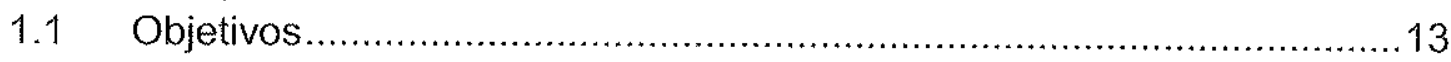

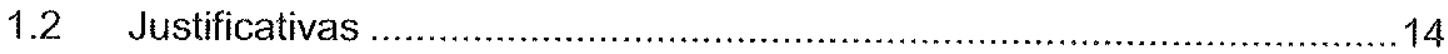

2. CLASSIFICAÇÃO DE RECURSOS E RESERVAS MINERAIS ....................15

2.1 Histórico dos padrões mundiais de classificação de recursos e reservas minerais

2.2 Discussão dos códigos mundiais de classificação de recursos e reservas minerais

3. ERROS E INCERTEZAS DECORRENTES DA PESQUISA MINERAL ...........31

3.1 Determinação do método de amostragem ............................................ 32

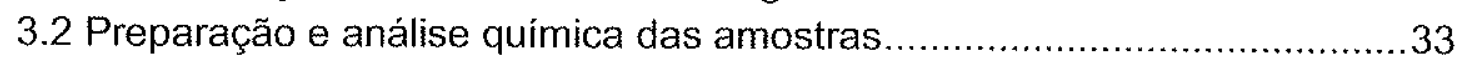

3.3 Geração do banco de dados geológicos ............................................34

3.4 Definição da densidade ............................................................... 35

3.5 Definição, interpretação e modelagem do depósito mineral ......................35

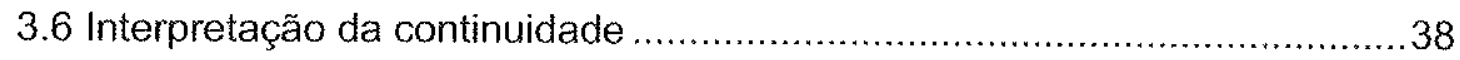

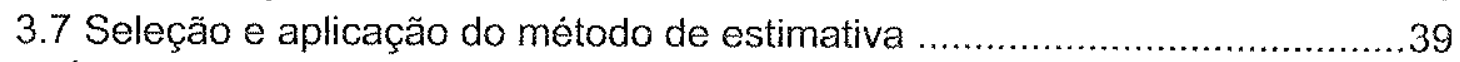

4. CÁLCULO DE RECURSOS MINERAIS .............................................. 41

4.1 Krigagem ordinária .................................................................. 41

4.2 Erros e incertezas......................................................................4. 42

4.3 Correção do efeito de suavização da krigagem ordinária........................45 45

4.4 Krigagem multi-Gaussiana .....................................................46

4.5 Simulação Estocástica ................................................................48

5. CLASSIFICAÇÃO DE RECURSOS MINERAIS BASEADOS NA MEDIDA DE

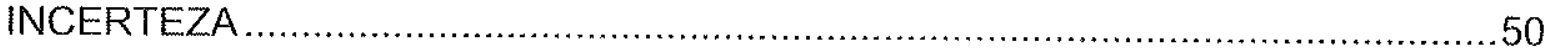

5.1 Uso do variograma para classificação de recursos minerais.....................51

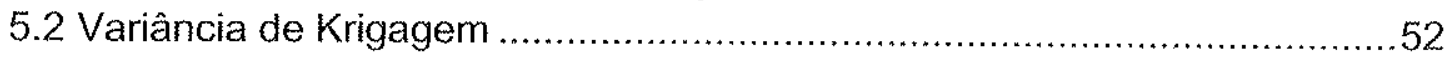

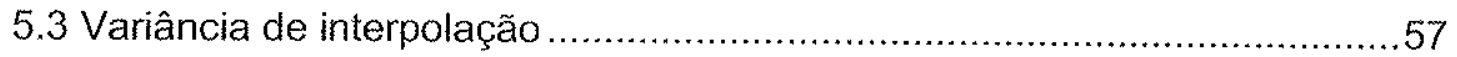

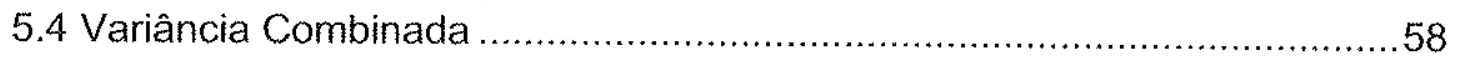

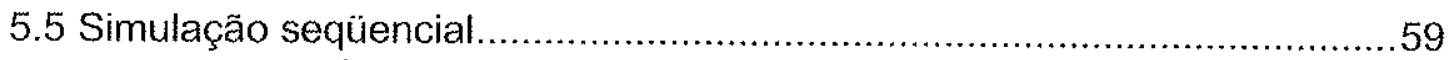

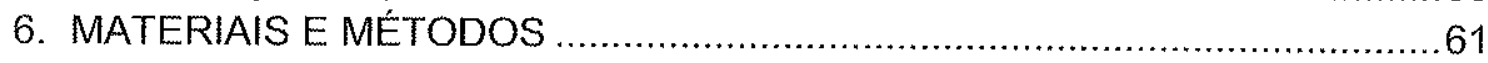

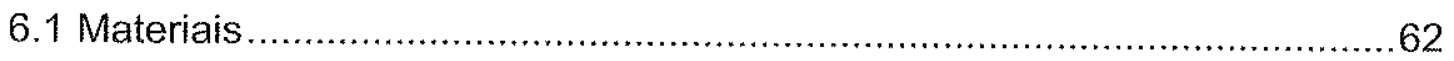

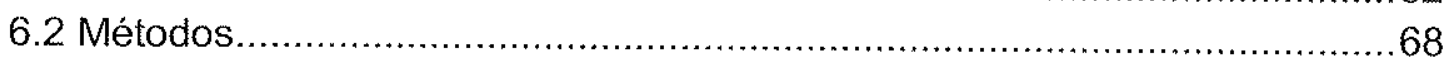

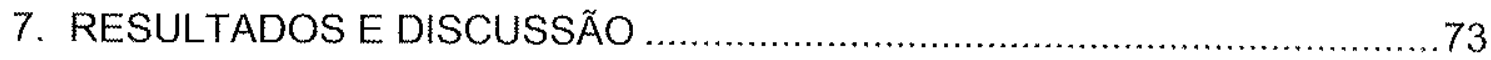

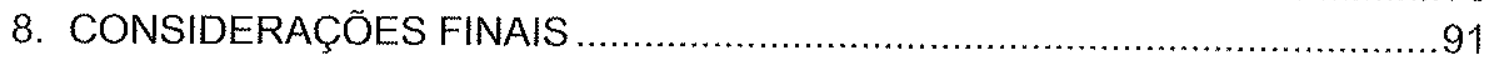

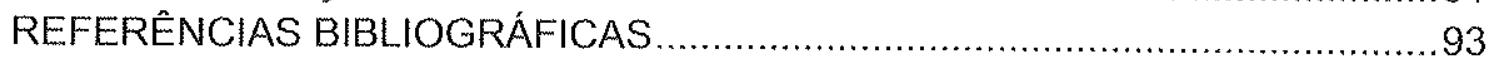

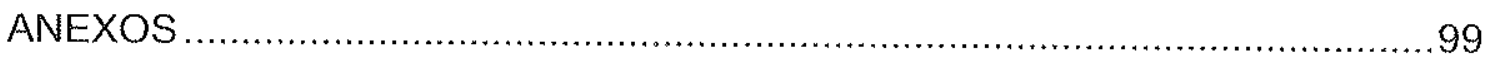




\section{CAPÍTULO 1 \\ INTRODUÇÃO}

Na indústria mineral, a classificação de recursos minerais baseada na estimativa de tonelagem e teores representa um grande problema geralmente de dificil solução, pois envolve diversas variáveis. O resultado dessa estimativa e conseqüente classificação dos recursos minerais é a base para a definição da viabilidade econômica de um depósito mineral. Sabe-se que o investimento necessário para a viabilização de um empreendimento mineiro é da ordem de milhares a dezenas de milhões de dólares e o retorno financeiro pode ser demorado se considerarmos todo o investimento em pesquisa desde sua fase inicial até o inicio da produção. Além do mais, o investimento em um empreendimento mineiro é considerado de risco por diversos fatores, entre estes, o nivel do conhecimento geológico da jazida é um dos mais importantes.

Atualmente, com o avanço das técnicas de produção e beneficiamento mineral, é possível explorar economicamente depósitos com teores mais baixos. Como exemplo, podemos citar depósitos sedimentares de ferro que nas décadas de 1970 1980 eram apenas economicamente viáveis se apresentassem teores de $\mathrm{Fe}_{2} \mathrm{O}_{3}$ acima de $60 \%$. Nos dias de hoje, devido à demanda e a escassez de depósitos tipo World Class, jazidas com teores entre 40 a $45 \%$ já são exploradas com lucratividade.

O risco do investimento em um empreendimento é ainda maior em depósitos que operam próximos ao limite econômico de teor (cutoff) e nesse caso a margem tolerável de erro nas estimativas de teores e tonelagens torna-se mais apertada e, conseqüentemente, é cada vez mais importante uma definição correta do nivel de confiabilidade associado às estimativas de recursos minerais. Por esses motivos, tal assunto é considerado de extrema importância para o setor extrativista mineral.

Antes mesmo de realizar o cálculo das estimativas para a classificação dos recursos minerais devemos conhecer e minimizar ao máximo as possiveis fontes de erros que podem ocorrer na geração e interpretação da base de dados geológica que será utilizada. O uso inadequado de métodos de amostragem, erros na definição da malha de sondagem, interpretação do modelo geológico e do corpo mineralizado, erros na obtenção dos dados geológicos e quimicos das amostras e 
escolha de um método inapropriado para a estimativa de teores de um depósito mineral são apenas alguns exemplos dessas fontes de incertezas que podem refletir no resultado final de uma avaliação.

A importância dos erros de amostragem e incertezas relacionadas à estimativa de um depósito mineral é evidente quando se constata a existência de uma grande quantidade de empreendimentos que fracassaram ou não operam com a lucratividade esperada. Outro fator ligado à avaliação de recursos minerais foram os casos de fraudes aplicadas no setor mineral que se tornaram pública e amplamente discutidas. Busang na Indonésia $(B r e-X)$, Josh nos Estados Unidos (Delgratia Mining) e Stenpad em Gana (Golden Rule Resources) são alguns exemplos de casos com grande repercussão (Neuss, 2001).

Desde a década de 1940 países com tradição no ramo de mineração já buscavam criar metodologias e terminologias para normatizar os resultados de uma pesquisa geológica, sendo os Estados Unidos, Alemanha, Chile e Canadá os países pioneiros. Entretanto, devido aos efeitos da globalização e conseqüente internacionalização da economia que iniciou no final da década de 1990, diversas entidades do setor mineral se uniram no sentido de criar uma terminologia reconhecida mundialmente.

Nota-se, ao analisar os mais recentes sistemas de classificação, é que estes não regulam uma metodologia para a estimativa dos recursos minerais nem qual técnica deve ser empregada para a classificação dos mesmos. Por esse motivo, diversas de abordagens historicamente foram e continuam sendo empregadas no setor mineiro para estimativa e classificação de recursos minerais, apesar de a maioria delas não ser capaz de realmente fornecer uma medida do erro associado às estimativas.

Os métodos clássicos para avaliação de recursos minerais, tais como método dos perfis, da área de influência ou dos poligonos permitem a interpretação dos valores da variável de interesse entre dois pontos contíguos de amostragem. Assim, por meio dessa interpretação, pode-se determinar volume e teores médio que são atribuidos aos blocos de cubagem. Portanto, os métodos tradicionais apenas estendem as caracteristicas observadas nas amostras para determinadas zonas do depósito definidas conforme o procedimento de cada um desses métodos (Yamamoto, 2001). 
Em uma estimativa, variáveis importantes como variabilidade $e$ incerteza, precisam ser combinadas para uma avaliação mais segura de recursos minerais. Assim, surgem os métodos geoestatisticos que, por meio do cálculo de uma função, descreve a variabilidade espacial da variável de interesse. Dentre os métodos geoestatísticos de estimativa, a krigagem ordinária se populariza como método mais difundido para fins de avaliação de recursos minerais.

Uma vantagem do uso da geoestatística decorre da possibilidade de se calcular a incerteza associada à estimativa, pois os métodos clássicos, bem como outros métodos numéricos não permitiam calcular essa incerteza. A medida de incerteza derivada da krigagem ordinária denomina-se variância de estimativa ou de krigagem. Assim, nas décadas de 1960-1970, a variância de krigagem foi aceita como uma medida de incerteza associada à estimativa por krigagem ordinánia. Dessa forma, a variância de krigagem foi utilizada intensamente para diversas finalidades, dentre as quais a classificação de recursos minerais. Entretanto, a variancia de krigagem apresentava um defeito à medida que não depende dos valores dos pontos amostrais, mas tão somente do modelo do variograma. Esta propriedade é conhecida em estatística como homoscedasticidade (Olea, 1999). Como o variograma é uma medida de variância espacial, a variância de krigagem representava realmente uma medida da variabilidade espacial. Em 1989, Joumel e Rossi (1989) descrevem que a variância de krigagem é tão somente uma medida da configuração espacial dos dados, sendo baixa na proximidade dos pontos amostrais e alta à medida cuse se afasta dos pontos de dados. Mesmo assim, mutos autores continuaram a utilizar a variancia de krigagem para fins de classificação de recursos minerais até que em 1994 Amstrong (1994) chama a atença pora que tal medida de incenteza seja abandonada.

Devido aos problemas encontrados no uso da variancia de krigagem Yamamoto (2000) propõe o uso de uma medida atemativa de inceteza, a qual foi denominada variância de interpolação. Ao contrário da variância de krigagem, a variância de interpolação depende dos valores dos pontos de dados e, portanto, é heteroscedástica. Uma rápida aproximaçāo usando a variância de interpolação foi proposta por Yamamoto (1999), Yamamoto e Conde (1999), nos chuas os recursos foram classificados por erros iguais à metade do intervalo de confiança, conforme o Teorema do Limite Central. Na realidade, contome esta aproximação, o bloco de 
cubagem é estimado por $n$ pontos de dados situados na vizinhança próxima, que resulta no teor médio e no desvio padrão de interpolação. Essas estatísticas são então combinadas para calcular a metade do intervalo de confiança em torno do teor médio, que foi usada como medida de incerteza para classificação de recursos minerais. Cabe ressaltar que o erro só é possível ser calculado quando se conhece o valor real. Como nunca se conhece o valor real de um bloco de cubagem até quando este é desmontado e enviado ao beneficiamento, trabalha-se com estimativas dos erros.

$\mathrm{Na}$ maioria das pesquisas minerais, amostras são utilizadas para estimar o depósito mineral. Tais amostras representam uma pequena parcela da população em estudo. Mesmo que as amostras tenham sido coletadas conforme os procedimentos indicados pela teoria da amostragem, deve-se considerar que a distribuição dos elementos de interesse dentro do depósito não é uniforme. Isso significa que em um depósito mineral com alta variabilidade, duas amostras coletadas em pontos próximos poderão apresentar teores completamente diferentes. Evidentemente, a variabilidade implica em se aumentar a taxa de anostragem para que tais diferenças possam ser verificadas, porém dentro do limite econômico do plano de amostragem.

Quando se faz uma estimativa de bloco, através de uma combinação linear dos valores de pontos amostrais o resultado esta sujeito a uma suavizacão, na qual os valores mais altos são subestimados e valores baixos são superestimados diminuindo assim, a variabilidade do resultado se comparado à variabilidade amostral. Uma solução para o problema relacionado ao efeito de suavização está na adição de um temo à estimativa resultante, o qual é denominado erro de suavização. Esse erro de estimação pode ser estimado ou simulado (Yamamoto, 2008).

Yamamoto (2005) propóe estimar o erro de suavização por meio de um algoritmo de pósmprocessamento para correção do efeito de suavização da krigagem ordinária. Esse trabalho analisa o uso do erro de suavização para fins de classificação de recursos minerais. 


\subsection{0bjetivos}

O objetivo principal desse estudo é testar a aplicação do erro de suavização, variável que é originária da utilização algoritmo de correção do efeito de suavização das estimativas realizadas por krigagem ordinária proposto por Yamamoto (2005), para fins de classificação dos recursos minerais.

Utilizando quatro bases de dados exaustivos com distribuição lognormal, que é o tipo de distribuição encontrado em mineralizações de metais raros, o estudo consiste em, a partir de uma amostragem aleatória estratificada, estimar o dominio através da aplicação da técnica de krigagem multi-Gaussiana. Comparar o método proposto nesse estudo com os métodos de classificação de recursos mais utilizados na indústria mineira e com o erro real que pode ser obtido devido aos dados reais serem conhecidos.

Por fim, serão selecionados alguns blocos com características distintas em relação à distância entre os pontos de amostragem e variabilidade dos dados com o objetivo de comparar os resultados através da aplicação do método proposto com demais metodologias.

Após o processo de globalização da economia ocorrido na década de 1990, que culminou na abertura dos mercados, diversas empresas do setor mineral optaram por lançar ações nos mercados de capitais a fim obter recursos para financiar sua pesquisa mineral. A partir de então, diversas nações com tradição no ramo de mineração somaram esforços, a fim de criar definições e metodologias universais, para a apresentação dos relatórios públicos de avaliaçâo de recursos e reservas minerais que as empresas devem apresentar a seus investidores. Esses conjuntos de normas e definições, mais conhecidos como códigos, têm por objetivo padronizar, informar e orientar empresas e investidores sobre como os recursos e reservas minerais devem ser avaliados e reportados. Nesse sentido, os principais códigos em vigência serão apresentados, comparados e discutidos demonstrando as normas e definições apresentadas. Um breve histórico sobre como esse códigos evoluiram aos formatos em que hoje se encontram tambern sera apresentado.

A incerteza em torno de uma estimativa não está relacionada apenas do método de estimativa tutizado. Erros cometidos durante a fase de obtenção dos dados 
podem ter um papel fundamental no resultado final de uma estimativa, podendo até inviabilizar um empreendimento mineiro ou tomá-lo atrativo demais devido a altos teores envolvidos que na realidade não existem. Nesse sentido, o presente trabalho pretende apresentar uma revisão dos principais erros que podem ser cometidos durante a pesquisa geológica e quais as melhores técnicas para evitámlos.

\subsection{Justificativas}

Uma correta classificação dos recursos minerais é o elemento chave para estudos de viabilidade econômica de um empreendimento mineiro. $O$ custo de execução de uma campanha de pesquisa geológica varia de milhares a dezenas de milhões de dólares e por isso deve-se utilizar da informação gerada da maneira mais eficaz, otimizando os recursos financeiros empregados.

Apesar dos avanços nos métodos de estimativa baseados no uso da geoestatistica, não existe uma definição precisa sobre como a classificação dos recursos deve ser realizada em função do nivel de conhecimento e confiabilidade dos resultados. 


\section{CAPITULO 2 \\ CLASSIFICAÇÃO DE RECURSOS E RESERVAS MINERAIS}

Este capitulo apresenta como evoluiram os padrões para classificação de recursos e reservas minerais. Desde a segunda metade do século XX já havia uma preocupaçäo em criar um sistema que padronizasse os relatórios técnicos que apresentam os resultados de uma pesquisa mineral e por isso, diversos paises publicaram seus próprios códigos de terminologias e métodos de classificação.

Atualmente, depois de esforços continuos ao logo dos anos do Intemational Resources/Resenves Definitions Group (Grupo CMMI), formado por entidades de diversos paises com tradição no ramo de mineração (Canadá, Estados Unidos, Austrália, África do Sul e Reino Unido), a maioria dos paises tem seu próprio sistema de classificação baseado em uma terminologia mundial que divide as ocorrências minerais em dois grupos: Recursos e Reservas.

Recurso Mineral, segundo o Internacional Reporting Template for the Public Reporting of Exploration Results, Mineral Resources and Mineral Reserves (CRIRSCO, 2006) é uma concentração ou depósito mineral com interesse econômico dentro ou sobre a crosta terrestre de tal forma que ocorra em qualidade e quantidade razoáveis para eventual extração econômica lucrativa. Suas caracteristicas são conhecidas, estimadas e interpretadas a partir de evidências geológicas. São subdivididos, de acordo com o nivel de confiança geológica, nas categorias: Inferido, Indicado e Medido, em ordem decrescente de incerteza.

Reserva mineral é parte ou totalidade de um recurso mineral economicamente lavrável, ou seja, é todo o recurso mineral que comprovadamente, mesmo depois de considerados os chamados fatores modificadores, podem ser lavrado gerando lucro. Os fatores modificadores incluem considerações de lavra (diluição, recuperaçāo, método de lavra), metalúrgicas, econômicas, de mercado, legais, ambientais, fatores sociais e governamentais.

Paralelamente, existe o sistema de classificação russo, desenvolvido na época da antiga URSS e utilizado até os dias de hoje em paises do leste europeu, Ásia e Rússia. Este divide a concentração de minerais em sete categorias agrupados em 
três grandes grupos: Reservas ou recursos totalmente explotaveis, reservas ou recursos avaliados e prognóstico de recursos.

No Brasil, o sistema de classificação adotado atualmente é baseado na terminologia proposta pelo Grupo CMMI com o acréscimo de uma metodologia de classificação baseados em métodos estatísticos e geoestatísticos (DNPM, 1992).

\subsection{Histórico dos padrões mundiais de classificação de recursos e reservas minerais}

Ao longo dos anos, diversos paises perceberam a necessidade de criar um padrão de classificação de recursos e reservas minerais a fim de definir uma terminologia única e objetiva para a apresentação de relatórios de avaliação de depósitos minerais. Com o passar do tempo, devido à internacionalização da economia e abertura dos mercados se notou que esse padrão deveria ter abrangência mundial.

No ano de 1942, o Instituto de Ingenieros de Minas de Chile (IIMCh) propôs uma padronização de termos técnicos utilizados na estimativa de recursos minerais que foi apresentada no First Pan-American Mining Engineering and Geology Congress realizado em Santiago, Chile (IIMCh, 2004).

No ano seguinte, o U.S. Bureau of Mines e U. S. Geological Survey publicaram a primeira metodologia de classificação de recursos e reservas minerais (Froidevaux, 1982), onde, pela primeira vez, foram adotados os termos medido, indicado e inferido para as classes de reservas. O recurso mineral ainda não apresentava Subdivisão (Figura 2.1). 


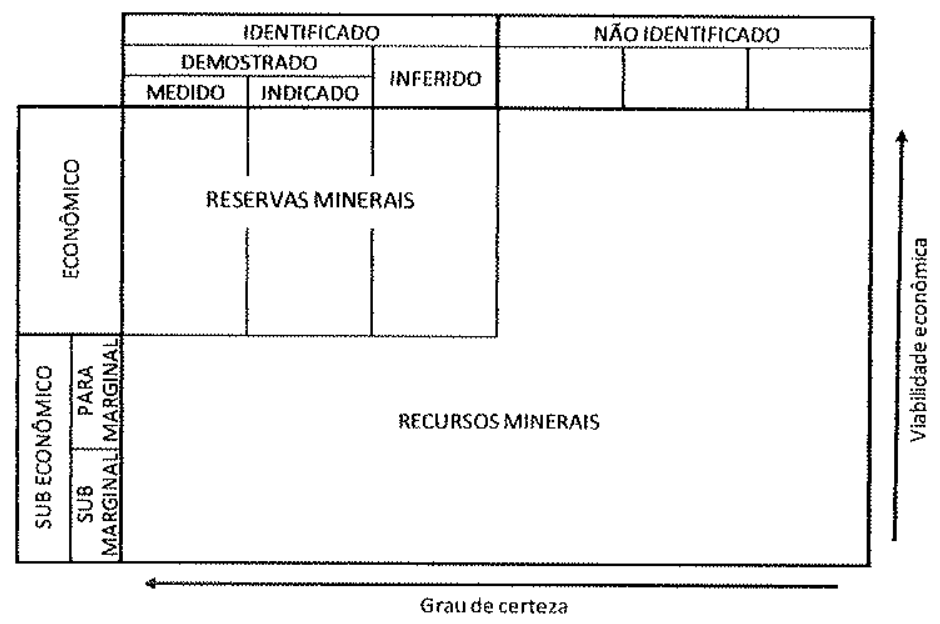

Figura 2.1 - Classificação de depósitos minerais adotada nos Estados Unidos em 1943 (Froidevaux, 1982)

Em 1959, na Alemanha, um grupo de trabalho da Gesellschaft Deutscher Metallhütten und Bergleute (Sociedade alemã de mineração e metalurgia) apresentou o primeiro sistema de classificação definindo os limites de erro para um determinado nivel de confiança de acordo com a Tabela 2.1 (Wellmer, 1983).

Tabela 2.1 - Sistema de classificação de depósitos minerais adotado na Alemanha em 1959 (Wellmer, 1983)

\begin{tabular}{lcc}
\hline Categoria & Limite do erro & Nivel de Confiança \\
\hline \hline Provada & $\pm 10 \%$ & $>90 \%$ \\
Provavel & $\pm 20 \%$ & $70-90 \%$ \\
Indicada 7 Possivel & $\pm 30 \%$ & $50-70 \%$ \\
Infericla $]$ Progńtico & $\pm 30 \%$ & $30-50 \%$ \\
Prognósto & & $>10-30 \%$ \\
\hline
\end{tabular}

No início da década de 70 o Canadá estabeleceu seu primeiro código de classificação de recursos e reservas através do Canadian Securities Administrators, Figura 2.2 (CIM, 2000). 


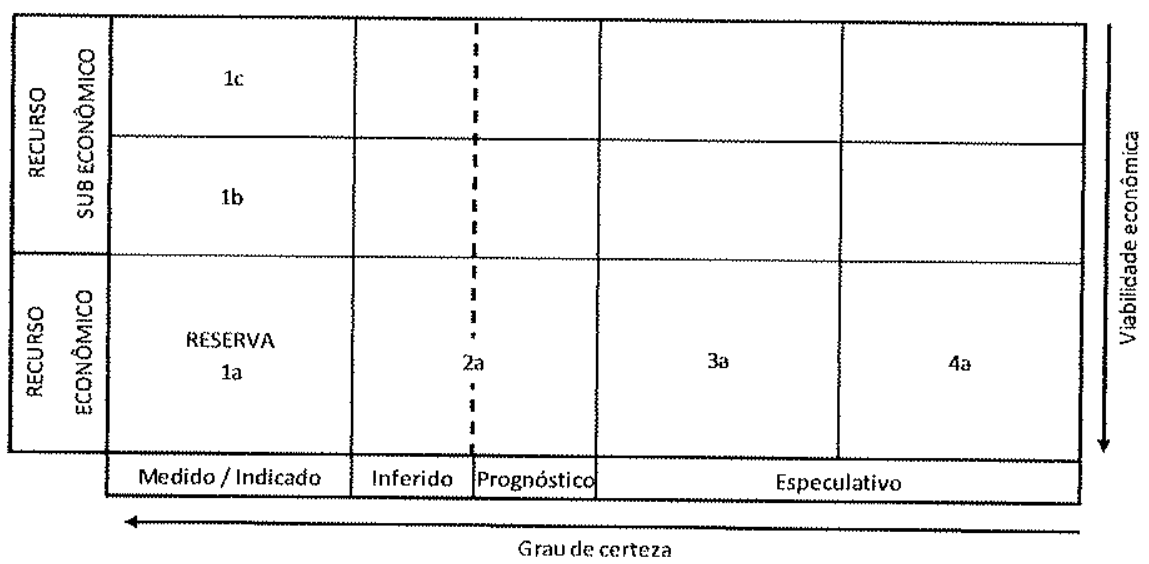

Figura 2.2 - Sistema de classificação de depósitos minerais adotado no Canadá na década de 1970 (CIM, 2000)

Posteriormente, em 1976 nos Estados Unidos, uma equipe composta por membros da U.S. Bureau of Mines e U.S. Geological Survey publicaram o Bulletin 1450-A "Principles of the Mineral Resource Classification Sistem of the U.S. Bureau of Mines and U.S. Geological Survey". Em 1980, essa mesma equipe publicou o Geological Circular 831 "Principles of Classification of Mineral Resources and Ore Reserves." (SME, 2007).

No ano de 1988 foi apresentada a primeira versão do código australiano de classificação de recursos e reservas minerais, o Australian Code for Reporting of Identified Mineral Resources and Ore Reserves pelo Joint Ore Reserves Committee (AusIMM, 2004). No ano seguinte o código foi incorporado às normas do Australian Stock Exchange (Vaughan; Felderhof, 2005).

No Reino Unido, em 1991, o Conselho do Institution of Mining and Metallurgy, aprovou as definições para classificação de recursos e reservas minerais que foram incluidas no London Stock Exchange Listing Rules (Chapter 19 - Mineral Companies).

O Canadian Institute Mining (CIM), no ano de 1994, criou um Comitê com a responsabilidade de melhorar as definições de reserva mineral em seu pais. 0 relatório da comissão especial foi apresentado pelo conselho CIM e publicado em outubro de 1994 (CIM, 2000).

No mesmo ano, nos Estados Unidos, a Society of Mining Engineers of the United States (SME) publicou o A Guide for Reporting Exploration Information Resources and Reserves (SME, 2007). 
Devido os efeitos da globalização e conseqüente internacionalização da economia no final da década de 1990, aliado a escândalos ocorridos no setor mineral como, por exemplo, o da $B r e-X$, com relação a depósitos de ouro ficticios em Busang, Indonésia; se tornou óbvio a necessidade de uma padronização internacional e um controle maior sobre os relatórios de avaliação de depósitos minerais (Neuss, 2001).

Os primeiros esforços a fim de criar um código internacional aconteceram em 1994 durante um encontro no $15^{\text {th }}$ Congress of the Council of Mining and Metallurgical Institutions (CMMI), que contou com a participação de representantes da África do Sul (SAMM - South African Institute of Mining and Metallurgy), Austrália (AusIMM - Australasian Institute of Mining and Metallurgy), Canadá (CIM - Canadian Institute Mining), Estados Unidos (SME - Society of Mining Engineers) e Reino Unido (IMM - Institution of Mining and Metallurgy). Durante esse evento foi criado o International Resources/Reserves Definitions Group (Grupo CMMI) (AusIMM, 2004).

Paralelamente, uma força tarefa criada pelas Nações Unidas (Task Force of the United Nations Economic Commission for Europe, UN-ECE) vinhe desenvovendo, desde 1992, um sistema internacional para classificação de recursos e reservas minerais e resultou na publicação do United Nacions Internacional Framework Classification for Reserves/Resources - Solid Fuels and Mineral Commodities no ano de 1996 (AusiMM, 2004).

Durante um encontro do Grupo CMMI realizado em Denver, Estados Unidos, em 1997 foi assinado um acordo (Acordo de Denver) entre os paises membro do CMMI que padronizava as definições e termos utilizados na classificação de recursos e reservas minerais (AusIMM, 2004).

Em Junho de 1997 alguns meses após o escândalo da Bre-X a Ontaro Securities Commission e a Toronto Stock Exchange criaram o Mininng Standarts Task Force que em seu relatório final publicado em janeiro de 1999 recomendou a inclusão dos padrões definidos pelo CIM para a publicação dos relatórios de classificação de recursos e reservas minerais (Vaughan; Felderhof, 2005).

No ano seguinte, em um encontro realizado em Genebra entre o Grupo CMMI e a força tarefa das Nações Unidas (UN-ECE) foi astabelecido o Acordo de Genebra 
onde estabelecia que os padrões e definições apresentadas pelo Grupo CMMI seriam incorporados, com pequenas alterações, ao sistema de classificação das Nações Unidas (AusiMM, 2004).

Após o Acordo de Genebra todos os paises membro do Grupo CMMI realizaram revisões em seus códigos de classificação baseando-se nas definições estabelecidas por esse acordo, sendo a Austrália a pioneira com a versão revisada do código JORC em 1999 (AusIMM, 2004).

No Canadá foi criada uma comissão formada pelas instituições financeiras Toronto Stock Exchange e Ontaro Securities Commission denominada Mining Standards Task Force que publicou um relatório final em 1999 Setting New Standards, Recommendations for Public Mineral Exploration and Mining Companies onde determinava uma série de padrões a serem seguidos pelas empresas de mineração e recomendava que o Canadian Institute of Mining, Metallurgy and Petroleum se aliasse a instituiçôes internacionais a fim de criar um padrão internacional. No ano de 2000 foi publicado o pela Canadian Securities Administrators o National Instrument 43-101 Standards of Disclosure for Mineral Projects (CSA, 2001).

Ainda no ano 2000, a South African Mineral Resource Committee publicou o South African Code for Reporting Mineral Resources and Mineral Reserves (The SAMREC Code) (SAMREC, 2007).

Em 2002, o Combined Reserves International Reporting Standards Committee (CRIRSCO, atualmente conhecido como Commitee for Mineral Resenes International Reporting Standards), foi criado substituindo o Grupo CMMI com a missão de continuar o desenvolvimento dos padrões internacionais de apresentação dos resultados de exploração mineral, recursos e reservas minerais. Esse comitê publicou a última revisão do Internacional Reporting Template for the Public Reporting of Exploration Results, Mineral Resources and Mineral Reserves no ano de 2006 (CRIRSCO, 2006).

Em 2004 foi publicada a última revisão do Código JORC. No ano seguinte foi apresenta a revisão do código canadense e em 2007 foi a vez da publicação das revisöes dos códigos norte-americano e da África do Sul (Weatherstone, 2008). 
$\mathrm{Na}$ Europa, em 2008, foi publicado o Pan-European Code for Reporting of Exploration Results, Mineral Resources and Reserves pelo The Pan-European Reserves and Resources Reporting Committee (PERC), que atualmente é o sistema de classificação de recursos e reservas minerais utilizado em todos os paises da União Européia e Reino Unido.

Em julho de 2009, o Joint Ore Reserves Committee (AusIMM, 2009) anunciou em seu website o início da revisão do Código JORC de 2004, essa revisão encontra-se em andamento e até julho de 2011 a nova versão não havia sido disponibilizada.

A Tabela 2.2 resume o histórico da evolução dos códigos de classificação dos recursos e reservas minerais mais importantes.

Como resultado da iniciativa do Grupo CMMI/CRIRSCO progressos consideráveís foram realizados na adoção de padrões consistentes para a comunicação de avaliação de recursos e reservas minerais em todo o mundo. Estes padröes foram incorporados nos códigos, diretrizes e normas publicadas $\mathrm{e}$ aprovadas por órgãos profissionais em diversos paises ao redor do mundo como Austrália, Canadá, Estados Unidos, África do Sul, Peru, Chile, Fillpinas e Europa. 
Tabela 2.2 - Histórico da evolução dos códigos de classificação de depósitos minerais

\begin{tabular}{|c|c|c|c|}
\hline Ano & Local & Entidade(s) & Evento \\
\hline 1942 & Chile & $\mathrm{IEMCh}$ & $\begin{array}{l}\text { Padronização de termos técnicos utilizados } \\
\text { na avaíiação de recursos minerais }\end{array}$ \\
\hline 1943 & EUA & USBM/USGS & $\begin{array}{l}\text { Primeiro sistema de classificação de recursos } \\
\text { e reservas minerais dos Estados Unidos da América. } \\
\text { Onde apareceu pela primeira vez os termos Medido } \\
\text { Indicado e Inferido }\end{array}$ \\
\hline 1959 & Alemanha & GDBM & $\begin{array}{l}\text { Sistema de classificação alemão de acordo com erro } \\
\text { e intervalo de confiança }\end{array}$ \\
\hline 1970 & Canadá & $\operatorname{CSA}$ & $\begin{array}{l}\text { Primeiro sistema de classificação de recursos } \\
\text { e reservas minerais do Canadá }\end{array}$ \\
\hline 1976 & EUA & USBM/USGS & $\begin{array}{l}\text { Publicação do Principles of the Mineral Resource } \\
\text { Classification System of the U.S. Bureau of Mines } \\
\text { and U.S. Geological Survey }\end{array}$ \\
\hline 1976 & EUA & USBM/USGS & $\begin{array}{l}\text { Publicação do Geological Circular } 831 \text { "Principles of } \\
\text { Classification of Mineral Resources and Ore Reserves." }\end{array}$ \\
\hline 1988 & Austrália & AusIMM/JORC & $\begin{array}{l}\text { Publicação da primeira versão do Australian Code for } \\
\text { Reporting of Identified Mineral Resources and } \\
\text { Ore Reserves }\end{array}$ \\
\hline 1992 & Brasil & DNPM & $\begin{array}{l}\text { Publicação do Bases técnicas de um sistema de } \\
\text { quantificação do patrimônio mineral brasileiro }\end{array}$ \\
\hline 1994 & EUA & SME & $\begin{array}{l}\text { Publicaçäo do A Guide for Reporting Exploration } \\
\text { Information Resources and Reserves }\end{array}$ \\
\hline 1994 & África do Sul & $\begin{array}{l}\text { SAIMM/AusIMM } \\
\mathrm{CIM} / \mathrm{SME} / \mathrm{IMM}\end{array}$ & $\begin{array}{l}\text { Criação do International Resources/Reserves } \\
\text { Definitions Group (Grupo CMMI) }\end{array}$ \\
\hline 1996 & - & ONU & $\begin{array}{l}\text { Publicação do United Nacians Internacional Framework } \\
\text { Classification for Reserves/Resources - Solid Fuels } \\
\text { and Mineral Commodities }\end{array}$ \\
\hline 1997 & EUA & Grupo CMMI & $\begin{array}{l}\text { Publicação do Acordo de Deriver durante encontro } \\
\text { do Grupo CMMI }\end{array}$ \\
\hline 1998 & Suiça & $\begin{array}{l}\text { Grupo CMMI } \\
\text { ONU }\end{array}$ & $\begin{array}{l}\text { Acordo de Genebra que incluiu as definiçôes do } \\
\text { Grupo CMMI ao siste ma adotado pela ONU }\end{array}$ \\
\hline 1999 & Austrália & AUsIMM/IORC & $\begin{array}{l}\text { Revisão do Australian Code for Reporting of Identified } \\
\text { Mineral Resources and Ore Reserves }\end{array}$ \\
\hline 2000 & Africa do Sul & SAMREC & $\begin{array}{l}\text { Publicação do South African Code for Reporting of } \\
\text { Mineral Resources and Mineral Reserves }\end{array}$ \\
\hline 2002 & - & Grupo CMMI & $\begin{array}{l}\text { Criação do Combined Reserves International Reporting } \\
\text { Standards Committee (CRIRSCO) substituindo o } \\
\text { Grupo CMMI }\end{array}$ \\
\hline $20 \times 24$ & Austrália & AusIMM/JORC & $\begin{array}{l}\text { Ultima revisão do Australian Code for Reporting of } \\
\text { Identified Mineral Resources and Ore Reserves }\end{array}$ \\
\hline 2006 & - & CRIRSCO & $\begin{array}{l}\text { Publicação do Internacional Reporting Template for the } \\
\text { Public Reporting of Explorotion Results, Mineral } \\
\text { Resources and Mineral Reserves }\end{array}$ \\
\hline \multirow[t]{2}{*}{2007} & EUA & SME & $\begin{array}{l}\text { Última revisão do SME Guide for Reporting of Exploration } \\
\text { Results, Mineral Resources and Mineral Reserves }\end{array}$ \\
\hline & África do Sut & SAMREC & $\begin{array}{l}\text { Uttima revisäo do South African Code for Reporting of } \\
\text { Mineral Resources and Mineral Reserves }\end{array}$ \\
\hline 2008 & Europa & PERC & $\begin{array}{l}\text { Publicação do Pan-European Code for Reporting of } \\
\text { Exploration Results, Mineral Resources and Mineral } \\
\text { Reserves }\end{array}$ \\
\hline
\end{tabular}


2.2 Discussão dos códigos mundiais de classificação de recursos e reservas minerais

Como já comentado anteriormente, o código JORC (AusIMM, 2004), se tornou a base para revisăo dos códigos nacionais dos paises membro da CRIRSCO e de diversos outros paises que adotaram as terminologias definidas por esse comitê (Chile, Peru, Irlanda, etc.).

A base de todos esses códigos nacionais de padronização é o reconhecimento de uma enorme diversidade e particularidades entre as jazidas minerais que impossibilita a regulamentação de se usar uma técnica padrão para a classificação ou método de estimativa de recursos e reservas minerais. Atualmente esses códigos são utilizados como um guia para a apresentação dos relatórios públicos de avaliação de recursos e reservas minerais contendo tópicos a serem apresentados e discutidos, além da explicação da terminologia que deve ser utilizada.

Os principios fundamentais que regem esses modelos para reportar recursos e reservas minerais são baseados na transparencia, materialidade e responsabilidade. O relatório deve apresentar informações suficientes, de forma clara e objetiva, evitando ambigüudade e deve conter todas as informações e dados que resultou na avaliação presente. É pratica comum, em todos as códigos, a presença de uma tabela em anexo com um check list das informações que o mesmo deve conter.

Todos os códigos de comunicação de recursos e reservas baseados no JORC (AusIMM, 2004), e, conseqüentemente, no Boletim CRIRSCO (CRIRSCO, 2006) apresentam a mesma teminologia com relação ảs classes de recursos e reservas minerais. Essa terminologia é baseada na evolução do conhecimento geológico do depósito mineral conforme ilustra a Figura 2.3. Esse conceito de classificação foi proposto e aceito no encontro entre o Gupo CMM e a comissão da UN-ENE (Acordo de Genebra) em 1999 e teve sua última revisão elaborada pela CRIRSCO em 2006, a terminologia utilizada

(i) Recursos Minerais;

(ii) Recursos Minerais Inferidos;

(iii) Recursos Minerais Indicados; 
(iv) Recursos Minerais Medidos;

(v) Reservas Minerais;

(vi) Reservas Minerais Provadas;

(vii) Reservas Minerais Prováveis.

As definições dos termos apresentados se encontram no Anexo 1.

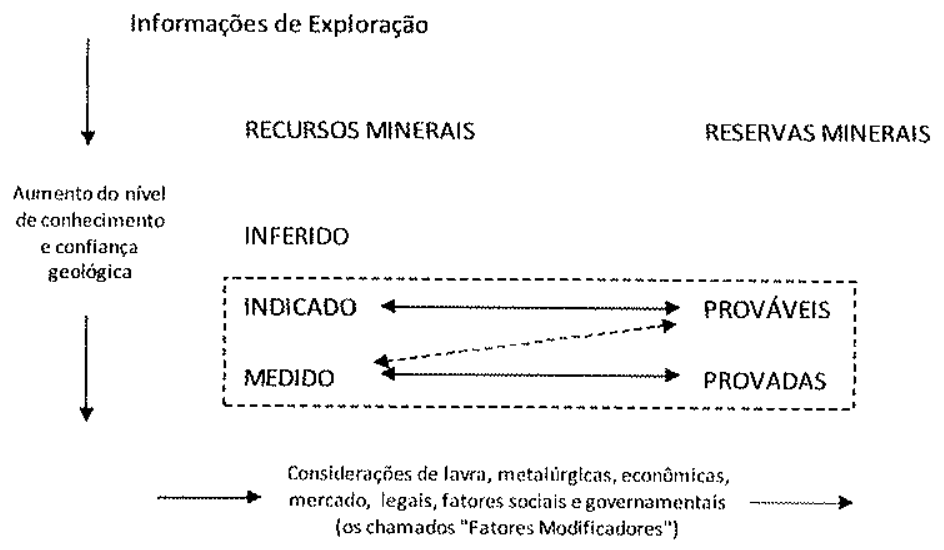

Figura 2.3 - Sistema de classificação de depósitos minerais adotado após o Acordo de Genebra (CRIRSCO, 2006)

Analisando essa terminologia notamos que não existe uma metodologia especifica de como as diferentes classes de recursos devem ser atribuídos. Os recursos/reservas minerais devem ser classificados de acordo com o grau de confiabilidade da continuidade do recurso mineral estimado. Esse grau de confiabilidade pode ser influenciado por diversos fatores como a variabilidade, tipo do depósito e do minério pesquisado assim como a quantidade e qualidade da informação geológica disponivel. Por esse motivo é muito difícil se ter uma função única que avalie todos esses fatores para todos os depósitos existentes.

Os códigos atuais entendem que cada depósito apresenta características particulares e a responsabilidade final pela metodologia empregada fica a cargo de uma pessoa competente (Competent Person) cuja experiência e bom senso irão decidir qual a método é mais adequado para um determinado depósito mineral sendo o código apenas um meio de orientação para auxiliar nessa classificação. 
Essa pessoa deverá assinar o relatório de avaliação e a partir de então se tornará o responsável legal e profissional da avaliação realizada (Phillips, 2000).

O termo "pessoa competente" corresponde à uma pessoa membro ou filiado a alguma instituição profissional relevante na área de mineração e/ou geociências e que está sujeito a Regras de Conduta obrigatória dessa instituição (CRIRSCO, 2006).

Uma pessoa competente deve ter um minimo de cinco anos de experiência relevante e comprovada para o modelo de mineralização, tipo de depósito e substância mineral do relatório no qual ela assinará. Por exemplo, se a pessoa competente está preparando um relatório sobre os resultados de exploração, a relevante experiência deve ser em exploração mineral. Se for um relatório de estimativa de recursos, a pessoa competente deve ter experiência em estimativa de recursos minerais e se for um relatório de estimativa de reservas, a pessoa competente deve apresentar experiência relevante em estimativa de reservas minerais, avaliação e extração econômica de reservas minerais.

A substância mineral e o tipo de mineralização são outros fatores que influenciam na capacidade de uma pessoa ser considerada "pessoa competente" para uma determinada avaliação. O código JORC (AusiMM, 2004) cita como exemplo que uma pessoa com experiência em avaliação de depósitos de cobre pórfiro não é considerada uma "pessoa competente" para uma avaliação de depósitos de ouro aluvionar. No entanto, o código näo obriga que a pessoa tenha cinco anos de experiência em cada tipo de depósito para atuar como pessoa competente e cita o exemplo de uma pessoa com 20 anos de experiência em avaliação em depósitos de cobre póriro pode não necessitar de 5 anos de experiência para ser "pessoa competente" em avaliações de depósitos metálicos em hard-rock. A decisão final sobre a competência ou não de um profissional em poder assinar um relatório de avaliação para um deteminado tipo de depósito o bem mineral fica a cargo da instituição na qual o profissional é fliado (CRIRSCO, 2006).

Outro sistema de classificação de recursos e reservas minerais ainda utilizado nos dias de hoje é o sistema russo (Henley, 2000). Desenvolvido inicialmente na antiga União Soviética, na década de 1960, pretende alcançar a objetividade total, prescrevendo todo o processo de exploração, recursos de computação e 
comunicaçăo. Há pouco ou nenhum espaço no sistema, como originalmente concebido, para a aplicação de julgamento profissional.

O código russo ainda é utilizado em diversos países do leste europeu e Ásia. Resumidamente, esse sistema divide a concentração de minerais em sete categorias agrupados em três grandes grupos (Figura 2.4), com base no nivel de exploração realizado (Henley, 2000):

(i) Reservas ou recursos totalmente explotáveis $\left(A, B, C_{1}\right)$;

(ii) Reservas ou recursos avaliados $\left(\mathrm{C}_{2}\right)$;

(iii) Prognóstico de recursos $\left(\mathrm{P}_{1}, \mathrm{P}_{2}, \mathrm{P}_{3}\right)$.

As definições dessa terminologia se encontram no Anexo 2.

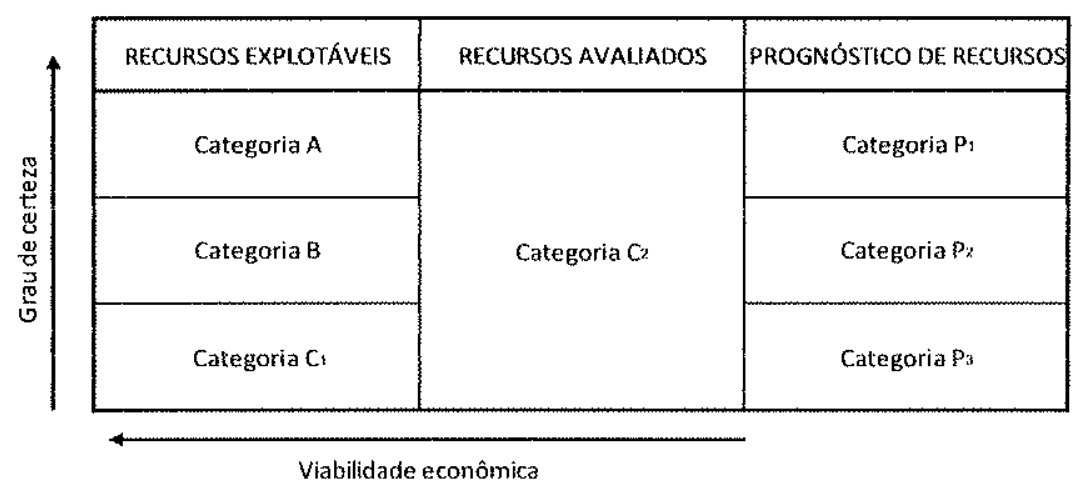

Figura 2.4 - Sistema de classificação de depósitos minerais adotado na Rússia e alguns países do leste europeu e Ásia (Henley, 2002)

À primeira vista, os dois sistemas apresentados, o russo e o ocidental, parecem totalmente incompativeis. No entanto, a partir do inicio dos anos 1990, com o fim da URSS e a abertura dos mercados dos paises comunistas, houve mudanças significativas na maneira em que o sistema russo tem sido aplicado na tentativa de compará-lo com o sistema ocidental. Graça a isso, atualmente já é possivel fazer uma comparaçâo entre os dois sistemas como ilustra a Tabela 2.3 (Henley, 2000). 
Tabela 2.3 - Comparação entre os sistemas de classificação de recursos e reservas minerais (Henley, 2000)

\begin{tabular}{ll}
\hline Sistema Russo & \multicolumn{1}{c}{ Template CRIRSCO } \\
\hline $\mathrm{A}, \mathrm{B}$ & Reserva Provada / Recurso Medido \\
$\mathrm{C}_{1}$ & Reserva Provada / Reserva Provável / Recurso Indicado \\
$\mathrm{C}_{2}$ & Recurso Indicado / Recurso Medido \\
$\mathrm{P}_{1}$ & Recurso Inferido \\
$\mathrm{P}_{2}$ & Recurso Mineral Reconhecido \\
$\mathrm{P}_{3}$ & Sem equivalente \\
\hline
\end{tabular}

Segundo Hendley (2000), para um depósito, ou parte dele, ser incluido nas Categorias $A, B, C_{1}$ estudos de viabilidade técnico-econômica foram executados $e$ por isso podemos compara-los as classes de reservas dos códigos ocidentais. A Categoria $\mathrm{C}_{2}$, dependendo das circunstancias pode ser comparada a recursos indicados, recursos inferidos ou reserva provável.

As categorias de prognósticos de recursos são, em alguns casos da Categoria $P_{1}$, classificados como recurso inferido se comparado ao sistema ocidental. A Categoria $P_{2}$ seria o equivalente a definição de Recurso Mineral ainda não pesquisado com detalhes e a Categoria $P_{3}$ não apresenta equivalente nos sistemas adotados nos paises do ocidente.

Entretanto, o código russo apresenta uma grande diferença se comparado aos demais códigos. Nesse sistema existe uma classificação adicional que leva em consideração a forma e variabilidade do depósito mineral. Dependendo do grupo em que o depósito se encontra, determinados tipos de categoria de classificação só podem ser alcançados após abertura da mina que poderá comprovar ou alterar a tonelagem e teor do corpo mineral. Ainda existem casos em que determinada categoria não pode ser alcançada devido sua complexibilidade geológica.

Os grupos de depósito existentes no sistema russo e suas definições são (Diatchkov, 1994):

Grupo 1: Grandes depósitos, de forma simples, com distribuição uniforme (exemplos: carvão, ferro e alguns depósitos de cobre disseminado). Dependendo da densidade de furos a classificação desses depósilos pode alcançar as Categorias de elevado indice de confiança (Categoria $A$ e B). 
Grupo 2: Grandes depósitos de maior complexidade geológica e por vezes com e elevada variabilidade de teores (exemplos: stockworks e alguns depósitos sedimentares de cobre e ferro). Os recursos podem ser classificados até a Categoria B, o depósito só é elevado a Categoria A após início da lavra.

Grupo 3: Depósitos de pequenas dimensões e alta variabilidade de teores (exemplos: depósitos em veios, lentes e diques). Os recursos podem ser classificados até a Categoria $C_{1}$. O depósito só é elevado as Categorias $A$ e $B$ após inicio da lavra.

Grupo 4: Depósitos de menores dimensões semelhantes às do Grupo 3 ou depósitos com formas complexas e elevada variabilidade (exemplos: depósitos em veios, lentes, diques e aluviões de ouro). A Categoria $A$ de recurso não pode ser estabelecida. Os recursos podem ser classificados até a Categonia $C_{1}$, o depósito só é elevado à Categoria B após inicio da lavra.

Grupo 5: Lentes pequenas e isoladas, veios e bolsões de pequena dimensão. As Categorias $A$ e $B$ de recurso não podem ser estabelecidas. Apenas reservas de Categoria $C_{4}$ pode ser estabelecida, por prospeção sistemática.

Com a inclusão dessa classificação do depósito em distintos grupos podemos notar que as diferentes categorias de recursos variam não apenas em função do conhecimento geológico. O código russo também leva em consideração o tipo de depósito avaliado, uma vez que um depósito de ouro aluvionar, mesmo após uma exaustiva pesquisa geológica, não atingirá a mesma classe de categoria que um extenso e homogêneo depósito de calcário.

Para a determinação do tipo de grupo e categoria que o deposito ou parte dele será classificado, o relatónio de avaliação de recurso/reserva mineral deve conter toda a informação da pesquisa realizada, a avaliação e em quais as categorias o depósito deve ser classificado. Porém, a palavra final é do corpo técnico da Comissão de Reservas Minerais do governo russo que poderá aceitar ou não a categoria proposta (henley, 2000). Por isso, podemos dizer que esse corpo técnico seria o equivalente ao termo "pessoa competente" dos sistemas ocidentais, pois cabe a eles a decisão final da classificação. 
No Brasil, o Código Brasileiro de Mineração (DNPM, 1987) instituiu o sistema de classificação de recursos e reservas minerais seguindo o modelo do código JORC adotando a terminologia de recurso e reserva assim como suas classes.

No ano de 1990 foi criado, pelo Departamento Nacional da Produção Mineral, um grupo de trabalho para revisar e estabelecer novas diretrizes para a quantificação do patrimônio mineral brasileiro (DNPM, 1992). Esse grupo, no ano de 1992 publicou o texto Bases técnicas de um sistema de quantificação do patrimônio mineral brasileiro que alterou o Código de Mineração (Figura 2.5).

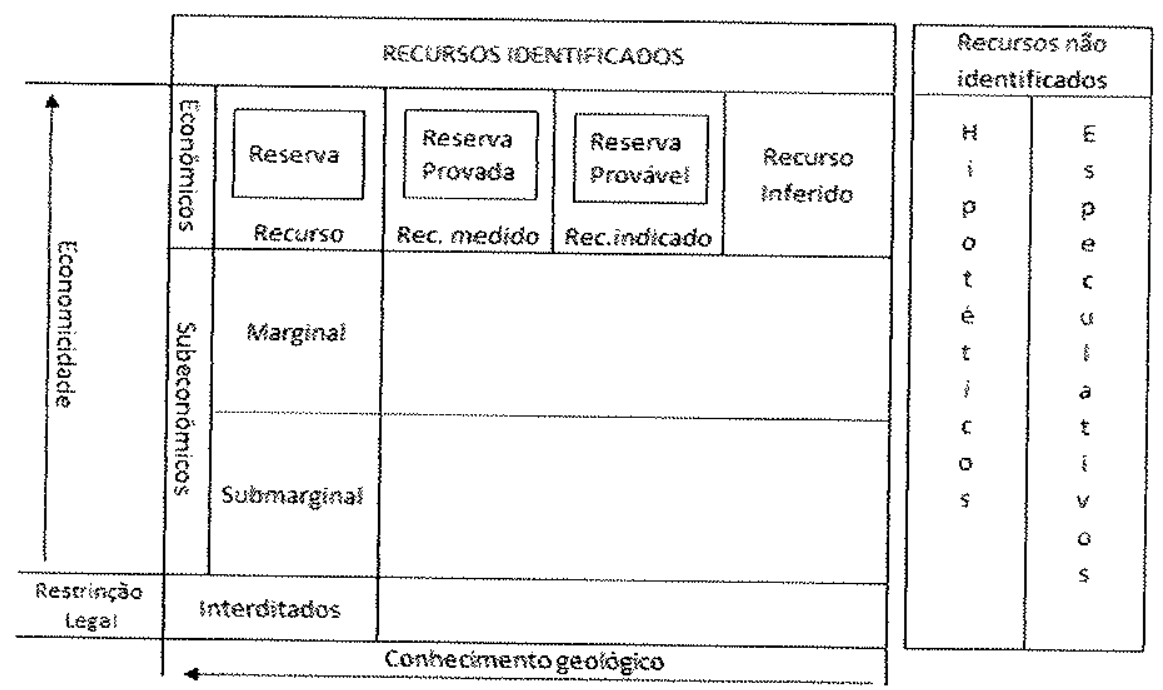
Figura 2.5 - Sistema de classificação de depósitos minerais adotado pelo Brasil (DNPM,
1992)

O sistema brasileiro (Anexo 3) difere-se dos demais sistemas baseados no código proposto pela CRIRSCO por causa da inclusão, a partir de 1992, de um sistema alternativo de classificação baseado em métodos estatísticos e geoestatísticos (DNPM, 1992). Para as diferentes classes de recursos são acrescentados os conceitos de confiabilidade e erro de estimativa e para as classes de reservas são incluídos conceitos geoestatísticos de alcances variográficos e tamanho de blocos.

Essa metodologia alternativa foi revisada por Yamamoto e Rocha (1996), onde consideraram que as definições dos recursos não levam em consideração a variabilidade natural dos depósitos minerais uma vez que depósitos de grande complexidade e alta variabilidade poderão não ser enquadrados em nenhuma das 
classes propostas. Classificações alternativas para reservas minerais não se justificam uma vez que o recurso medido é correlacionável à reserva provada e recurso indicado à reserva provável, portanto, não há motivos para propor definições alternativas, pois o conhecimento e confiança geológicos são os mesmos para as classes de recursos e reservas minerais.

É possivel perceber que, mesmo com a existência de diversas propostas de classificação de recursos e reservas minerais existente na bibliografia especializada, - padrão mundial dos códigos de classificação de recursos e reservas minerais é atribuir a uma pessoa com experiência a decisão final. Os métodos estatísticos e geoestavisticos de classificação do erro associado à estimatua servem como base para essa decisão, porém o conhecimento geológico do depósito é mais importante do que qualquer método de classificação.

Seguindo esse critério, Stephenson e Vann (2001) apresentaram uma metodologia para a definição das classes de recursos e reservas onde a pessoa responsável pela avaliação deve se questionar o quanto a presença de uma amostragem adicional infuenciará no formato, tonelagem e teor he área em estudo.

Se a presença de furos ou amostragem adicional não afetaria significativamente a interpretação geológica, forma e localização do corpo de minério elou a confiança na distribuição de teores dessa região do depósito, então esses recursos poderiam ser classificados como medido.

Se a presença de furos ou amostragem adicional afetarem significativamente a forma e/ou distribuça das zonas mineralizadas, mas não afetarem substancialmente a estimativa de tonelagem e teor, essa parte do depósito provavelmente pode ser classificada como Recurso Indicado.

Outro ponto de vista, segundo Stephenson e Vann (2001), fala sobre a tentativa de classificar os recursos entre as classes indicado e inferido. Se pessoa competente tem suficiente confrança na estimativa de recursos a ponto que estes possam ser utilizados em decisöes de planejamento de lavra e de investimento, então provavelmente esses recursos preenchem os requisitos para a classe de recursos indicado. Entretanto, se não há essa confiança, o recurso deve ser classificado como interido. 


\section{CAPITULO 3 \\ ERROS E INCERTEZAS DECORRENTES DA PESQUISA MINERAL}

A estimativa dos recursos minerais é a base para a avaliação da viabilidade de qualquer empreendimento de mineração, os estudos de viabilidade técnica e econômica dependerão da estimativa realizada. Uma correta avaliação desses recursos é crucial para todas as operações mineiras independente de seu tamanho e commodities (Stone; Dunn, 1996).

Essa avaliação é baseada na interpretação de dados obtidos a partir de diversas fontes de informações geológicas como mapeamento geológico, geoquímica, geofísica, sondagem e outras técnicas de amostragem, interpretação e modelagem geológica estimativa de tonelagem e teor do depósito mineral. A avaliaçâo das recursos minerais, além da precisão da estimativa dos recursos minerais, depende também da estimativa da dituição e recuperação do minério, definição do teor de corte, do método e seletividade de lavra, problemas geotécnicos e hidrogeológicos, processamento e recuperação metaúrgica, avaliação econômica da commodities, fatores de saúde e segurança do trabalho assim como fatores legal, financeiro, ambiental e governamental.

Esses dados e suas interpretações podem conter uma série de erros e incertezas associados que influenciarão no resultado final da estimativa, muitos desses erros são não quantificáveis por diversas razões e afetarão todo o processo de avaliação dos recursos minerais podendo continuar presentes durante toda operação da mina (Dominy; Annels; Noppé, 2002a).

Estudos realizados em empreendimentos mineiros em atividade demonstraram o quanto esses erros e incertezas afetam na vida útil, investimento e retomo financeiro de uma atividade mineral. Sinclair (1998) constatou que em $60 \%$ das minas estudadas, no seu primeiro ano de produção, a taxa média de produção foi $70 \%$ menor do que a capacidade projetada. Tais falhas foram causadas por problemas na planta de beneficiamento e na estimativa incorreta de tonelagem e teor de minério. Burmeister (1988) avaliou 35 projetos de mineração na Austrália e concluiu que dois terços desses projetos não conseguram atingir a meta de producão e apenas dois projetos alcancaram os objetivos em temos de teores. Clow (1991) examinou 25 
mineraçōes de ouro no Canadá e verificou que apenas 3 projetos cumpriram as expectativas.

O erro em uma estimativa não ocorre apenas no cálculo dos recursos minerais. Existem diversas fontes de erro nas várias etapas de uma pesquisa geológica que devem ser conhecidas e minimizadas. Por esse motivo, antes mesmo de iniciar o processamento do cálculo das estimativas de recursos e reserva mineral deve-se ter em mente quais as possíveis fontes de erros e incertezas podem estar presentes e quais as melhores técnicas para evitá-los. Aumentando assim a confiabilidade nos resultados obtidos na estimativa. Encontram-se listado abaixo as principais fontes de erros e incertezas associados à avaliação ce recursos minerais.

\subsection{Determinação do método de amostragem}

Antes mesmo do inicio de uma pesquisa mineral já devemos estar atentos para os possiveis erros que os métodos a serem empregados podem gerar. A definição do método de amostragem a ser utilizado é de extrema importancia para a caracterização do minério em estudo. Atualmente, o método de amostragem mais aceito e mais utilizado em uma pesquisa mineral é a sondagem rotativa diamantada que tem como principal caracteristica a geração de núcleos de amostragem (testemunhos) pouco deformados sendo possivel visualizar texturas e estruturas da rocha e do minério em estudo, com baxxo indice de contaminaça e sendo possivel a amostragem em grandes profundidades.

Outros métodos de amostragem também são utilizados como a escavação de poços, trincheiras e canaletas além de outros métodos de sondagem como a sondagem a trado e a rotopercursiva.

Poços, trincheiras e canaletas apesar de serem métodos bem menos custosos não conseguem amostrar em profundidade. A sondagem a trado só pode ser utilizada para sedimentos inconsolidados não perfurando a rocha fresca. A sondagem rotopercursiva é outro método bastante utilizado sendo mais barato que a sondagem rotativa, entretanto, este não alcança a mesma profundidade de investigação de uma sondagem rotativa além de apresentar problemas de contaminacão nas amostras. 


\subsection{Preparação e análise química das amostras}

Os efeitos de uma amostragem mal realizada podem proporcionar uma grande variação na avaliação final. Muitas vezes, essa fonte de erro é ignorada ou não levada em consideração com merecida importância. De acordo com Dominy, Annels e Noppé (2002a), o erro total do resultado de uma amostragem é composto por uma série de possiveis fontes de erro (representatividade e preparação da amostra, erros de preparação e análise da amostragem e transcrição dos dados obtidos).

A representatividade de uma amostragem pode ser influenciada pela escolha da malha que pode ser inadequada para o depósito em avaliação e não determinará, com relativa confiança, a continuidade geológica e de teor do corpo mineralizado. Métodos de amostragem e volume da amostra também podem ser inadequados para um determinado depósito. Problemas de contaminação e mudança no suporte amostral alteraram, significativamente, a precisão do resultado final.

As potenciais fontes de erro durante as fases de preparação e análises da amostras incluem as elapas de reduça da amostra, britagem e preparação da polpa, contaminaçäo, falsificação, escolha de procedimentos e método analítico, transcrição dos dados e experiência do técnico do laboratónio. Grande parte desses erros pode ser minimizado através de técnicas de controle de qualidade das análises, equipamentos adequados e criação de procedimentos para a realização da preparação e análise da amostra.

Os erros provenientes dos resultados químicos das amostras podem influenciar na construção do semivariograma, afetando assim a estimativa de todo o depósito mineral. Esse fator é mais evidente na determinação do efeito pepita do semivariograma. O efeito pepita é um termo em geoestatística que descreve o nivel de variabilidade entre duas amostras muito próximas, entretanto, Donniny (2004) demonstra que altos valores no efeito pepita podem estar relacionados a uma má qualidade nas análises quimicas.

O tema da garantia da qualidade e controle de qualidade das análises químicas (quality control/quality assurance - QA/QC) durante todas as fases de um empreendimento tem estado em evidência na indústria mineral desde o caso Bre- $X$ (Dominy; Amers; Noppe, 20020). O controle de qualidade e garantia das análises é 
realizada através de normas e procedimentos laboratoriais que certificam os resultados obtidos com a introdução e análise de amostras de controle como padrões, duplicatas, triplicatas e amostras em branco (amostra que não contém o elemento que está sendo analisado).

As técnicas de QA/QC são obrigatórias no Canadian National Instrument 43-101 (CSA, 2001) e apesar de não estarem descritas como procedimento obrigatório no Template CRIRSCO, a utilização dessa metodologia está implícita nas descrições dos procedimentos de amostragem (CRISCO, 2006).

\subsection{Geração do banco de dados geológicos}

Toda a avaliação de recursos minerais é feita a partir de uma base de dados geológicos obtido durante toda a etapa da pesquisa mineral. o banco de dados é gerado a partir da coleta, gravação, armazenamento e processamento dos dados obtidos.

Diversos erros podem ocorrer nessa etapa do processo. Entre eles podemos citar o erro na entrada de dados, erros de localização e inclinação de furos de sonda, erros na transcrição dos intervalos geológicos dos furos de sonda, erros de escala, erros na conversão de norte magnético/norte verdadeiro e na conversão de datum.

Outro tipo de erro muito comum durante a geração do banco de dados é a importação dos resultados analíticos de laboratónio para o software a ser utilizado. Muitas vezes essa importação é feita digitando os dados recebidos pelo laboratório para uma planilha digital. Com isso erros de digitação são comuns de acontecer. Atualmente, a fim de minimizar essa forma de erro, diversos softwares de mineração apresentam uma interface de comunicação com o laboratório onde os resultados gerados por um determinado equipamento de análise química são automaticamente impontados para o banco de dados geológico.

Atenção especial deve ser dada na verificação e validação do bando de dados geológicos, pois um erro cometido nessa fase poderá afetar toda a classificaça dos recursos minerais de um depósito. Sua validação é essencial e faz parte dos procedimentos de QAQC (Dominy; Annels; Noppé, 2002b). 


\subsection{Definição da densidade}

A determinação da densidade in situ de um depósito é outro fator importante, pois influenciará diretamente no volume de minério estimado, mas muitas vezes é negligenciado. Em muitos casos, a densidade é determinada a partir de um inadequado número de análises ou não se leva em consideração a variabilidade da densidade do depósito em função do grau de oxidação, intemperismo e presença do nivel freático ou zonas mineralizadas (Dominy; Annels; Noppé, 2002a).

Erros na determinação da densidade, em geral, não afetam significativamente a determinação do volume de um depósito mineral, entretanto, erros de poucos por centos nas estimativas de volume pode ser um fator decisivo para a viabilidade econômica de um projeto (Lipton, 1997).

\subsection{Definição, interpretação e modelagem do depósito mineral}

A massa mineralizada de uma jazida é interpretada a partir dos dados de amostragem gerados durante a pesquisa mineral. Os limites desse depósito mineral podem, muitas vezes, apresentar erros na interpretação de sua geometria. Esse tipo de erro é agravado em depósitos disseminados e de contatos gradacionais onde, geralmente o teor de corte é que irá definir as bordas do corpo mineralizado (Annels, 1996).

A interpretação e definição dos limites influenciam diretamente na determinação do volume de minério existente. A falta de informação, erros de interpretação e erros de localização da amostragem são as principais fontes para uma definição equivocada dos limites do minério.

Atualmente, a interpretação geológica de um depósito mineral é feita com o auxilio de softwares especificos para esse fim. Os dados da pesquisa mineral são importados para uma determinada plataforma computacional onde podem ser visualizados em três dimensões. A partir destes dados o depósito mineral é desenhado. Geralmente essa interpretação é realizada a partir da construção de perfis em duas dimensöes que posteriormente são unidos originando um corpo tridimensional. 
O erro de interpretação mais comum nessa fase é cometido na extrapolação do corpo mineralizado para locais além do último furo onde o minério foi encontrado. Essa extrapolação pode muitas vezes ser exagerada aumentando consideravelmente o volume do depósito (Figura 3.1a), ou conservadora demais a ponto de diminuir drasticamente a tonelagem de minério (Figura 3.1b). Para evitar esse tipo de interpretação equivocada é comum adotar a metodologia de extrapolar o limite do depósito até a metade do espaçamento entre a amostragem (Figura 3.1c) a não ser em casos onde alguma estrutura geológica interfira nesse limite.
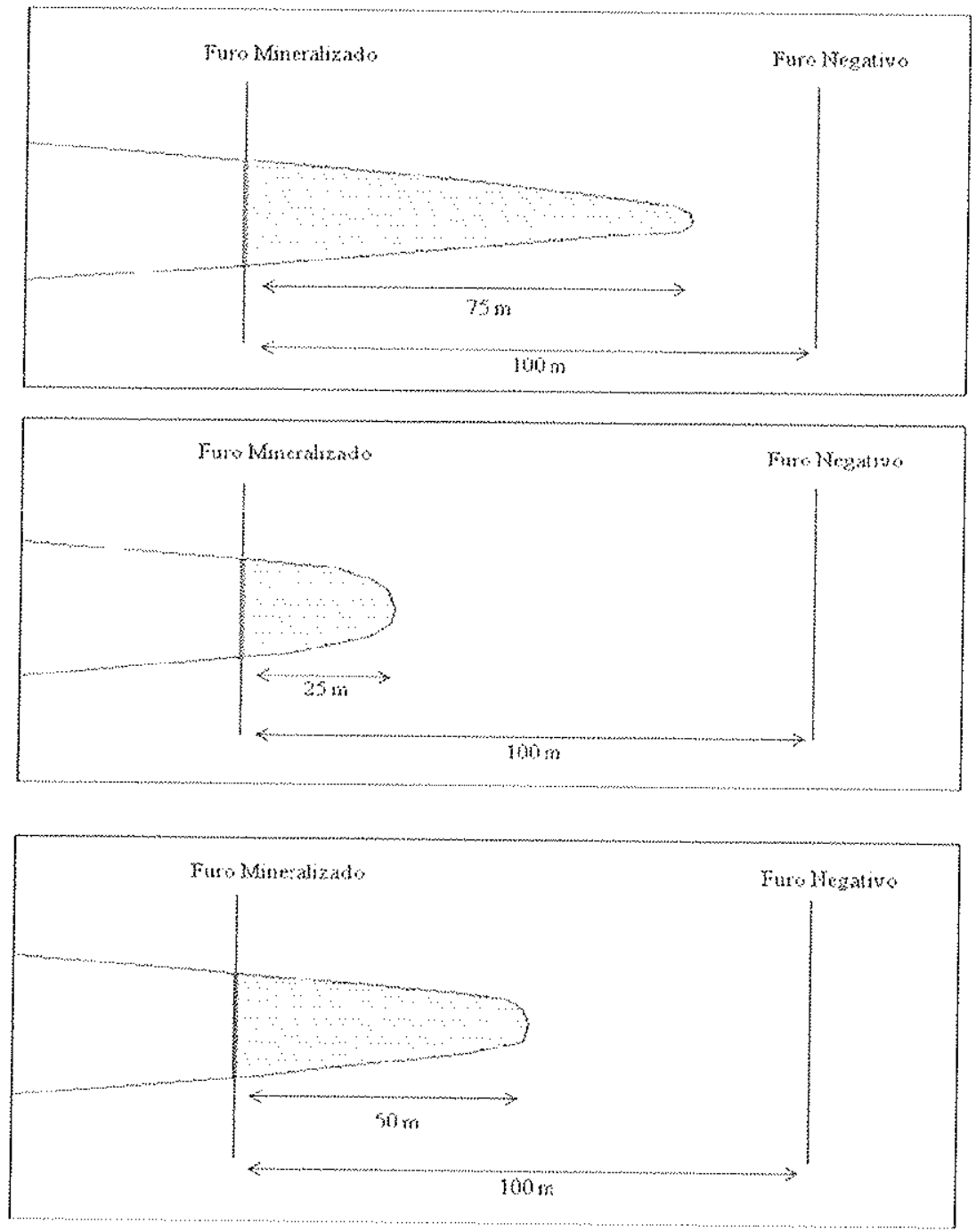

Figura 3.1 - Exemplos de interpretação do limite do corpo mineralizado por extrapolação a partir do último furo de sonda com intervalo mineralizado. A) Interpretação otimista com o limite a $3 / 4$ de distância entre os furos. B) Interpretação conservadora com o limite a $1 / 4$ de distância entre os furos. C) Interpretação padrão com o limite na distância média entre os furos. Considerando a área do corpo entre o último furo mineralizado e o limite (área hachurada). A) corresponde a uma área $31 \%$ maior que a interpretação padrão (C). B) representa apenas $56 \%$ da área mineralizada da interpretação padrão (C) 
Outro fator importante e muitas vezes ignorado é a medição do desvio da inclinação de um furo de sonda. Geralmente, a inclinação do furo é considerada constante em toda sua extensão, no entanto, sabe-se que furos profundos tendem a desviar devido o peso das hastes, dureza da rocha, presença de cavidades e velocidade de perfuração. Dominy, Annels e Noppé, (2002a) descrevem que se um furo de sonda tiver um desvio em sua inclinação de apenas $1^{\circ}$ a cada 50 metros e este desvio não for considerado, após 500 metros, a localização dessa amostra teria um erro de aproximadamente 40 metros com relação a sua posição original (Figura $3.2)$.

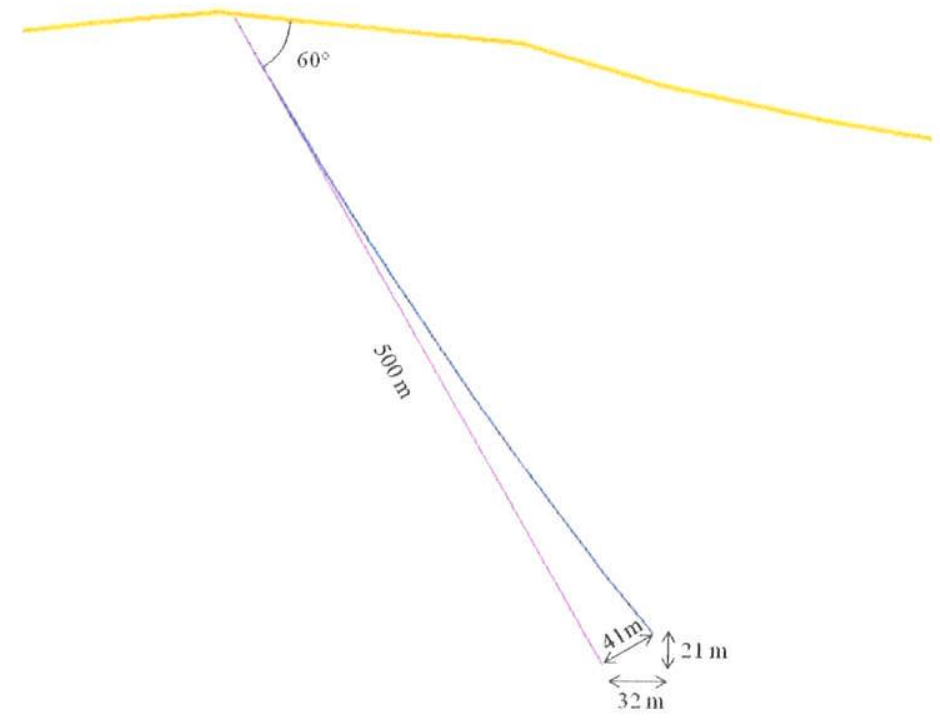

Figura 3.2 - Exemplo de um furo de sonda com desvio de $1^{\circ}$ a cada 50 metros interpretado como furo sem desvio. Após 500 metros de perfuração a diferença entre a real locação e a interpretação é de aproximadamente 41 metros

A interpretação do corpo mineralizado depende muito do conhecimento geológico da área em estudo, por isso essa deve ser feita ou acompanhada pelos profissionais que trabalharam na execução da pesquisa geológica, pois o conhecimento adquirido é de extrema importância para o resultado final da interpretação geológica. Por exemplo, a falta de conhecimento na geologia de uma jazida pode resultar na não inclusão de estruturas geológicas como falhas e dobras que podem interferir na estrutura e limites da jazida. 


\subsection{Interpretação da continuidade}

A qualidade da estimativa dos recursos minerais depende do grau de conhecimento geológico e da variabilidade dos teores que são definidos através dos dados obtidos durante a pesquisa mineral. A interpretação desses dados é que irá definir o modelo litológico do depósito, o corpo mineralizado e suas relações.

Segundo Dominy, Annels e Noppé (2002b) dois tipos de continuidade devem ser bem entendidos antes de se processar o cálculo de estimativa de um depósito mineral:

(i) continuidade geológica - continuidade geométrica do corpo mineralizado, seu formato, atitude, mergulho e relações com o modelo litológico.

(ii) continuidade dos teores - a variabilidade do teor na zona mineralizada, conhecimento das zonas de alto e baixo teor e suas relações com o modelo litológico.

A continuidade geológica do depósito está intimamente ligada ao cálculo de volume do bem mineral enquanto a continuidade dos teores determinará as zonas de alto e baixo teor, variabilidade e direção de anisotropia ao longo do depósito.

O nivel de conhecimento e interpretação da continuidade de um dado setor do depósito mineral influência diretamente na classe de recurso ou reserva mineral em que este deverá ser classificado. A Tabela 3.1 ilustra os critérios de continuidade que devem ser levados em consideração para a determinação da classe de recurso/reserva de acordo com o grau de conhecimento da continuidade. 
Tabela 3.1 - Critério geral de continuidade para as diferentes classes de recursos/reservas minerais (Dominy; Annels; Noppé, 2002b)

\begin{tabular}{|c|c|c|c|}
\hline Classe de Recurso/Reserva & Densidade de informaf̧āo & Continuldade geológica & Continuidade com relação ao teor \\
\hline Recurso inferido & $\begin{array}{l}\text { - Baseado em interpretação geológica } \\
\text { e dados isolados au muito espaçados. }\end{array}$ & $\begin{array}{l}\text { - Continuidade global interpretada } \\
\text { mas não confirmada. } \\
\text { - Sem dacios suficientes para } \\
\text { confirmar a continuidade local. } \\
\text { - Estimativa da tonelagem local com } \\
\text { gfande margem de erro. }\end{array}$ & $\begin{array}{l}\text { - Continuidade nâo estabeletia a näo } \\
\text { ser ao longo dos furos. } \\
\text { - Estimativa do teor global definida com } \\
\text { grande margem de erro. } \\
\text { - Sem precisão local. }\end{array}$ \\
\hline $\begin{array}{l}\text { Recurso Indicado } \\
\text { (Reserva Provável) }\end{array}$ & $\begin{array}{l}\text { - Baseado em interpréaçăo geológica } \\
\text { e dadas moderadamente espaçados. }\end{array}$ & $\begin{array}{l}\text { - Continuidade global definida. } \\
\text { - Continuidade local não definida ao } \\
\text { longo de todo o corpo mineralizado mas } \\
\text { confirmada ao longo dos furos. } \\
\text { - Estimativa da tonelagem giobal e local } \\
\text { definida com mediana margem de erro. }\end{array}$ & $\begin{array}{l}\text { - Continuidade do teor global definido. } \\
\text { - Continuidade do teor local parcialmen- } \\
\text { te estahelecido mas não confirmado. } \\
\text { Confirmado apenas ao longo dos furos. } \\
\text { - Estimativa do teor global e local } \\
\text { definido com mediana margem de erro. }\end{array}$ \\
\hline $\begin{array}{l}\text { Recurso Medido } \\
\text { (Reserva Provada) }\end{array}$ & $\begin{array}{l}\text { - Baseado em interpretação geológica } \\
\text { e dados pouco espaçados. }\end{array}$ & $\begin{array}{l}\text { - Continuidade global definida. } \\
\text { - Continuidade local definida. } \\
\text { - Estimativa da tonelagem giobal a local } \\
\text { definida com baixa margem de erro. }\end{array}$ & $\begin{array}{l}\text { - Continuidade do teor global definido. } \\
\text { - Continuidade do teor local definido. } \\
\text { - Detalthamento da variaçáo do teor } \\
\text { ao longo do depósito. } \\
\text { - Estimativa do teor global e local } \\
\text { definido com baixa margem de erro }\end{array}$ \\
\hline
\end{tabular}

\subsection{Seleção e aplicação do método de estimativa}

O método a ser empregado na estimativa dos recursos minerais é de extrema importância e deve ser cuidadosamente escolhido. A definição do método apropriado deve levar em consideraçăo a geologia, continuidade e variabilidade do deposito (Annels, 1996).

A maioria dos erros introduzidos nessa fase da avaliação está intimamente ligada à escolha da dimensão dos tamanhos dos blocos em relação ao modelo, espaçamento e densidade da amostragem, definição da vizinhança e construção e interpretação do semivariograma no caso de avaliações realizadas por técnicas geoestalisticas. Recomenda-se a utilização da técnica de validação cruzada para verificar a eficiência do método escolhido. Essa técnica compreende na retirada de um valor do conjunto de dados para então se estimar esse mesmo ponto com os parâmetros a serem usados na interpolação dos pontos não amostrados, ou seja, o modelo teórico do variograma e as condições de vizinhança. Após a estimativa compara-se o valor real e o estimado, com essa análise é possivel observar possiveis vieses na estimativa (Davis, 1997).

Como pode ser observado, existem diversas fontes de erros que podem interferir no resultado final de uma avaliação de recursos minerais. Por esse motivo, em todas as fases de uma pesquisa mineral e viabilidade econômica de um empreendimento mineiro deve-se conhecer, avaliar e evitar ao máximo a ocorrência desses erros. 
Para avaliar a precisão e confiabilidade das informações geológicas utilizadas na classificação de recursos minerais, Annels (1996) propôs um método de classificação baseado nos moldes do sistema de classificação geomecânica de maciços rochosos proposto inicialmente por Bieniawski (1989) que atribui uma nota de 0 a 100 para determinar a classe na qual o maciço se encontra. Esse sistema denominado Resource Reliability Rating System (RRR) constitui uma série de questionamentos em relação à qualidade dos dados obtidos e atribui uma nota ranqueada de 0 a 100 que poderá auxiliar na definição das classes de recursos do depósito em estudo. 


\section{CAPÍTULO 4 \\ CÁLCULO DE RECURSOS MINERAIS}

A avaliação dos recursos e reservas minerais de uma jazida depende fundamentalmente de estimativas efetuadas a partir de variáveis (teor, densidade, espessura etc.) medidas no depósito. Estas estimativas podem ser realizadas através de diversos métodos que, na literatura especializada, são classificados como tradicionais e métodos com abordagem geoestatística, sendo esse último o método mais utilizado nos dias de hoje.

A geoestatistica foi definida inicialmente por Matheron (1963) como a aplicação da Teoria das Variáveis Regionalizadas para a estimativa de depósitos minerais. Atualmente, a geoestatistica tem aplicação nas mais diversas áreas do conhecimento (geotecnia, agronomia, engenharia florestal, meio ambiente, petróleo e hidrogeologia). A grande vantagem da aplicação dos métodos geoestatísticos para o cálculo dos recursos minerais é a possibilidade de calcular a incerteza associada a esta estimativa.

\subsection{Krigagem ordinária}

A krigagem ordinária tornou se padrão na indústria mineral para o cálculo de recursos minerais. Como introduzido anteriormente, esta técnica foi a primeira a oferecer uma medida de incerteza associada à estimativa, por meio da varianncia de krigagem. Essa técnica faz o melhor uso do conhecimento existente, levando em consideração a maneira com que uma dada propriedade varia no espaço através de um modelo de variograma. O variograma ou semivariograma descreve a correlação espacial da variável em estudo.

Em sua formulação original, uma estimativa obtida por krigagem para uma determinada localização é, na verdade, nada mais que a combinação linear ou uma média ponderada dos dados em sua vizinhança, onde os pesos são alocados para cada amostra dessa vizinhança, de maneira que seja minimizada a variância do erro da estimativa (Souza, L. E., 2007). 
Considerando a estimativa de um valor em um ponto não amostrado $Z\left(x_{0}\right)$ com uma vizinhança de dados $Z\left(x_{i}\right)$ onde $i=1,2, \ldots, n$, o estimador de krigagem ordinária pode ser descrito pela seguinte equação (Armstrong, 1998):

$$
Z_{k o}^{*}\left(x_{0}\right)=\sum_{i=1}^{n} \lambda_{i} Z\left(x_{i}\right)
$$

onde os ponderadores $\left\{\lambda_{i}, i=1, n\right\}$ são obtidos a partir de um sistema linear de equações (sistema de krigagem) construído com a finalidade de não enviesar a estimativa e obter a mínima variância de krigagem possivel. Esse sistema de krigagem é expresso em notação matricial:

$$
\left[\begin{array}{cccc}
\gamma\left(\mathrm{x}_{1}, x_{1}\right) & \ldots & \gamma\left(\mathrm{x}_{1}, x_{n}\right) & 1 \\
\vdots & \ddots & \vdots & \vdots \\
\gamma\left(\mathrm{x}_{n}, x_{1}\right) & \cdots & \gamma\left(\mathrm{x}_{n}, x_{n}\right) & 1 \\
1 & \cdots & 1 & 0
\end{array}\right] x\left[\begin{array}{c}
\lambda_{1} \\
\vdots \\
\lambda_{n} \\
\mu
\end{array}\right]=\left[\begin{array}{c}
\gamma\left(\mathrm{x}_{1}, x_{0}\right) \\
\vdots \\
\overline{\gamma\left(\mathrm{x}_{n}, x_{0}\right)} \\
1
\end{array}\right]
$$

onde $\mu$ é o multiplicador de Lagrange.

Essa matriz é calculada para cada ponto a ser estimado e indicará o peso a ser aplicado em cada mostra que participará da estimativa do ponto. Esses pesos são baseados no modelo de variograma (ou covariância) e são definidos de acordo com a distância e anisotropia da amostragem. A definição das amostras que serão utilizadas para a estimativa de um determinado ponto é feita através da utilização de um elipsóide de busca. Sua forma e tamanho são baseados na elipse de anisotropia do modelo de variograma (Souza A. L., 2007).

\subsection{Erros e incertezas}

Devemos atentar e distinguir com cuidado os termos erro e incerteza. Esses termos não são sinônimos, ao contrário, representam conceitos completamente diferentes e não devem ser confundidos nem mal empregados.

Por definição, erro é a diferença entre o valor obtido por um processo de medição e o valor verdadeiro da grandeza medida (JCGM, 2008a). Como tal, o erro é um valor único. Em principio, o valor de um determinado erro pode ser aplicado na correção do resultado. Supondo-se o valor conhecido no ponto $x_{i}$ e o valor 
estimado neste mesmo ponto, sem considerar a informação desse ponto, ou seja, o valor real; pode-se calcular o erro como:

$$
\varepsilon=Z_{K o}^{*}\left(x_{0}\right)-Z\left(x_{0}\right)
$$

O erro relativo percentual $\varepsilon(\%)$ é definido por:

$$
\varepsilon(\%)=\frac{Z\left(x_{o}\right)-Z_{K O}^{*}\left(x_{o}\right)}{Z_{K O}^{*}\left(x_{v}\right)} 100
$$

$\mathrm{Na}$ teoria de erros, o erro $\varepsilon$ é uma quantidade desconhecida que é determinada em termos de probabilidades. A distribuição de probabilidades para valores do erro $\varepsilon$, em um particular processo de medida pode ser entendida como distribuição de erros. $O$ erro $\varepsilon$ em um valor experimental $y$ tem diversas causas, que significa que o erro total pode ser escrito como a soma de erros elementares $\varepsilon_{1}, \varepsilon_{2}, \ldots, \varepsilon_{n}$.

Portanto, temos:

$$
\varepsilon=\varepsilon_{1}+\varepsilon_{2}+\cdots+\varepsilon_{n}
$$

Como, por definição, erro é a diferença entre o valor obtido no processo de medição e o valor verdadeiro do mensurando, decorre que o erro é uma quantidade, ora positiva ou ora negativa. Portanto, a avaliação do erro de uma medida depende do conhecimento prévio sobre o valor real do mensurando (Vuolo, 1996).

Já a incerteza de uma medida, por outro lado, caracteriza-se por uma faixa de valores que são provavelmente próximo do valor real (Vuolo, 1996). A incerteza, por sua vez, é uma estatistica que expressa quantitativamente a qualidade do resultado de uma medição (JCGM, 2008a). E um valor não negativo que caracteriza a dispersão dos valores que razoavelmente podem ser atribuidos ao mensurando (JCGM, 2008b). Quanto maior for essa dispersão, menos confiável será o resultado da medição. Por isso, a incerteza pode ser considerada uma medida da dúvida racional que se tem no valor experimentalmente atribuido a uma grandeza.

Como mencionado anteriormente, a krigagem ordinária foi a primeira técnica a proporcionar uma medida de incerteza, por meio da variância de estimativa ou de krigagem: 


$$
\sigma_{k v}^{2}=\sum_{i=1}^{n} \lambda_{i} \bar{\gamma}\left(x_{i}-x_{o}\right)+\mu
$$

A variância de krigagem não considera os valores dos pontos de dados, ao invés disto, leva em consideração somente os valores médios da função variograma entre os pontos da vizinhança $x_{i}, i=1, n$ e o ponto não amostrado a ser estimado $x_{0}$. Journel e Rossi (1989) demonstraram que a variância de krigagem nada mais é que um índice da configuração espacial dos pontos vizinhos utilizados para a estimativa de um ponto não amostrado. Assim, se uma mesma configuração espacial de pontos vizinhos se repetir a variância de krigagem será a mesma para arranjos iguais, independentemente dos valores dos pontos de dados. Essa característica é conhecida em estatistica como homoscedasticidade da variância (Olea, 1999).

Uma alternativa à variância de krigagem foi oferecida por Yamamoto (2000) e foi denominada variância de interpolação:

$$
s_{o}^{2}=\sum_{i=1}^{n} \lambda_{i}\left(Z\left(x_{i}\right)-Z_{K o}^{*}\left(x_{o}\right)\right)^{2}
$$

Em oposição à variância de krigagem, a variância de interpolação tem um caráter heteroscedástico, ou seja, depende dos valores dos pontos de dados.

As fontes de incertezas são as mesmas que as dos erros, apesar de representarem indicadores e conceitos diferentes. As incertezas são quantificações aproximadas, com um determinado grau de confiança dos erros decorrentes de um processo de medida. Em problemas ligados à avaliação de recursos minerais, a principal fonte de incerteza está ligada à variabilidade natural dos depósitos minerais, sendo que a incerteza é diretamente proporcional à variabilidade. Na realidade, toda estimativa baseada em amostragern está sujeita a erros e incertezas. Evidentemente, quando a mineralização apresentar grande variabilidade a amostragem deve ser direcionada a capturar essa variação. Mas, isso nem sempre é possivel, pois a amostragem está limitada ao orçamento da pesquisa mineral. Assim, sempre existirá uma incerteza com a qual se deve fazer o melhor uso para a classificação de recursos minerais.

A incerteza pode ser utilizada para calcular o intervalo de confiança em torno de uma estimativa. Esse intervalo é a faixa onde se espera encontrar o valor verdadeiro 
da estimativa e indica qual é a probabilidade que essa estimativa pertença a faixa de valores. Yamamoto (1999) e Yamamoto e Conde (1999) utilizaram a metade do intervalo de confiança calculado com base no desvio padrão de interpolação para classificação de recursos minerais.

\subsection{Correção do efeito de suavização da krigagem ordinária}

A krigagem ordinária tem sido utilizada pela indústria para avaliação de recursos minerais, pois apresenta grande precisão local, a qual pode ser medida pela correlação entre os valores estimados e os valores utilizados para obtenção dos mesmos. Os resultados, contudo, apresentam uma suavização, dada pela variância reduzida quando comparada à variância das amostras. O efeito de suavização ocorre porque a krigagem ordinária realiza as estimativas, por meio da minimização da variância do erro. O resultado desse efeito é que áreas de alto teor são subestimadas e áreas de baixo teor são superestimadas suavizando o teor em áreas anômalas do depósito (áreas com alto ou baixo teor). Este comportamento resulta na perda de precisão global da estimativa, refletido pelo fato de que o histograma e variograma da estimativa não reproduzirem seus correspondentes amostrais. $O$ problema da ocorrência do efeito de suavização é acentuado em situações em que o interesse esteja nos valores extremos da variável aleatónia. O que é bastante comum em estimativas de depósitos minerais, por exemplo, na estimativa da concentração em depósitos de metais raros, são os altos teores que viabilizam o empreendimento (Watanabe, 2008).

Apesar da recente popularização das técnicas de simulação seqüencial, alguns autores buscaram aprimorar as técnicas de geoestatistica linear com o objetivo de tentar corrigir o efeito de suavização. Estes trabalhos apresentam como principal caracteristica o pós-processamento das estimativas através de parâmetros obtidos a partir do déficit de variância, entre os quais podemos citar Journel e Xu (1994), Guertin (1984), Olea e Pawlowsky (1996), Pan (1998), Joumel, Kyriakidis e Mao (2000) e Yamamoto (2005).

Dentre esses métodos, o algoritmo de pós processamento publicado por Yamamoto (2005) e atualizado por Yamamoto (2007) corrige o efeito de suavização da krigagem ordinária recuperando a precisão global mantendo a precisão local. 
Segundo Yamamoto (2005), pode-se derivar o erro verdadeiro em todos os pontos de amostragem através da validação cruzada. Após este processo, além dos valores observados ou reais, os pontos de amostragem apresentam os valores estimados e a incerteza medida por meio da variância de interpolação ou sua raiz quadrada o desvio padrão de interpolação. A idéia básica desse algoritmo é justamente transferir para os pontos não amostrados um erro dado pela diferença entre o valor estimado e o valor verdadeiro ou observado. Contudo, ao invés de transferir diretamente o erro que pode flutuar largamente, dependendo da variação dos pontos de dados, Yamamoto (2005) propôs transferir por meio de uma nova variável, que foi denominada número de desvios padrão de interpolação:

$$
N_{S_{o}}=\frac{- \text { ErroVerdadeiro }}{S_{0}} \operatorname{com} S_{o} \neq 0
$$

Essa nova variável é estimada em todos os pontos não amostrados e depois utilizada para fazer a correção do efeito de suavização da krigagem ordinária. Após o processamento da krigagem ordinária, o valor estimado e sua incerteza são combinados com o número de desvios padrão de interpolação resultando no valor corrigido. A expressão da krigagem ordinária corrigida fica (Yamamoto, 2007):

$$
Z_{K o}^{* *}\left(x_{o}\right)=Z_{K o}^{*}\left(x_{n}\right)+Z_{N S_{s}^{*}}^{*}
$$

onde $Z_{N S,}^{*}$ representa o erro de suavização. Os detalhes desse algoritmo de pósprocessamento se encontram em Yamamoto $(2005,2007)$. Deve-se observar que a nova variável combina erro com incerteza.

\subsection{Krigagem multi-Gaussiana}

Nesse trabalho serão utilizados modelos hipotéticos de depósitos minerais com distribuição lognormal que é o tịpo de distribuição mais comum encontrado em depósitos minerais de metais raros. Para esse tipo de distribuição, Journel (1980) propõe o uso da krigagem lognormal que trabaha no dominio logaritmico e após as estimativas os dados são novamente transformados para o dominio real. No entanto, Yamamoto e Furuie (2010), após testar diversos algoritmos de transformação, concluiram que a krigagem multi-Gaussiana é a que apresenta os melhores resultados em lemos de reproduçäo to histograma amostral. Assim como a 
krigagem lognormal que faz a transformada logaritmica, processa o cálculo da krigagem ordinária dos dados transformados e depois é realizada a transformada reversa para o dominio original. A krigagem multi-Gaussiana faz a krigagem ordinária dos dados transformados para o campo Gaussiano e depois, por meio da transformada reversa, se obtém as estimativas no domínio original dos dados. Contudo, durante o processo da transformação reversa as estimativas transformadas para o dominio original irão sempre apresentar vieses devido ao efeito de suavização da krigagem ordinária. A grande diferença do método proposto por Yamamoto (2007) para a krigagem lognormal e depois generalizado por Yamamoto e Furuie (2010) está na correção do histograma das estimativas krigadas no domínio transformada para depois fazer a transfomada reversa. A efetividade do método foi testada pelos artigos mencionados.

A krigagem multi-Gaussiana pode ser realizada para se obter a média e variância da variável transformada que é suficiente para definir a distribuição condicional completa no domínio Gaussiano. A distribuição condicional completa em unidades originais pode ser recuperada através da transformação reversa dos valores de $z$ no dominio Gaussiano. Em teoria, a informaçăo disponivel nos permite calcular a estimaliva de minima variancia em qualquer ponto do dominio a partir das técnicas de krigagem (Ortiz; Leauangthong; Deutsch, 2004).

No entanto, para a utilização da krigagem multi-Gaussiana, deve-se testar a multigaussianidade dos dados, ou seja, não basta fazer a transformada Gaussiana e garantir a gaussianidade do histograma amostral, mas também que as distribuições de $2,3, \ldots, n$ pontos também sejam Gaussianas. Como é extremamente trabalhoso testar a hipótese de gaussianidade para as distribuições de $2,3, \ldots, n$ pontos, Goovaerts (1997) propõe que a hipótese de gaussianidade seja testada comparando os variogramas de funçōes indicadoras para certos percentis da distribuição com o modelo teórico Gaussiano. Se o ajuste for bom, considera-se a hipótese de bigaussianidade dos dados e assim, conseqüentemente aceita-se a hipótese de multigaussianidade dos dados. Yamamoto e Chao (2009) propõe que o teste seja realizado comparando os variogramas de funções indicadoras para três quartis ou nove decis da distribuição. 


\subsection{Simulação Estocástica}

$\mathrm{Na}$ tentativa de corrigir o problema gerado pelo efeito de suavização nas estimativas foram desenvolvidas as técnicas de simulação estocástica (Deutsch; Journel, 1992). Esses métodos nos permitem gerar imagens equiprováveis de um fenômeno regionalizado nas quais são reproduzidas, em cada uma delas, a média, o histograma, a variabilidade espacial (representada pelo semivariograma) e a influência espacial dos valores experimentais (Soares, 2006).

Os modelos mais recentes e mais utilizados pela indústria mineira são os métodos de simulação de imagens equiprováveis tem por base uma abordagem de simulação seqüencial que buscam adicionar a precisão local às múlitiplas realizaçôes da simulação mantendo a precisão global.

Segundo Caers (2000), o principal defeito da krigagem, que resulta na suavização dos valores estimados ocorre, pois os pontos não amostrados são estimados independentemente, ou seja, o valor estimado em um ponto $x_{0}$ não leva em consideração um valor previamente estimado em $x_{0}$. Ainda segundo esse autor, esta é a principal razão pela qual a krigagem não reproduz a associação espacial correta, como descrita pelo semivariograma.

Nos métodos seqüenciais, o valor simulado em cada ponto $x_{o}$ é retirado de uma função de distribuição de probabilidade, a qual é computada usando tanto os dados reais como também os dados previamente simulados na vizinhança desse ponto (Hohn, 1999). A seqüência dos nós da malha regular a ser simulada, é definida aleatoriamente, que resulta no chamado passeio aleatório (Deutsch; Joumel, 1992). Segundo Hohn (1999), o que difere nos métodos seqüenciais, é a maneira como a função de distribuição de probabilidade é calculada.

Assim, as simulações seqüenciais geram para cada nó da malha regular um valor que é resuntado da estimativa local mais ou menos um valor derivado da variancia de krigagem simples. A adição ou subtração desse valor garante a reprodução do histograma e conseqüentemente da variabilidade espacial descrita pelo semivariograma. Entretanto, este mesmo procedimento é responsável pela perda da precisão local, pois a estmativa da knjgagem simples já apresenta certa precisão local. O grande problema da simulação estocástica é a adição ou subtração de uma 
quantidade aleatória, que é responsável pela perda da precisão local (Souza, A. L., 2007).

A grande vantagem de ordem prática dos modelos de simulação é que estes permitem o acesso à incerteza da estimativa, que pode ser quantificada através de mapas de probabilidades das imagens equiprováveis calculadas fornecendo assim subsídios para analises de risco (Soares, 2006).

Yamamoto (2008) comparando a simulação seqüencial Gaussiana com a krigagem ordinária após o processamento do algoritmo de correção do efeito de suavização demonstra que a krigagem é uma melhor alternativa, pois consegue reproduzir em uma única imagem as precisões locais e globais. 


\section{CAPÍTULO 5 \\ CLASSIFICAÇÃO DE RECURSOS MINERAIS BASEADOS \\ NA MEDIDA DE INCERTEZA}

Ao longo do tempo, a indústria mineira vem utilizando diversas metodologias para classificar os recursos minerais de seus depósitos. Essa classificação é base dos estudos de viabilidade econômica que determinará se o depósito poderá vir a ser explotado futuramente. Além disso, esse inventário mineral é utilizado em negociações financeiras como compra e venda de jazidas, capitação de recursos para investimento, garantia de empréstimo, entre outras.

As estimativas de volume e teor de um bem mineral são obtidas a partir um conjunto de amostras representativas em um determinado domínio. A partir dos dados de amostragem o corpo mineralizado é interpretado em três dimensões através de algum software especifico para mineração. Esse corpo então é subdivido em um conjunto de blocos com tamanho definido dependendo da malha de amostragem e fatores de mineração (tipo de lavra, produção anual etc.). O teor médio de cada bloco é estimado, por algum método, a partir dos dados amostrais mais próximos. Dependendo do nivel de confiança (subjetivo ou estatístico) dessa estimativa para um determinado blocolárea do depósito, os recursos minerais são agrupados nas distintas classes de recursos minerais.

A avaliação dos recursos minerais está sujeita a erros e incertezas, pois é baseada em amostragem. Esse erro pode estar relacionado às etapas de obtenção dos dados amostrais ou associado diretamente à estimativa realizada a partir dos dados obtidos. Portanto, classificar recursos minerais de uma jazida, compreende em não só determinar qual a quantidade existente do minério, seu teor global e local, mas também em compreender qual é o grau de certeza associado a essa estimativa.

Como exposto no Capítulo 2 , os códigos que visam à padronização da classificação de recursos e reservas minerais não citam qual método deve ser utilizado em sua classificação, deixando a cargo de um profissional competente tal escolha. Com a falta de normas que prescrevam uma metodologia para a estimativa de teores nesses códigos, vários trabalhos, apresentando diferentes abordagens com o objetivo de determinar a incerteza associada às estimativas podem ser encontrados em Froidevaux (1982), Wellmer (1983), Diehl e David (1982), Annels 
(1991), Vallée e Côte (1992), Stephenson e Stoker (1999), Sinclair e Blackwell (2002), entre outros.

Existem atualmente diversas metodologias para classificação de recursos minerais, que podem ser divididas em dois grupos: os critérios tradicionais ou clássicos e os critérios com abordagem geoestatistica.

Os métodos tradicionais foram muito utilizados na indústria mineira antes da popularização da geoestatística para a avaliação de recursos minerais e vêm sendo utilizados até os dias de hoje. Esses métodos se baseiam principalmente na continuidade geológica do corpo de minério e densidade amostral da pesquisa geológica. Onde as regiōes do depósito que estão compreendidas entre pontos de amostragem e com uma malha mais densa são classificadas com maior grau de certeza que áreas onde o corpo é extrapolado ou a malha de amostragem é espaçada. Dentre os métodos tradicionais, os mais utilizados atualmente são os métodos geométricos, de seçōes, isolinhas, densidade amostral e área de influência da amostragem. Os métodos de classificação com abordagem geoestatística baseiam-se principalmente na determinação da incerteza da estimativa a partir de um determinado intervalo de confiança.

\subsection{Uso do variograma para classificação de recursos minerais}

As propriedades do variograma, construido para estimar as variáveis de interesse de um depósito mineral, muitas vezes são utilizadas para a classificação dos recursos minerais. Usualmente são utilizados dois métodos de classificação de recursos a partir das propriedades do variograma.

A primeira envolve o uso do alcance do variograma. As classes de recursos são classificadas de acordo com a distância das amostras em relação ao alcance do variograma. Por exemplo, todos os blocos estimados com um determinado número de amostras com distância inferior ao alcance do variograma são classificados como medido, com menos amostras, recurso indicado e sem amostra nessas condições, recurso inferido.

Pela segunda metodologia as categorias de recursos seriam baseadas nos valores de patamar. Por exemplo, somente os blocos compreendidos no alcance do variograma correspondente a $2 / 3$ do valor do patamar poderiam ser classificados 
como medidos, acima desse valor ficariam os recursos indicados e fora do valor do patamar seriam os recursos inferidos.

Froidevaux (1982) propôs três classes de classificação utilizando o alcance do variograma:

- blocos dentro da área amostrada e estimado com amostras dentro do raio de influência definido pelo alcance do variograma,

- blocos dentro da área amostrada mas estimado com amostras além do raio de influência definido pelo alcance do variograma $e$,

- blocos do mesmo depósito mas com grande distância dos dados (incluindo blocos extrapolados)

\subsection{Variância de Krigagem}

A variância de krigagem foi bastante utilizada ao longo das últimas décadas para a classificação de recursos minerais. Por ser um método de estimativa que minimiza a variância do erro, a krigagem ordinária pode fornecer uma medida de variância do erro local estimado. Segundo Goovaerts (1997), a modelagem da incerteza associada a um ponto desconhecido consiste em calcular por krigagem o valor do ponto e associar à estimativa a variância de krigagem conforme:

$$
\sigma_{k o}^{2}=\sum_{i=1}^{n} \lambda_{i} \bar{\gamma}\left(x_{i}-x_{0}\right)+\mu
$$

onde $\bar{\gamma}\left(x_{i}-x_{0}\right)$ é a variância espacial entre a vizinhança e o local estimado, $\left\{\lambda_{i}, i=1\right.$, $n\}$ e $\mu$ são, respectivamente, os ponderadores e o Multiplicador de Lagrange.

A partir da variância de krigagem, Froidevaux (1982) e Diehl e David (1982) sugeriram a utilização do Teorema do Limite Central para o cálculo da incerteza da estimativa uma vez que a distribuição dos erros tende a ser uma distribuição tipicamente Gaussiana.

O Teorema do Limite Central é um dos mais importantes teoremas da estatística matemática relacionada com distribuições de freqüências de amostragem e pode ser enunciado, segundo Barnes (1980 apud Yamamoto; Bettencourt; Montaneiro, 2001, 
p. 57) como: 'Se amostras aleatórias de tamanho fixo são retiradas de uma população cuja distribuição teórica é de forma arbitrária, mas com média e variância finitas, a distribuição das amostras tende mais e mais a uma distribuição normal com média $\mu$ e variância $\sigma^{2} / n$ tanto quanto o tamanho das amostras aumenta.'

A partir desse teorema e independentemente do tipo de variância a ser adotada podemos calcular o intervalo de confiança da média com $\mathrm{x} \%$ de probabilidade de conter a média utilizando (David, 1977):

$$
Z *\left(u_{n}\right) \pm t_{n, 1,1 \ldots \alpha / 2,} / \sqrt{\frac{\sigma^{2}}{n}}
$$

onde $Z^{*}\left(u_{0}\right)$ é o valor estimado, $t_{n-1,1-\alpha / 2}$ é $01-\alpha / 2$ ponto crítico superior para a distribuição $t$ de Student com $n-1$ graus de liberdade. O valor de $n$ será igual a o número de dados utilizados na estimativa de cada ponto, no caso de krigagem pontual ou o número de pontos nos quais os blocos foram discretizados no caso de krigagem de blocos.

Assumindo que a distribuição dos erros de uma estimativa é baseada no Teorema do Limite Central e utilizando a variância de krigagem, Diehl e David (1982) e Wellmer (1983) propuseram calcular o erro em torno de uma estimativa, para um determinado intervalo de confiança, através da seguinte expressão:

$$
\text { Erro }=\frac{\sigma_{O K}}{Z *\left(x_{0}\right) \sqrt{n}} t
$$

onde té o valor da distribuição de Student em função do grau de liberdade e nivel de confiança.

Utilizando a metodologia acima descrita Diehl e David (1982) e Wellmer (1983) propuseram classificar recursos minerais conforme a Tabela 5.1. 
Tabela 5.1 - Classificação de recursos baseada na quantificação do erro a partir do desvio padrão de krigagem

\begin{tabular}{cllll}
\hline Autores & \multicolumn{1}{c}{ Provado } & \multicolumn{1}{c}{ Provável } & \multicolumn{1}{c}{ Possível } & \multicolumn{1}{c}{ Inferido } \\
\hline $\begin{array}{c}\text { Diehl e David } \\
(1982)\end{array}$ & Erro: $\pm 10 \%$ & Erro: $\pm 20 \%$ & Erro: $\pm 40 \%$ & Erro: $\pm 60 \%$ \\
& Conf.: $>80 \%$ & Conf.: $60-80 \%$ & Conf.: $40-60 \%$ & Conf.: $20-40 \%$ \\
\hline \multirow{2}{*}{ Wellmer (1983) } & Erro: $\pm 10 \%$ & Erro: $\pm 20 \%$ & Erro: $\pm 30 \%$ & Erro: $\pm 50 \%$ \\
& Conf.: $90 \%$ & Conf.: $90 \%$ & Conf.: $90 \%$ & Conf.: $90 \%$ \\
\hline
\end{tabular}

Saubourin (1983) propôs um sistema de classificação de recursos minerais tomando como base as definições utilizadas pelo Mine Evaluation Group of Energy, Mine and Resources para avaliar depósitos de urânio no Canadá. O método consiste basicamente em calcular experimentalmente a variância real do depósito a partir da seguinte equação:

$$
D^{2}(Z)=D^{2}\left(Z^{*}\right)+\sigma_{K}^{2}
$$

onde $D^{2}(Z)$ é a variância dos teores reais dos blocos de lavra com o mesmo tamanho, $D^{2}\left(Z^{*}\right)$ é a variância dos teores obtidos por krigagem ordinária e $\sigma_{K}^{2}$ é a média da variância de krigagem dos blocos estimados.

A partir disso os recursos são classificados como medido, se o bloco apresentar variância de krigagem menor do que $10 \% \times D^{2}(Z)$ e indicado, se o bloco apresentar variância de krigagem menor do que $20 \% \times D^{2}(Z)$. O restante é classificado como recurso inferido.

Froidevaux (1982) e posteriormente, isaaks e Srivastava (1989) e Chiles e Delfiner (1999), assumindo que a distribuição dos erros segue uma distribuição Gaussiana e o erro de variância de uma função aleatória é uma estimativa exata da variância real do erro, propuseram que uma estimativa $\hat{v}$ combinada com o erro de variância $\widetilde{\sigma}_{K O}^{2}$ produz um intervalo de valores, com $95 \%$ de confiança, determinado por: $-2 \widetilde{\sigma}_{K O} \leq \hat{v} \geq+2 \widetilde{\sigma}_{K O}$.

Chiles e Delfiner (1999) sugerem ainda que se a distribuição dos erros não seguir uma distribuição Gaussiana ou se não houver certeza sobre a forma de sua 
distribuição, deve-se então utilizar o intervalo $\pm 3 \widetilde{\sigma}_{K o}$ para um intervalo de confiança de $90 \%$.

Sahin (2001) também utiliza o intervalo $\pm 2 \widetilde{\sigma}_{K O}$ e o nivel de confiança de $95 \%$ para calcular a incerteza das estimativas de volume, tonelagem e teor de $\mathrm{TiO}_{2}$ em depósitos de areia em Dhahran, Arábia Saudita.

Vallée e Côte (1992) propõem um intervalo de confiança de $80 \%$ como critério para a classificação de recursos minerais. Ainda segundo esses autores, o método para calcular a margem de erro de uma estimativa depende do tipo de distribuição da população amostral. Assim, para uma estimativa T e desvio padrão $\sigma_{l}$ a margem de erro é $1.28 \sigma_{l} / T$.

Babak e Deutsch (2008) considerando que as técnicas de krigagem ordinária e inverso da distância produzem modelos teóricos válidos de estimativa e incerteza para um mesmo local $(u)$, propõe a utilização da sobreposição os intervalos de incerteza gerados pela aplicação de ambas as técnicas no utilizando o mesmo conjunto de amostras para um mesmo domínio. Para o cálculo do intervalo de confiança da krigagem ordinária é proposta a utilização da variância de krigagem para um intervalo de confiança de $80 \%$.

Ainda segundo esses autores a probabilidade de uma variável de interesse $Z(u)$ ser igual a um valor que esteja no intervalo de apenas um dos métodos de estimativa é zero. Por isso a sobreposição dos intervalos é válida e reduz significativamente o intervalo da incerteza de uma estimativa, tornando-o mais preciso (Figura 5.1). 


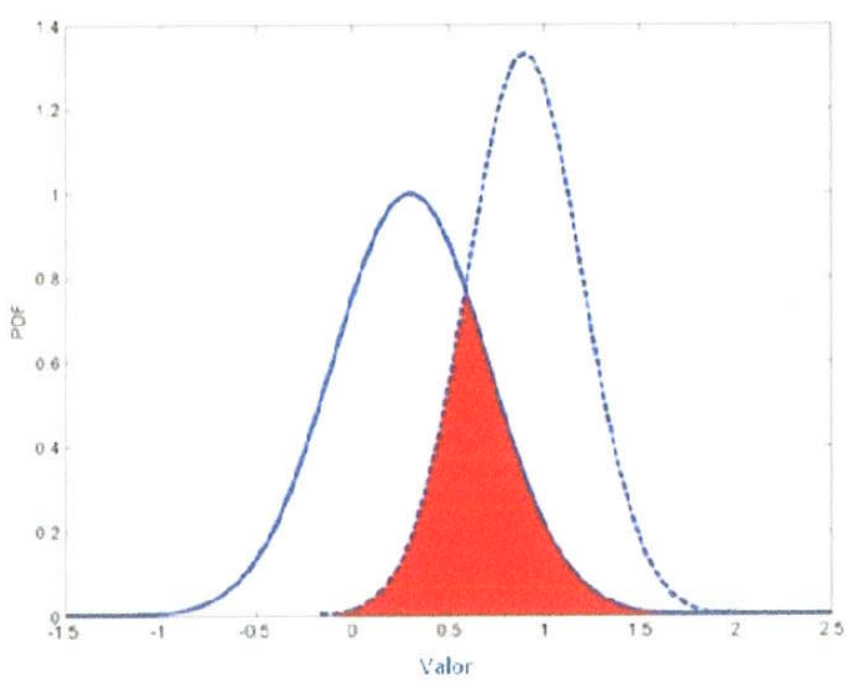

Figura 5.1 - Representação esquemática dos resultados da distribuição da incerteza para uma localização $u$. Linhas contínuas e tracejadas representam incertezas locais obtido por duas abordagens diferentes (ex. krigagem ordinária e inverso da distância). A área vermelha é a sobreposição (Babak; Deutsch, 2008)

Samal (2009) propõe a construção de intervalos de confiança para uma estimativa por krigagem ordinária através do uso da função de anamorfose do bloco.

Esse método consiste em calcular o intervalo de confiança de $95 \%$ definido por:

$$
\left\{\Phi_{v}^{-1}\left(Z_{g}^{k}-2 \sigma_{g}^{k}\right)\right\},\left\{\Phi_{v}^{-1}\left(Z_{g}^{k}+2 \sigma_{g}^{k}\right)\right\}
$$

onde $\Phi_{v}^{-1}$ é a transformada reversa da função de anamorfose do bloco, $Z_{g}^{k}$ é o definido por $Z_{g}^{k}=\Phi_{v}\left(Z^{k^{*}}\right)$, onde $Z^{k^{*}}$ é o valor obtido por krigagem ordinária e $\Phi_{v}$ é a função de anamorfose do bloco. $2 \sigma_{g}^{k}$ é o desvio padrão associado a $Z_{g}^{k}$ que pode ser obtido através da variância de krigagem.

A função de anamorfose do bloco é calculada a partir da transformação dos dados de amostragem para o domínio Gaussiano (função de anamorfose de pontos) multiplicado pelo coeficiente de mudança de suporte $\left(r_{v}\right)$.

Segundo Samal (2009) os intervalos de confiança obtidos a partir desse método não podem ser utilizados para diferenciar os blocos nas diferentes classes de recursos minerais, no entanto intervalos de confiança para os diferentes tipos de recursos podem ser estimados e utilizados para avaliar os fatores de risco. 
Armstrong (1994), ao analisar a falta de avanços para o cálculo e avaliação de recursos na geoestatística, chama atenção para o fato de ainda se usar a variância de krigagem na análise de recursos uma vez que este método se comprovou ser pouco preciso para se estabelecer os intervalos de confiança essenciais na classificação de recursos. Essa autora exemplifica o caráter homoscedástico da variância de krigagem (Figura 5.2), em que dois blocos estimados a partir da mesma configuração espacial entre os dados apresentam o mesmo valor de variância de krigagem apesar dos dados apresentarem variabilidades discrepantes.

A)

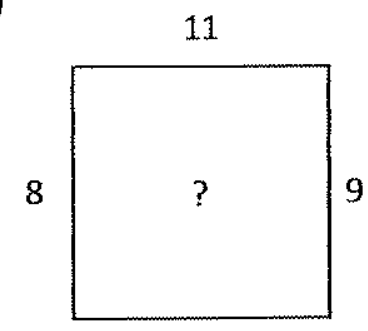

12
B)

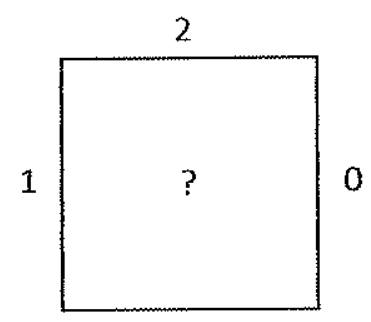

37

Figura 5.2 - Estimativa de blocos a partir da mesma configuração de dados. (Armstrong, 1994). Em (A), a variância do erro deveria ser menor que em (B) por causa de dados mais consistentes

A variância de krigagem não reflete a variação local. Usando o mesmo variograma e os mesmos pontos ao redor do bloco que está sendo estimado, obterse-á a mesma variância de krigagem independentemente dos valores dos dados (Olea, 1999; Arik, 1999; Yamamoto, 2000).

\subsection{Variância de interpolação}

A variância de interpolação foi proposta por Yamamoto (2000) e por definição é uma média ponderada, pelo peso obtido na krigagem ordinária $\left(\lambda_{\alpha}\right)$, das diferenças quadráticas entre os valores dos dados utilizados na estimativa e o valor estimado conforme a equação:

$$
s_{0}^{2}=\sum_{\alpha=1}^{n} \lambda_{\alpha}\left[Z\left(u_{\alpha}\right)-Z^{*}\left(u_{0}\right)\right]^{2}
$$

Por isso, a variância de interpolação, calculada pelo método da ponderação espacial é mais representativa que a variância de krigagem, pois leva em consideração não só a distribuição espacial dos dados como a dispersão dos 
mesmos na vizinhança onde a estimativa foi feita. Os erros provenientes da confiança local seriam então usados para atribuir categorias de classificação de acordo com o grau de certeza para um dado nivel de confiança.

Yamamoto (2000) sugere a classificação de recursos minerais baseada na variância de interpolação utilizando a mesma fórmula para o cálculo do erro e nível de confiança utilizada para a variância de krigagem (5.3), substituindo as variâncias (de krigagem pela de interpolação) conforme expressão:

$$
\text { Erro }=\frac{s_{0} t}{Z *\left(x_{0}\right) \sqrt{n}}
$$

A partir dessa expressão, os recursos seriam classificados de acordo com a Tabela 5.2 (Yamamoto, 2000).

Tabela 5.2 - Classificação de recursos baseada na quantificação do erro a partir a variância de interpolação (Yamamoto, 2000)

\begin{tabular}{lll}
\hline \multicolumn{1}{c}{ Medido } & \multicolumn{1}{c}{ Indicado } & \multicolumn{1}{c}{ Inferido } \\
\hline Erro: $0-20 \%$ & Erro: $20-50 \%$ & Erro: $>50 \%$ \\
Conf.: $90 \%$ & Conf.: $90 \%$ & Conf.: $90 \%$ \\
\hline
\end{tabular}

\subsection{Variância Combinada}

A variância combinada, segundo Arik (1999), também é uma alternativa capaz de levar em consideração a variabilidade dos valores utilizados na estimativa de um bloco. O método propõe uma combinação entre a variância de krigagem $\left(\sigma_{k \nu}^{2}\right)$ com a variância local $\left(\sigma_{w}^{2}\right)$ que é calculada como:

$$
\sigma_{w}^{2}=\sum_{\alpha=1}^{n} \lambda_{\alpha}^{2}\left[Z^{*}\left(u_{0}\right)-Z\left(u_{\alpha}\right)\right]^{2}
$$

Assim, a variância combinada $\left(\sigma_{c w}^{2}\right)$ seria calculada como:

$$
\sigma_{c y}^{2}=\sqrt{\left(\sigma_{k s}^{2} x\right.} \sigma_{w}^{2}
$$




\subsection{Simulação seqüencial}

Diversos autores consideram os métodos de simulação superiores aos métodos de krigagem devido à possibilidade de se ter acesso à incerteza em torno dessa estimativa através da geração de diversas imagens equiprováveis para variável em estudo.

Ortiz, Leauangthong e Deutsch (2004) descrevem o procedimento típico para calcular a incerteza associada a uma estimativa usando as técnicas de simulação seqüencial em:

- Gerar L simulações para uma variável;

- Calcular o valor do bloco para cada $L$ simulação;

- Os $L$ valores do bloco são utilizados para a construção da distribuição da incerteza através do histograma;

- A média e qualquer quantil do histograma podem ser calculados a partir do conjunto de $L$ valores para cada bloco.

A partir desse histograma é possivel ter acesso ao formato da distribuição da incerteza e calcular o erro associado à média das realizações para qualquer intervalo de confiança a partir do cálculo dos quantis do histograma. Geralmente é utilizado o intervalo de confiança de $90 \%$ (quantis $5 \%$ e $95 \%$ ) para determinar o erro da estimativa por simulação condicional, no entanto existem casos onde a variabilidade do teor é tal que intervalo de confiança de $80 \%$ (quantis $10 \%$ e $90 \%$ ) poderiam ser utilizados.

Segundo Wawruch e Betzhold (2005), o método de classificação de recursos minerais mais utilizado, através da técnica de simulação seqüencial é denominado de regra dos $15 \%$. Tal método consiste em agrupar os blocos por período de produção (meses/anos) e aceitar um erro de no máximo 15\% para um intervalo de confiança de $90 \%$ no periodo determinado. Em outras palavras, isso quer dizer que o valor estimado de tonelagem e teor para um determinado período de produção deverá ter um erro máximo de $15 \%$ para 9 em cada 10 periodos de produção. 
Utilizando a regra dos $15 \%$ os recursos minerais, segundo Wawruch e Betzhold (2005) são classificados da seguinte forma:

- são classificadas como medido quando, para uma unidade de produção que pode ser de 1 ou até 3 meses, é estimado com 15\% de erro para um intervalo de confiança de $90 \%$;

- são classificadas como indicado quando, para uma unidade de produção anual, é estimado com $15 \%$ de erro para um intervalo de confiança de $90 \%$;

- são classificados como inferido as áreas/blocos que não atendem os requisitos anteriores.

Mesmo com os consideráveis avanços nas técnicas de determinação da incerteza em torno de uma estimativa para a classificação de recursos minerais sua aplicação não é freqüentemente utilizada nos dias de hoje. Nota-se que apenas as grandes mineradoras têm acesso a essas novas técnicas, pois estas disponibilizam recursos para investir, treinar e capacitar os profissionais responsáveis pela avaliação dos recursos e reservas minerais ou para contratar consultorias que utilizem desse conhecimento em suas avaliações.

Palmer e Palmer (2010) analisaram os relatórios públicos de 28 minas de ouro localizadas no Canadá que foram aceitos pela Canadian Securities Administrators e, portanto, preenchem os requisitos exigidos pela NI 43-101 para a classificação de recursos e reservas minerais e contataram que $36 \%$ utilizaram o método do inverso da distância para a classificação dos recursos e reservas minerais, $46 \%$ utilizaram técnicas de krigagem e $11 \%$ utilizaram outras técnicas para estimar os teores do depósito. Os $7 \%$ restantes não utilizaram nenhuma técnica de interpolação de teores (métodos dos polígonos e raio de influência da amostragem). 


\section{CAPÍTULO 6 \\ MATERIAIS E MÉTODOS}

Este trabalho tem por objetivo o teste de procedimentos para classificação de recursos minerais. O procedimento para classificação de recursos minerais tem como ponto de partida a base de dados amostrais gerados durante as fases de exploração ou produção de um depósito mineral. Entretanto, para testar se o procedimento é confiável, seria necessário o conhecimento dos dados de produção da mina. Que serviriam para aferir a precisão do sistema de classificação proposto.

Os dados de produção de um empreendimento mineiro podem ser representados pelos furos de desmonte das frentes de lavra durante a operação da mina ou a partir de amostragem sistemática, através de um determinado intervalo de tempo, do minério que entra no sistema de beneficiamento. Geralmente essa amostragem é realizada após a britagem do material em intervalos de tempo determinados. Esse material é analisado e as amostras são compostas para intervalos de uma hora. Assim, sabendo-se de onde o material foi lavrado em determinado período $e$ calculando a média ponderada (teor $\mathrm{x}$ tonelagem de material que foi beneficiado no intervalo de tempo escolhido) das amostras de minério que entra na planta de beneficiamento obtemos os dados de produção para uma determinada região do jazimento.

Para a realização do trabalho proposto, há necessidade obter duas bases de dados: os da fase de pesquisa mineral e de produção. Informações completas de um empreendimento mineiro, desde a fase de pesquisa mineral até o beneficiamento são dificeis de serem disponibilizadas pelas empresas devido ao caráter sigiloso das mesmas.

Assim, optamos por trabalhar com quatro bases de dados de modelos exaustivo sintético representando mineralizações de metais raros, ou seja, apresentando distribuições lognormais com assimetrias positivas crescentes, como será exposto no item seguinte. 


\subsection{Materiais}

Para este estudo foram consideradas quatro bases de dados completas, as quais são constituídas por 2.500 blocos de 1x1, distribuídos como uma malha regular de 50 por 50 blocos.

Em termos práticos essas bases poderiam ser consideradas como dados de uma bancada de lavra com 2.500 blocos, para as quais se conhecem os teores obtidos por furos de desmonte. Os blocos teriam dimensões unitárias nos três eixos para fins de determinação dos volumes. As quatro bases de dados completas, disponibilizadas pelo orientador desta dissertação serão assim denominadas: LOG5, LOG10, LOG15 e LOG20 e encontram-se ilustradas na Figura 6.1. Os parâmetros populacionais para as quatro bases de dados estão na Tabela 6.1.
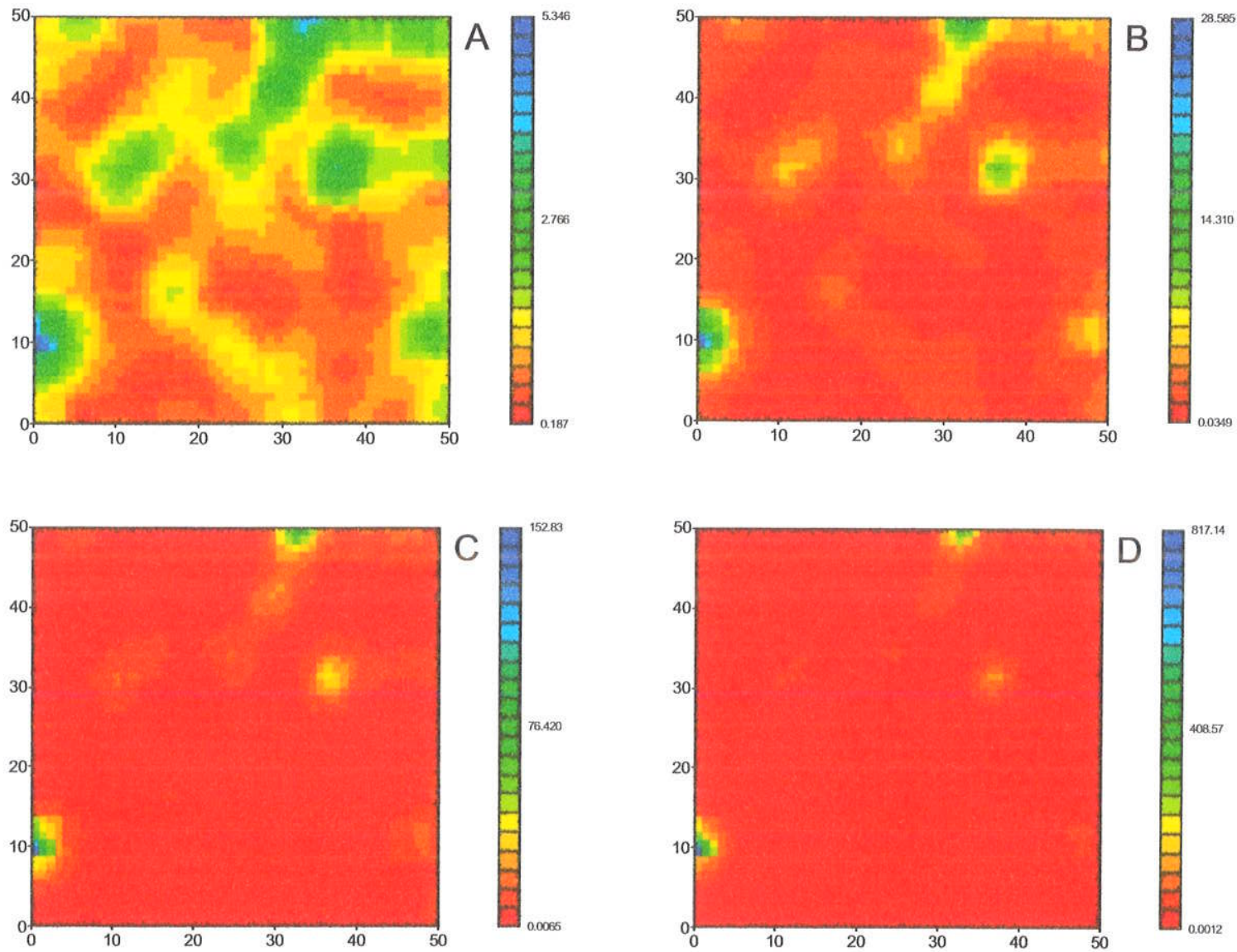

Figura 6.1 - Mapas imagens das bases de dados exaustivas: A: LOG5; B: LOG10; C: LOG15; D: LOG20 
Tabela 6.1 - Parâmetros populacionais das bases de dados utilizadas

\begin{tabular}{lcccc}
\hline Parâmetros & \multicolumn{4}{c}{ BASES DE DADOS COMPLETAS } \\
\cline { 2 - 5 } Populacionais & LOG5 & LOG10 & LOG15 & LOG20 \\
\hline $\mathrm{N}$ & 2500 & 2500 & 2500 & 2500 \\
Média & 1,132 & 1,640 & 3,016 & 6,919 \\
Desvio & 0,598 & 2,057 & 7,323 & 29,668 \\
Coef. Var. & 0.529 & 1,254 & 2,429 & 4,288 \\
Máximo & 5,347 & 28,586 & 152,835 & 817,140 \\
Quartil sup. & 1,400 & 1,961 & 2,746 & 3,846 \\
Mediana & 1,000 & 0,999 & 0,999 & 0,999 \\
Quartil inf. & 0,714 & 0,509 & 0,363 & 0,259 \\
Mínimo & 0,187 & 0,035 & 0,007 & 0,001 \\
\hline
\end{tabular}

Verifica-se na Tabela 6.1 que as bases de dados LOG10, LOG15 e LOG20 representam distribuições lognormais, pois apresentam coeficientes de variação maiores que 1,2 que pode ser confirmado observando a Figura 6.2 onde os histogramas dessas bases de dados estão representados.
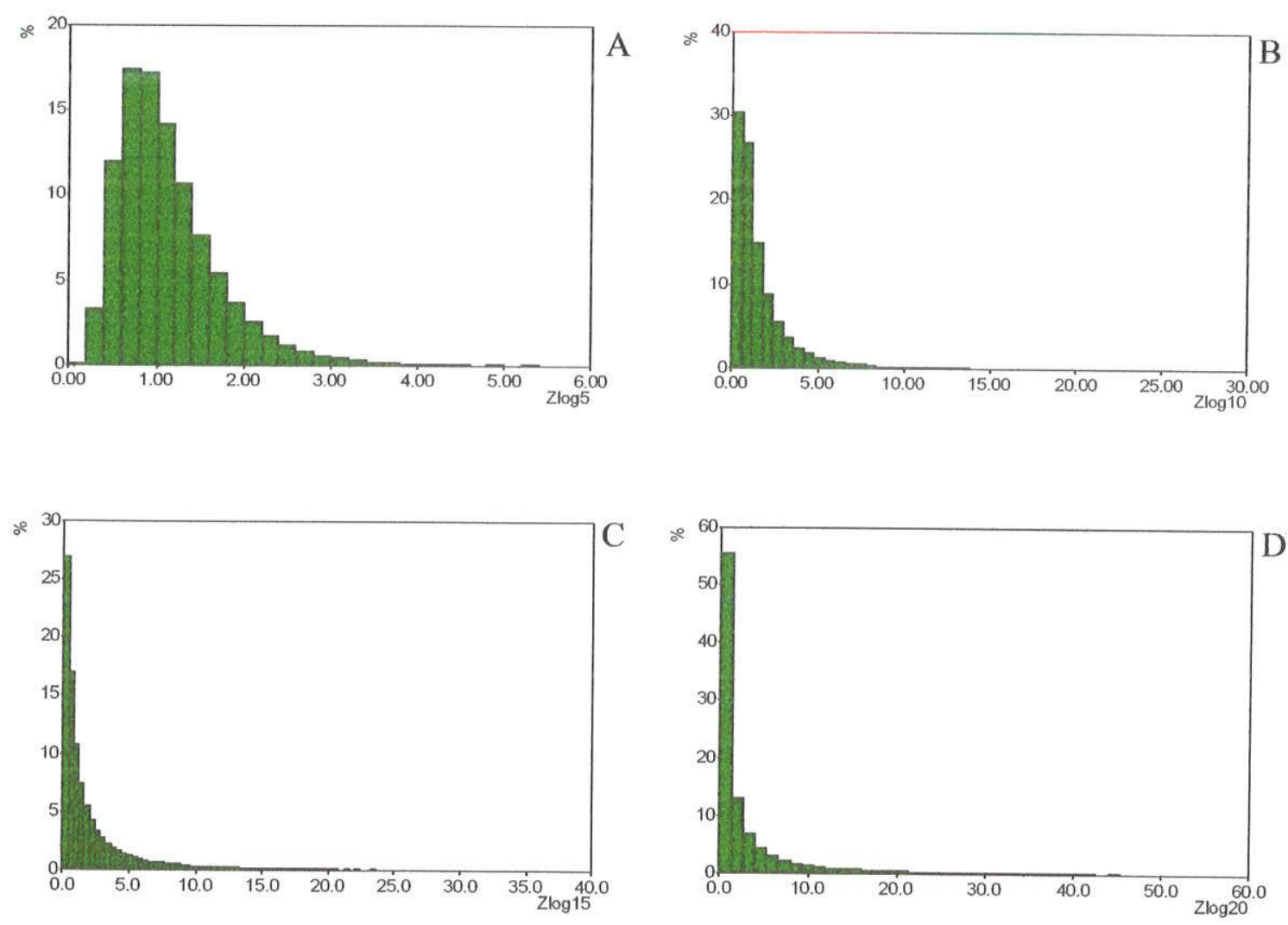

Figura 6.2 - Histograma das bases de dados exaustivos: A: LOG5; B: LOG10; C: LOG15; D: LOG20 
A partir dessas bases de dados foram retiradas amostras aleatórias estratificadas com 90 pontos de dados, ou seja, 3,6 \% do total que é um nível considerado razoável na prática da mineração em função da relação custo benefício. Todas as amostras podem ser representadas por um único mapa de localização de pontos, pois os mesmos pontos foram utilizados para amostrar as quatro bases exaustivas. Apesar de estarmos imaginando uma situação hipotética onde a partir de dados de furos de desmontes buscamos estimar todo o domínio, optou-se por realizar uma amostragem aleatória, pois se pretende analisar o comportamento do método proposto em situações distintas de configuração espacial das amostras e variabilidade.

As amostras aleatórias estratificadas retiradas das bases de dados exaustiva encontram-se ilustradas na Figura 6.3. As estatísticas amostrais encontram-se na Tabela 6.2 e a os histogramas dos conjuntos de amostras na Figura 6.4.
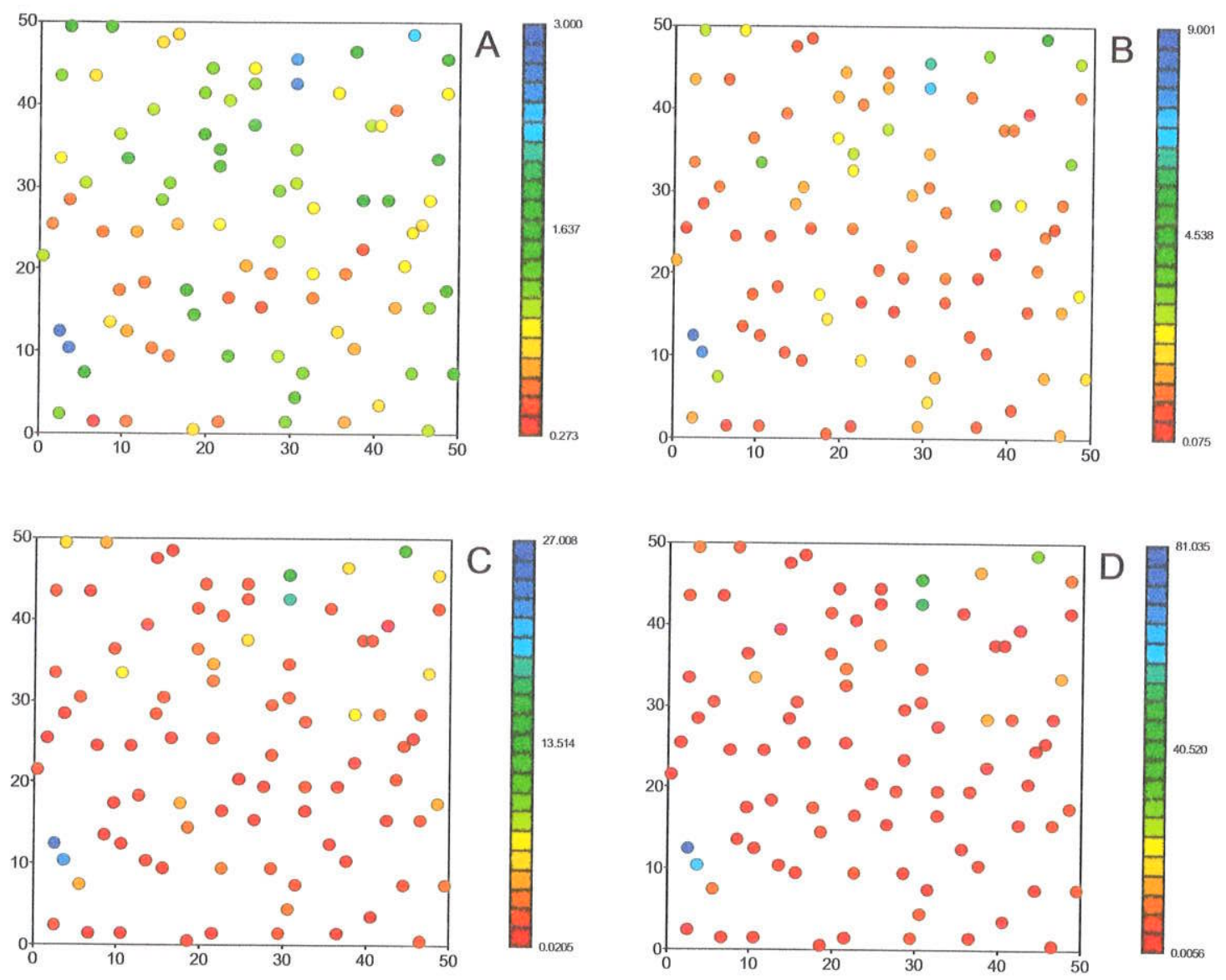

Figura 6.3 - Mapas de localização das amostras aleatórias estratificadas. A: amostra da base LOG5; B: amostra da base LOG10; C: amostra da base LOG15 e D: amostra da base LOG20 
Tabela 6.2 - Estatísticas das amostras aleatórias estratificadas

\begin{tabular}{lcccc}
\hline Parâmetros & \multicolumn{4}{c}{ BASES DE DADOS COMPLETAS } \\
\cline { 2 - 5 } Populacionais & LOG5 & LOG10 & LOG15 & LOG20 \\
\hline $\mathrm{N}$ & 90 & 90 & 90 & 90 \\
Média & 1,093 & 1,476 & 2,427 & 4,729 \\
Desvio & 0,530 & 1,597 & 4,416 & 12,305 \\
Coef. Var. & 0,485 & 1,082 & 1,820 & 2,602 \\
Máximo & 3,000 & 9,002 & 27,009 & 81,035 \\
Quartil sup. & 1,291 & 1,669 & 2,160 & 2,797 \\
Mediana & 0,991 & 0,983 & 0,974 & 0,966 \\
Quartil inf. & 0,708 & 0,502 & 0,355 & 0,252 \\
Mínimo & 0,274 & 0,075 & 0,021 & 0,006 \\
\hline
\end{tabular}
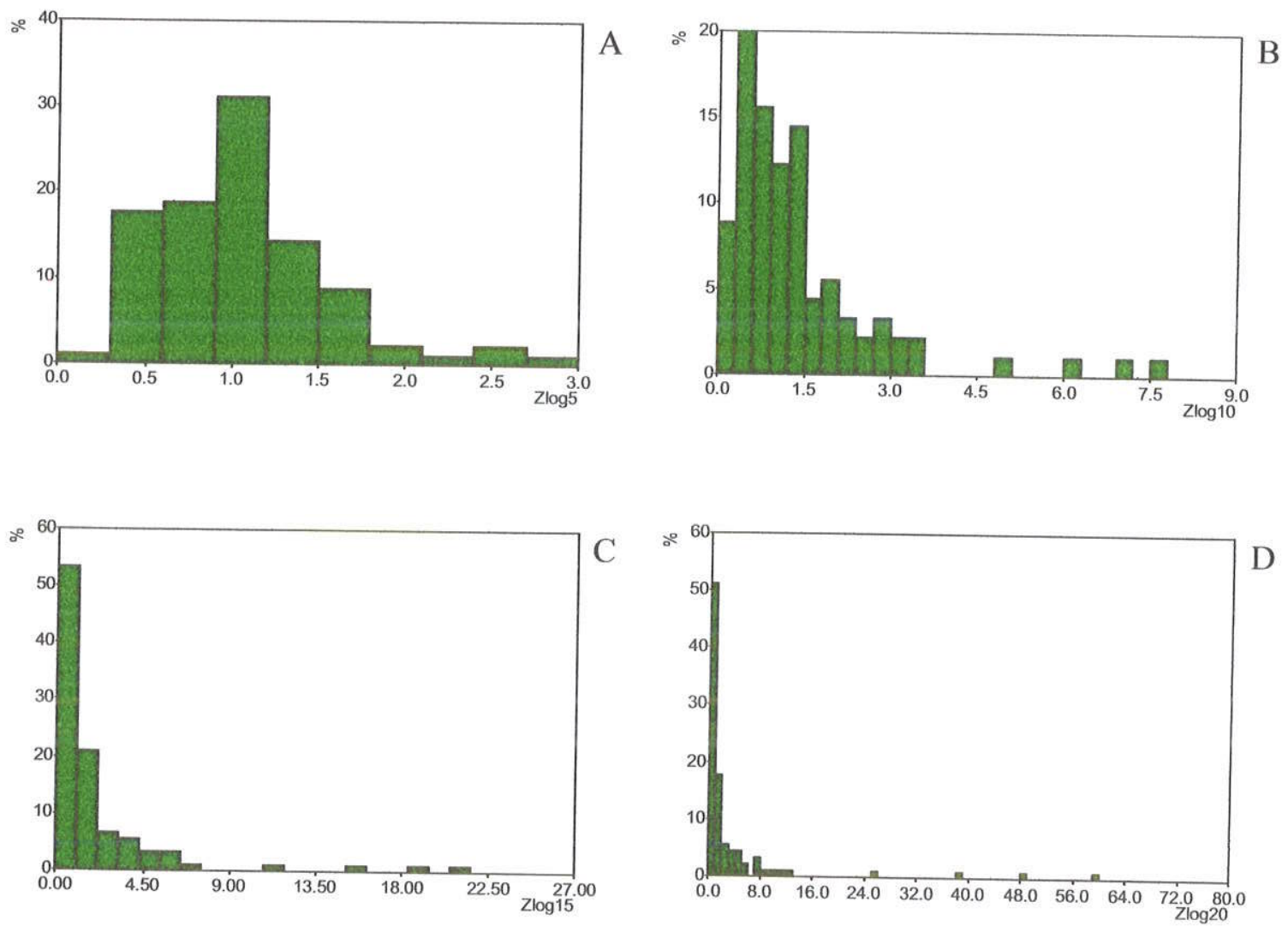

Figura 6.4 - Histograma das amostras aleatórias estratificadas: A: LOG5; B: LOG10; C: LOG15; D: LOG20

Comparando os histogramas da população (Figura 6.2) com os histogramas das amostras aleatórias estratificadas (Figura 6.4) podemos notar que as amostras retiradas de suas respectivas populações representam razoavelmente bem a população, entretanto, os extremos não são reproduzidos e conseqüentemente os 
dados das amostras apresentam menores coeficientes de variação. Evidentemente, como em casos reais não se tem a informação sobre o restante da população. As amostras obtidas devem ser usadas para inferir os parâmetros populacionais por meio de algum algoritmo de estimativa. No caso do presente trabalho será utilizada a krigagem ordinária com a aplicação do algoritmo de correção do efeito de suavização proposto por Yamamoto $(2005,2007)$.

Como se pode verificar nas distribuições dos histogramas das amostras aleatórias (Figura 6.4) e nas estatísticas apresentadas na Tabela 6.2, as distribuições de freqüência dos dados apresentam assimetria positiva com coeficientes de variação que vão de 0,485 a 2,602. Nesses casos, a krigagem ordinária direta dos dados originais não é uma boa solução, pois os poucos valores altos presentes nessas distribuições acabam por contaminar a vizinhança com valores baixos.

A aplicação da krigagem lognormal proposta por Journel (1980) pode ser uma solução, mas Yamamoto e Furuie (2010) concluiram que dentre as transformações de dados existentes a krigagem multi-Gaussiana é a que apresenta os melhores resultados em termos de reprodução do histograma amostral. No entanto, para utilização da krigagem multi-Gaussiana, deve-se testar a multigaussianidade dos dados (Goovaerts, 1997).

Como as amostras a serem utilizadas nesse trabalho, para quatro populações, foram coletadas conforme uma localização comum (Figura 6.3) e nesses pontos os valores da variável de interesse aumentam conforme uma função matemática, a transformada Gaussiana resulta em um único conjunto de dados gerando um modelo de variograma único para todos os dados. Assim, o variograma experimental foi calculado e modelado para utilização da krigagem multi-Gaussiana (Figura 6.5). 


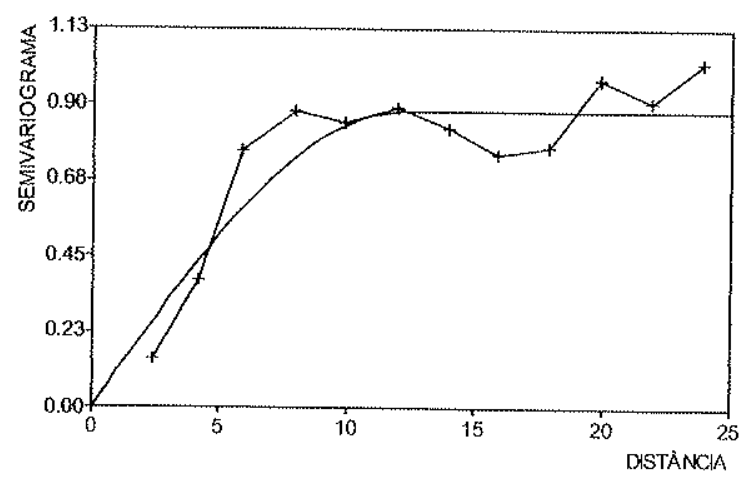

Figura 6.5 - Modelo de variograma após transformação Gaussiana nos dados

O modelo do variograma, após transformação Gaussiana, pode ser descrito pela seguinte equação:

$$
\left\{\begin{array}{l}
\gamma(h)=0,88\left[\frac{1,5 h}{12}-0,5\left(\frac{h}{12}\right)^{3}\right] \text { para } h<12 \\
\gamma(h)=0,88 \text { para } h \geq 12
\end{array}\right.
$$

O teste de bigaussianidade dos dados foi realizado conforme os procedimentos descritos por Yamamoto e Chao (2009) e utilizando o programa BiGauss do Sistema Geovisual. Os resultados encontram-se na Figura 6.6.
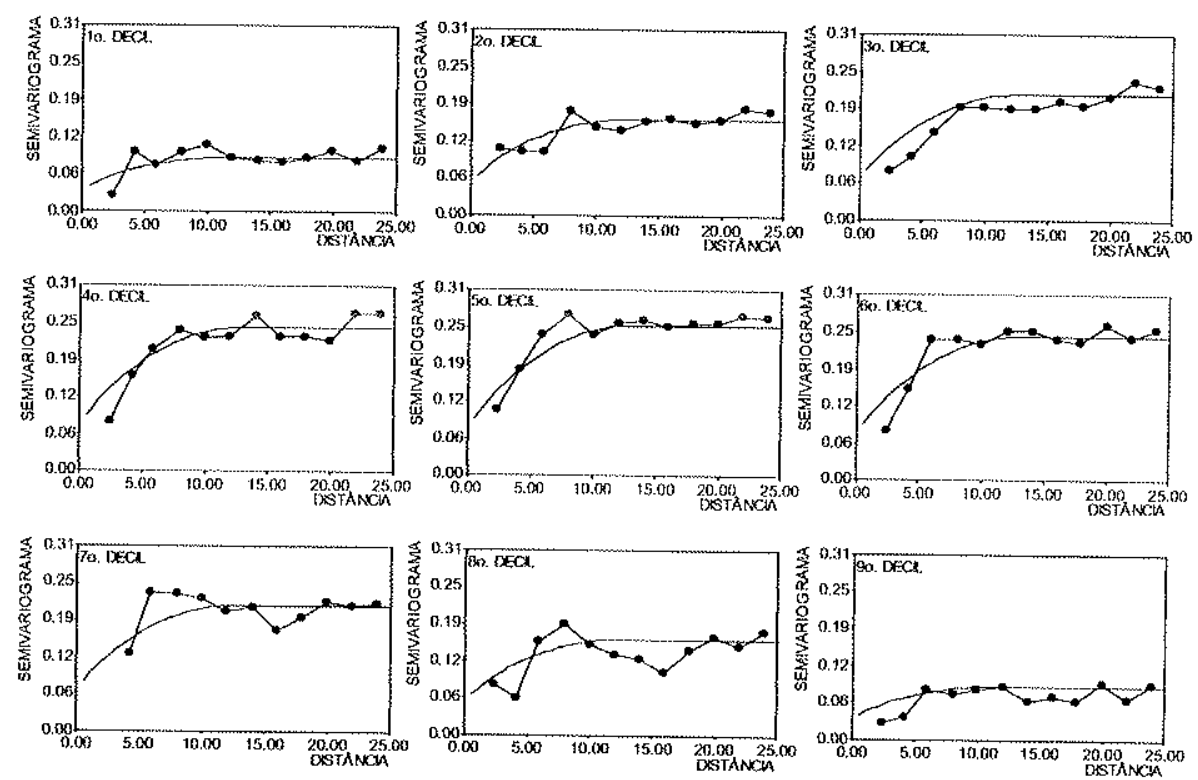

Figura 6.6 - Variogramas de funções indicadoras para 9 decis comparados com os respectivos modelos teóricos 
Analisando os variogramas experimentais das funçôes indicadoras para os nove decis verifica-se que o ajuste é bastante razoável e com isso podemos afirmar que a distribuição de dois pontos é também Gaussiana. Portanto, aceita-se a hipótese de bigaussianidade dos dados e conseqüentemente a multigaussianidade dos dados para aplicação da krigagem multi-Gaussiana.

As quatro bases de dados completas e as respectivas amostras aleatórias estratificadas constituem os materiais dessa pesquisa, os quais serão submetidos aos procedimentos descritos no item seguinte. Todos os cálculos foram realizados no Sistema Geovisual.

\subsection{Métodos}

As amostras aleatórias estratificadas com 90 pontos de dados serão utilizadas para a estimativa dos demais blocos do modelo de um depósito mineral hipotético com 2.500 blocos. É preciso ressaltar que os pontos de dados representam teores de variáveis aleatórias que apresentam distribuições com assimetria positiva, sendo que dois conjuntos de amostras podem ser consideradas tipicamente lognormais (LOG15 e LOG20), pois apresentam coeficientes de variação maiores que 1,2.

Além disso, deve-se considerar também que os valores dos dados obtidos pela amostragem aleatória estratificada para cada população representam valores médios do bloco recuperados através de alguma técnica de amostragem durante a fase de produção. Assim, temos a situação em que a partir de 90 resultados de análise de teores médio do bloco queremos estimar os demais blocos como se estivéssemos fazendo um trabalho de avaliação de uma bancada para fins de planejamento de curto e médio prazos.

Para avaliação dos 25.00 blocos da bancada distribuidos em uma malha regular de 50 por 50 blocos deve-se utilizar a informação dos blocos vizinhos que foram amostrados. Os blocos a serem estimados devem estar dentro dos limites da amostragem, ou seja, dentro da fronteira convexa dos dados (Yamamoto, 1997). Para as amostras aleatórias estratificadas a fronteira convexa única pode ser visualizada na Figura 6.7. 


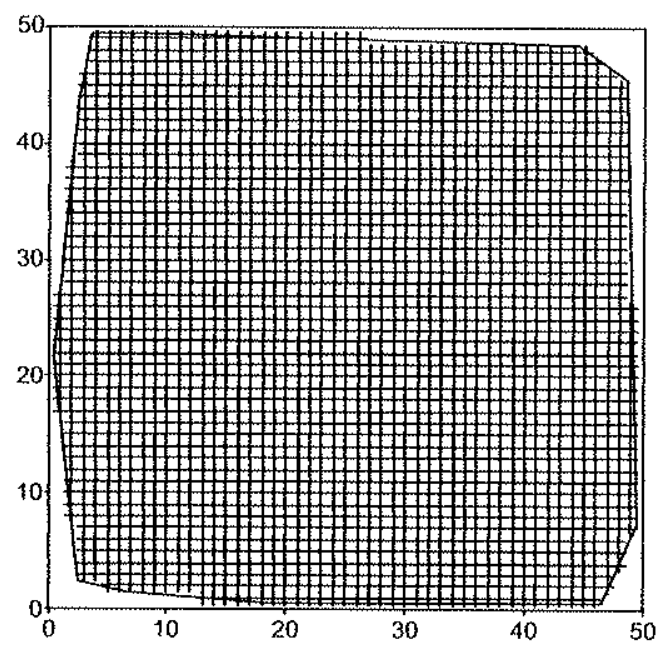

Figura 6.7 - Desenho da fronteira convexa e indicação dos blocos a serem estimados na bancada do depósito mineral hipotético

Dentro da fronteira convexa pode ser estimado um total de 2.290 blocos. Os blocos que estão fora dos limites da fronteira convexa e conseqüentemente não serão estimados representam $9,17 \%$ da bancada hipotética.

A técnica consagrada da krigagem ordinária será utilizada para fins de estimativa dos teores dos blocos desconhecidos. O processamento da krigagem ordinária de bloco resulta na estimativa do teor médio e da variância de interpolação para cada bloco conforme equações 6.2 e 6.3. A variância de krigagem não será considerada nesse trabalho haja vista a manifestação de Armostrong (1994) sobre o uso dessa medida para fins de classificação de recursos minerais:

$$
\begin{gathered}
Z_{K O}^{*}\left(x_{o}\right)=\sum_{i=1}^{n} \lambda_{i} Z\left(x_{i}\right) \\
S_{o}^{2}=\sum_{i=1}^{n} \lambda_{i}\left[Z\left(x_{i}\right)-Z_{K O}^{*}\left(x_{o}\right)\right]
\end{gathered}
$$

As informações dos $n$ blocos vizinhos foram selecionadas pelo critério dos quadrantes, tomando-se os 3 blocos mais próximos por quadrante, resultando assim em um total máximo de 12 blocos de dados para avaliação dos blocos desconhecidos.

Os resultados da krigagem ordinária serão pós-processados para fins de correção do efeito de suavização por meio do algoritmo proposto por Yamamoto 
(2005) e atualizado por Yamamoto (2007). Desse pós-processamento deriva-se o erro de suavização representado por uma nova variável aleatória $Z_{N S_{o}}^{*}\left(x_{o}\right)$.

Como o objetivo desse trabalho é propor um método alternativo para a classificação de recursos minerais a partir do erro de suavização da krigagem ordinária o resultado será comparado com outros métodos propostos.

Mesmo com o desenvolvimento das técnicas de simulação nos últimos anos, Palmer e Palmer (2010) descrevem que dos relatórios públicos de avaliação de recursos e reservas minerais de 28 minas de ouro localizadas no Canadá e pertencentes a empresas listadas na Toronto Stock Exchange, 46\% utilizaram as técnicas de krigagem em suas avaliações.

Dentre os diversos métodos propostos para avaliação da incerteza através da krigagem os mais utilizados são aqueles que utilizam a variância de krigagem e o Teorema do Limite Central para o cálculo do intervalo de confiança e do erro da estimativa. Como a variância de krigagem não é um método eficiente para o calculo de incertezas iremos substituí-la pela variância de interpolação. O método proposto por Froidevaux (1982), Isaaks e Srivastava (1989) e Chiles e Delfiner (1999) que usa o intervalo $\pm 2 \widetilde{\sigma}_{k}$, para um intervalo de confiança de $95 \%$ só pode ser aplicado para depósitos extremamente homogêneos (Yamamoto; Rocha, 2001), o que não é o caso dos conjuntos de dados apresentados. Optou-se então pela utilização do sistema de classificação proposta por Yamamoto (2000) para classificação de recursos utilizando a variância de interpolação que é derivada da proposta apresentada por Wellmer (1983) que utiliza um intervalo de confiança de $90 \%$.

A proposta desse trabalho é utilizar o erro relativo porcentual para a classificação de recursos minerais das estimativas realizadas por krigagem ordinária utilizando o algoritmo de pós-processamento proposto por Yamamoto $(2005,2007)$ para a correção do efeito de suavização. Esse erro pode ser calculado dividindo-se o erro de suavização $Z_{N S_{i}}^{*}\left(x_{o}\right)$ pela estimativa da krigagem de bloco $Z_{K O}^{*}\left(x_{o}\right)$ :

$$
\operatorname{Erro}_{Z_{N S o}^{*}}(\%)=\frac{100 * Z_{N S_{o}}^{*}\left(x_{o}\right)}{Z_{K O}^{*}\left(x_{o}\right)}
$$


Uma aproximação tradicional para cálculo do erro que é baseada no Teorema do Limite Central e faz o uso da construção do intervalo de confiança da média para um nível de confiança de $90 \%$ através da seguinte expressão:

$$
I C_{90}=\frac{S_{0,} t_{5, n-1}}{\sqrt{n}}
$$

onde $t_{5, n-1}$ representa o valor crítico da distribuição $t$ de Student tomado a $5 \%$ com n1 graus de liberdade.

$O$ erro pode ser obtido dividindo-se a metade do intervalo de confiança pela estimativa da krigagem ordinária de bloco:

$$
\operatorname{Erro}_{I C_{x_{0}}}(\%)=\frac{100^{*} I C_{90}}{Z_{K O}^{*}\left(x_{0}\right)}
$$

Para esse estudo foi considerado apenas o nível de confiança de $90 \%$, pois não faz sentido utilizar niveis superiores devido à natureza dos dados e das incertezas existentes. Além disso, deve-se sempre levar em consideração que existe um fator que é a variabilidade natural intrínseca dos fenômenos espaciais naturais (Yamamoto; Conde, 1999).

Como nesse estudo se dispõe da base de dados exaustiva pode-se também calcular o erro real a partir do teor real do bloco $Z\left(x_{0}\right)$ :

$$
\operatorname{Erro}_{R E A L}(\%)=\frac{100 *\left[Z\left(x_{o}\right)-Z_{K O}^{*}\left(x_{o}\right)\right]}{Z_{K O}^{*}\left(x_{o}\right)}
$$

O cálculo do erro proposto nesse trabalho (Equação 6.4), assim como o erro calculado a partir do Teorema do Limite Central para um intervalo de confiança de 90\% (Equação 6.6) e o cálculo do erro real (Equação 6.7) serão então utilizados para classificar os blocos em recurso medido, indicado e inferido, de acordo com a porcentagem do erro conforme Tabela 6.3.

Tabela 6.3 - Niveis de erros para classificação de recursos minerais

\begin{tabular}{cccc}
\hline CLASSE & MEDIDO & INDICADO & INFERIDO \\
\hline ERRO $(\%)$ & $<20 \%$ & $20-50 \%$ & $>50 \%$ \\
\hline
\end{tabular}


Com isso, as diferentes classificações resultantes, conforme aplicação das equações (6.4) e (6.6) poderão ser comparados com o erro real calculado por meio da equação (6.7).

Nesse trabalho será considerada a vertente quantitativa para classificação de recursos minerais com base nas informações obtidas de um processamento da krigagem ordinária. A classificação de recursos minerais com base em critérios subjetivos deve ser evitada à medida que temos acesso a informações quantitativas precisas de campo e laboratório. Os trabalhos de pesquisa mineral atualmente têm à disposição avançados equipamentos de campo e laboratório, tais como sistemas de posicionamento global do tipo diferencial, equipamentos de perfuração com medidas de desvio, testemunhagem contínua, procedimentos padronizados de laboratório, análises químicas de alta precisão etc. Através do processamento desses dados define-se a base para a estimativa de recursos minerais por meio de técnicas geoestatísticas.

A incerteza medida reflete o grau de conhecimento geológico que se tem sobre um determinado bloco de cubagem e assim ela deve ser utilizada como um critério objetivo e prático para classificação de recursos minerais. Os resultados da krigagem ordinária são a estimativa e o desvio padrão de interpolação. A partir dessas variáveis pode-se derivar o erro de suavização, bem como o intervalo de confiança da média a um determinado nível de confiança, como exposto neste item. Devido ao caráter inédito dessa proposta, o trabalho tem o objetivo de fazer a proposição e sua validação estatística por meio da comparação com erros reais. 


\section{CAPÍTULO 7 \\ RESULTADOS E DISCUSSÃO}

Os resultados do processamento dos quatro conjuntos de dados encontram-se na Figura 7.1. Como se pode observar, todas elas apresentam a mesma distribuição de cores, mas associadas a valores diferentes, pois a representação se dá no campo Gaussiano.

A distribuição linear dos valores em uma mesma escala de cores para os diferentes conjuntos de dados não permitiria visualizar os detalhes da variação espacial da variável de interesse, como se observa nos dados completos da Figura 6.1. O pós-processamento das estimativas da krigagem ordinária melhora bastante a qualidade das imagens no sentido de realçar as regiões anômalas do depósito compensando assim o efeito da suavização. Como mencionado anteriormente, as amostras representam blocos com teores conhecidos em uma bancada de um depósito mineral hipotético. Justifica-se assim a aplicação do algoritmo de correção da suavização para trazer as estimativas no mesmo nivel de variância. Caso o estudo fosse realizado com furos de sonda, essa mesma correção não poderia ser aplicada, pois os teores dos blocos estimados certamente apresentariam menor variância, devido ao efeito da mudança de suporte. A questão da mudança de suporte não será tratada nesta dissertação. Além da comparação visual, os resultados podem ser comparados numericamente por meio de suas estatisticas (Tabela 7.1).

Tabela 7.1 - Estatisticas das estimativas da krigagem ordinária e das estimativas pósprocessadas

\begin{tabular}{lllllllll}
\hline \multicolumn{1}{c}{ EST. } & \multicolumn{2}{c}{ LOG5 } & \multicolumn{2}{c}{ LOG10 } & \multicolumn{2}{c}{ LOG15 } & \multicolumn{2}{c}{ LOG20 } \\
& $Z_{k o}^{*}\left(x_{o}\right)$ & $Z_{k o}^{*}\left(x_{o}\right)$ & $Z_{k o}^{*}\left(x_{o}\right)$ & $Z_{k o}^{* *}\left(x_{o}\right)$ & $Z_{k o}^{*}\left(x_{o}\right)$ & $Z_{k o}^{* *}\left(x_{o}\right)$ & $Z_{k o}^{*}\left(x_{o}\right)$ & $Z_{k o}^{*}\left(x_{o}\right)$ \\
\hline $\mathrm{N}$ & 2290 & 2268 & 2290 & 2268 & 2290 & 2268 & 2290 & 2268 \\
Média & 1,014 & 1,103 & 1,108 & 1,494 & 1,307 & 2,462 & 1,684 & 4,803 \\
Desvio & 0,280 & 0,526 & 0,674 & 1,600 & 1,456 & 4,405 & 3,338 & 12,114 \\
C.V. & 0,276 & 0,477 & 0,608 & 1,071 & 1,114 & 1,789 & 1,982 & 2,522 \\
Max. & 2,874 & 2,994 & 8,272 & 8,964 & 23,844 & 26,843 & 68,824 & 80,394 \\
Q.S. & 1,147 & 1,362 & 1,317 & 1,856 & 1,511 & 2,529 & 1,735 & 3,449 \\
Med. & 0,991 & 0,991 & 0,983 & 0,982 & 0,974 & 0,974 & 0,966 & 0,965 \\
Q.I. & 0,840 & 0,736 & 0,707 & 0,542 & 0,595 & 0,399 & 0,500 & 0,294 \\
Min. & 0,320 & 0,274 & 0,104 & 0,075 & 0,034 & 0,021 & 0,011 & 0,006 \\
\hline
\end{tabular}



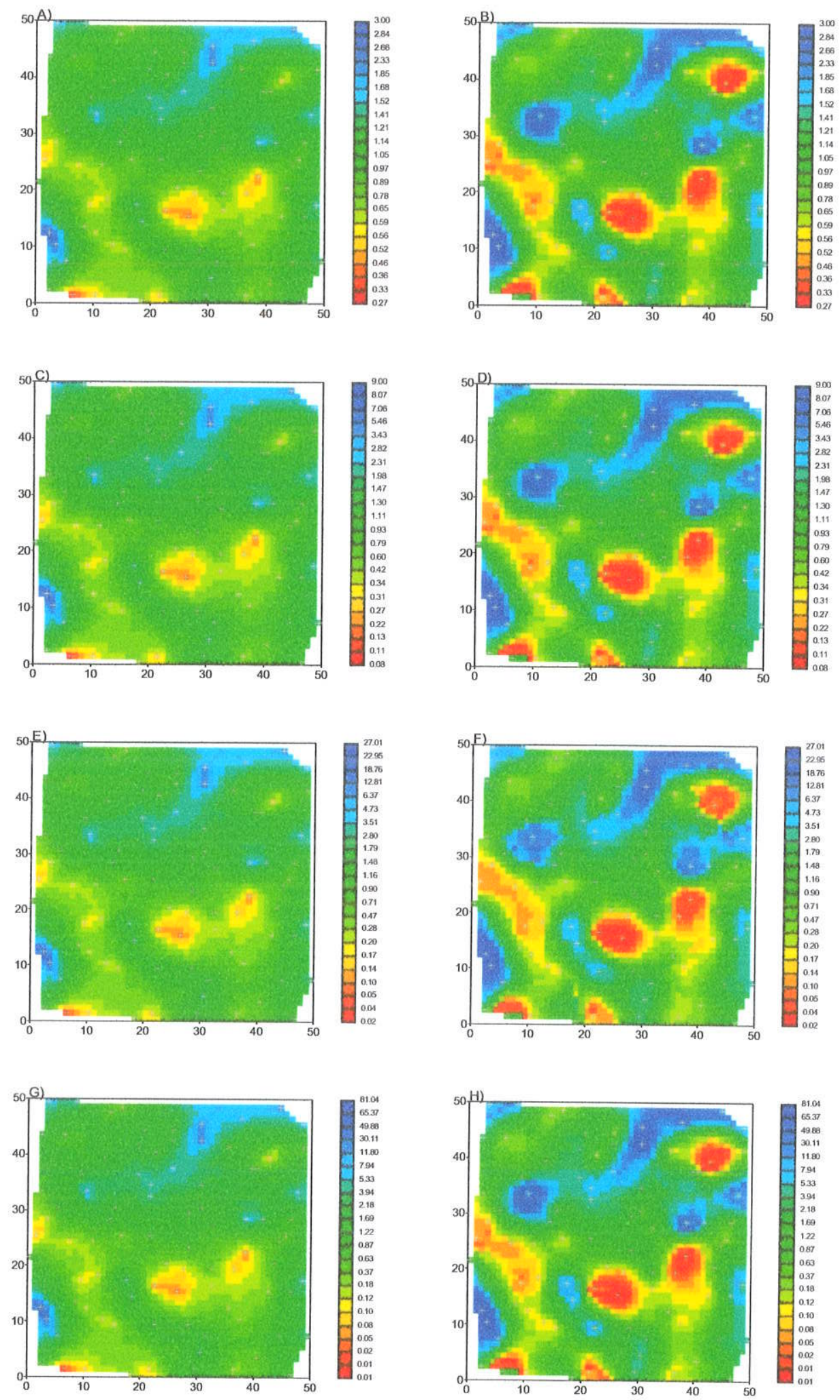

Figura 7.1 - Mapas imagens dos processamentos para LOG5 (A: krigagem ordinária; B: pós-processada), para LOG10 (C: krigagem ordinária; D: pós-processada), para LOG15 (E: krigagem ordinária; F: pós-processada) e para LOG20 (G: krigagem ordinária; H: pósprocessada) 
Há uma diferença de 22 blocos entre o número de blocos estimados pela krigagem ordinária com relação aos blocos pós-processados. Essa diferença se dá devido ao processo de transformada reversa dos valores corrigidos que ultrapassam os limites da tabela de conversão baseada nos pontos amostrais. Comparando as estatísticas da Tabela $7.1 \mathrm{com}$ a estatistica dos dados amostrais (Tabela 6.2), podemos observar que as estatisticas das estimativas pós-processadas encontramse muito mais próximas das amostrais.

A Figura 7.2 compara as distribuições estimadas com as respectivas distribuições amostrais, onde se verifica que há uma boa aderência da distribuição das estimativas pós-processadas. Os diagramas P-P e as distâncias médias para a reta bissetriz confirmam a melhor aproximação das distribuições das estimativas corrigidas com as distribuições amostrais.

A partir do processamento da krigagem ordinária obtemos a medida de incerteza, desvio padrão de interpolação. Do pós-processamento pode-se determinar o erro de suavização, os quais serão utilizados para calcular erros porcentuais relativos para fins de classificação de recursos minerais por meio das equaçōes (6.4) e (6.6). Como se dispõe dos dados completos, ou seja, se conhece todos os teores dos blocos de uma bancada de um depósito hipotético, pode-se calcular o erro real que servirá de referência para comparação com os erros experimentais.

A única forma de se comparar os valores estimados com os valores reais é através do cálculo do erro verdadeiro (Equação 6.7), pois a simples comparação de teores reais e estimados em um diagrama de dispersão não permitiria concluir sobre a validade das fórmulas para cálculo dos erros no sentido de agrupar os resultados nas diferentes classes de recursos minerais. 

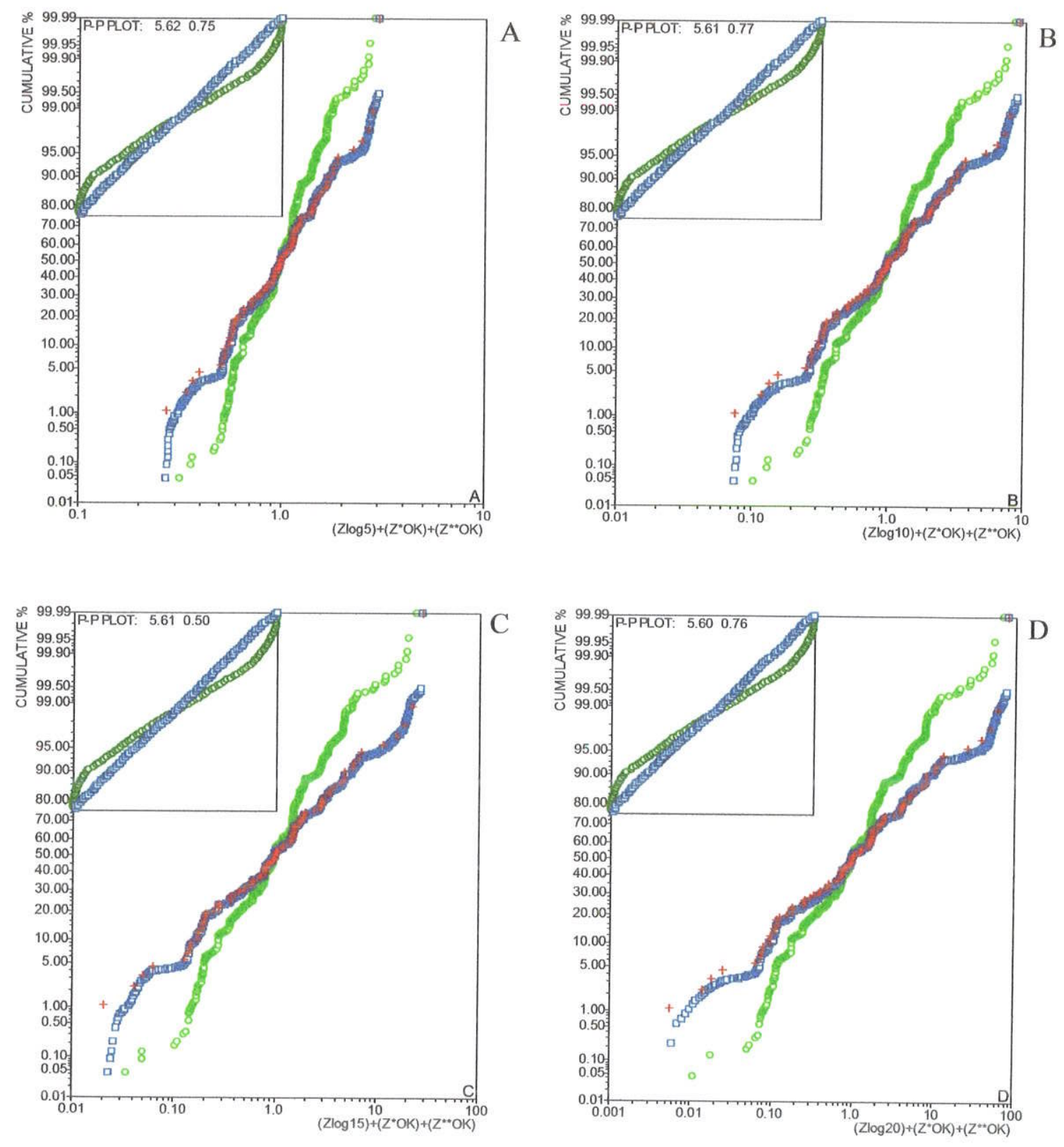

Figura 7.2 - Distribuições de freqüências acumulativas e diagramas P-P: A: LOG5; B: LOG10; C: LOG15; D: LOG20. (Legenda: cruz vermelha - ponto amostral; círculo verde krigagem ordinária; quadrado azul - krigagem ordinária corrigida)

Os resultados da classificação dos recursos minerais dos blocos para as amostras retiradas dos conjuntos LOG5, LOG10, LOG15 e LOG20 encontram-se nas Figuras 7.3, 7.5, 7.7 e 7.9, respectivamente. Os gráficos comparativos entre a classificação atribuída para cada método utilizado em cada conjunto de dado se encontram nas Figuras 7.4, 7.6, 7.8 e 7.10. 

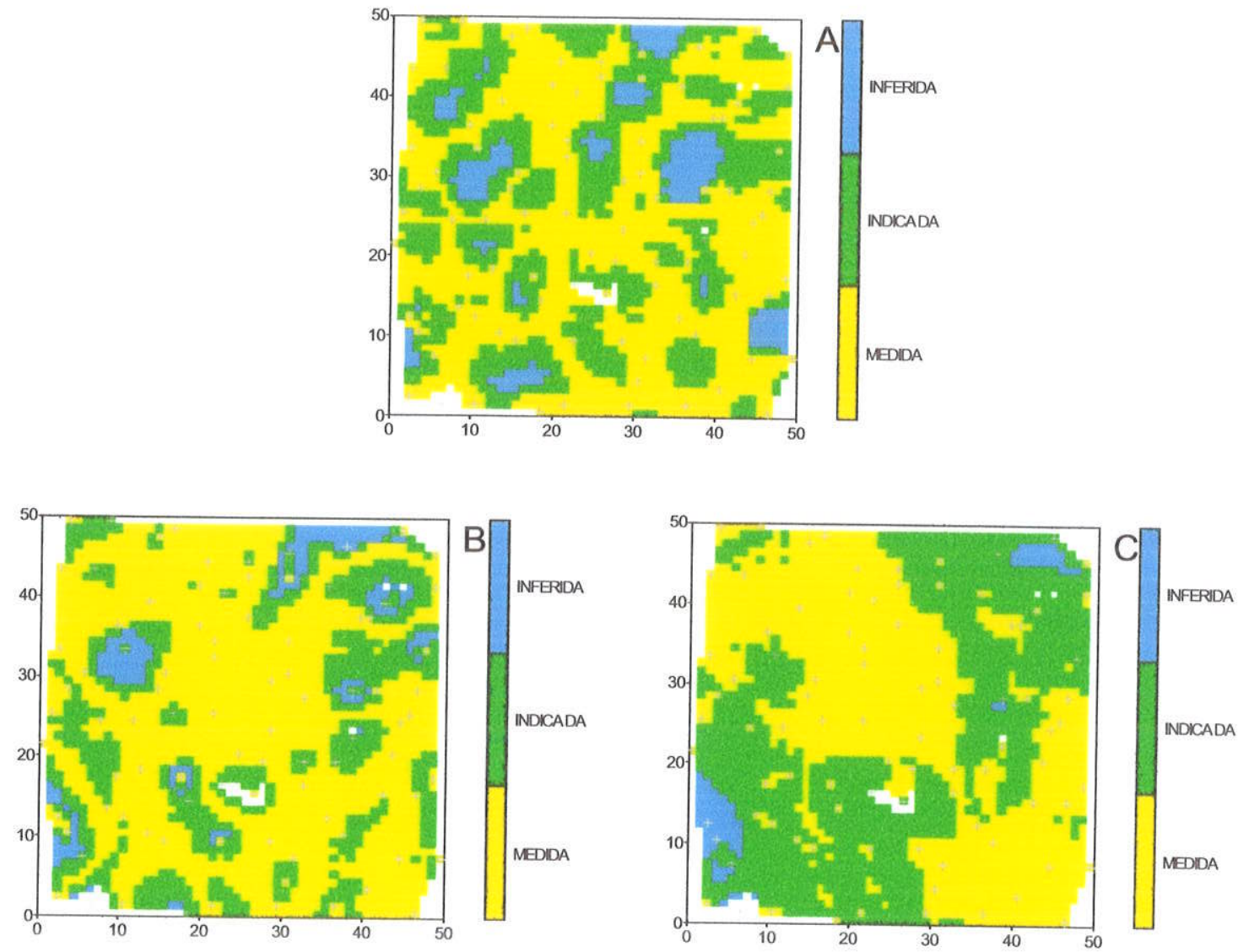

Figura 7.3 - Classificação dos recursos minerais dos blocos para os dados LOG5. A: erro relativo real; B: conforme erro de suavização e C: conforme o intervalo de confiança da média

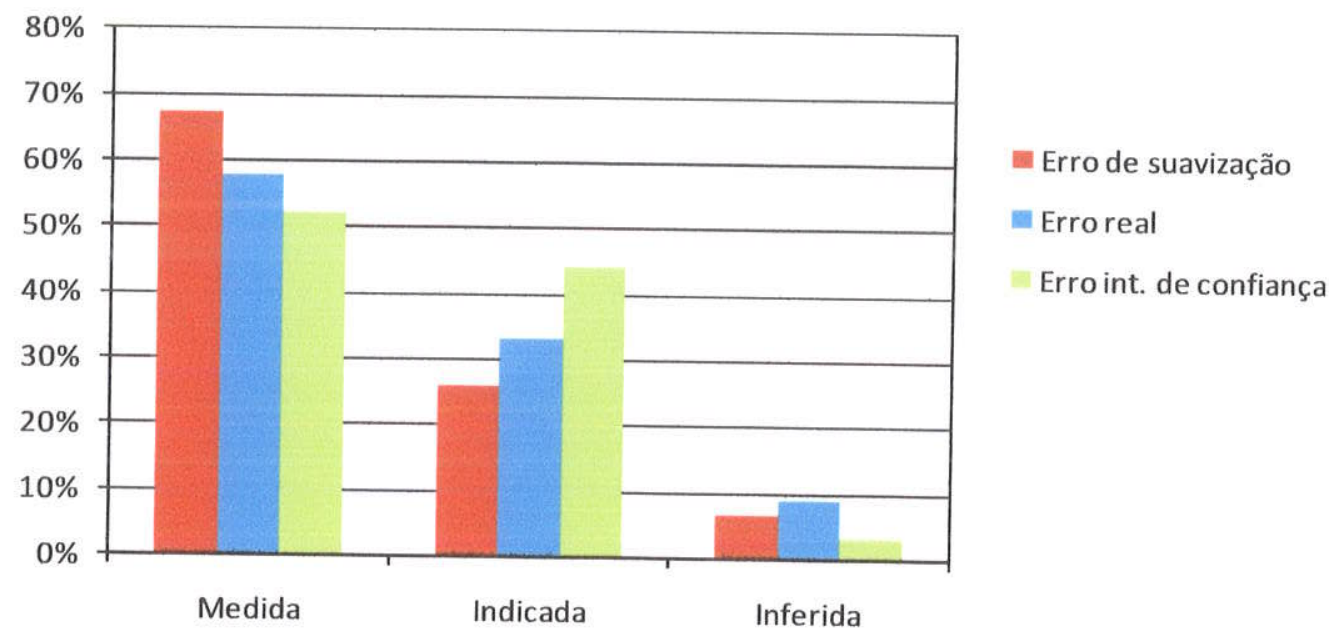

Figura 7.4 - Gráfico comparativo da definição das classes de recursos para os métodos aplicados no conjunto LOG5 

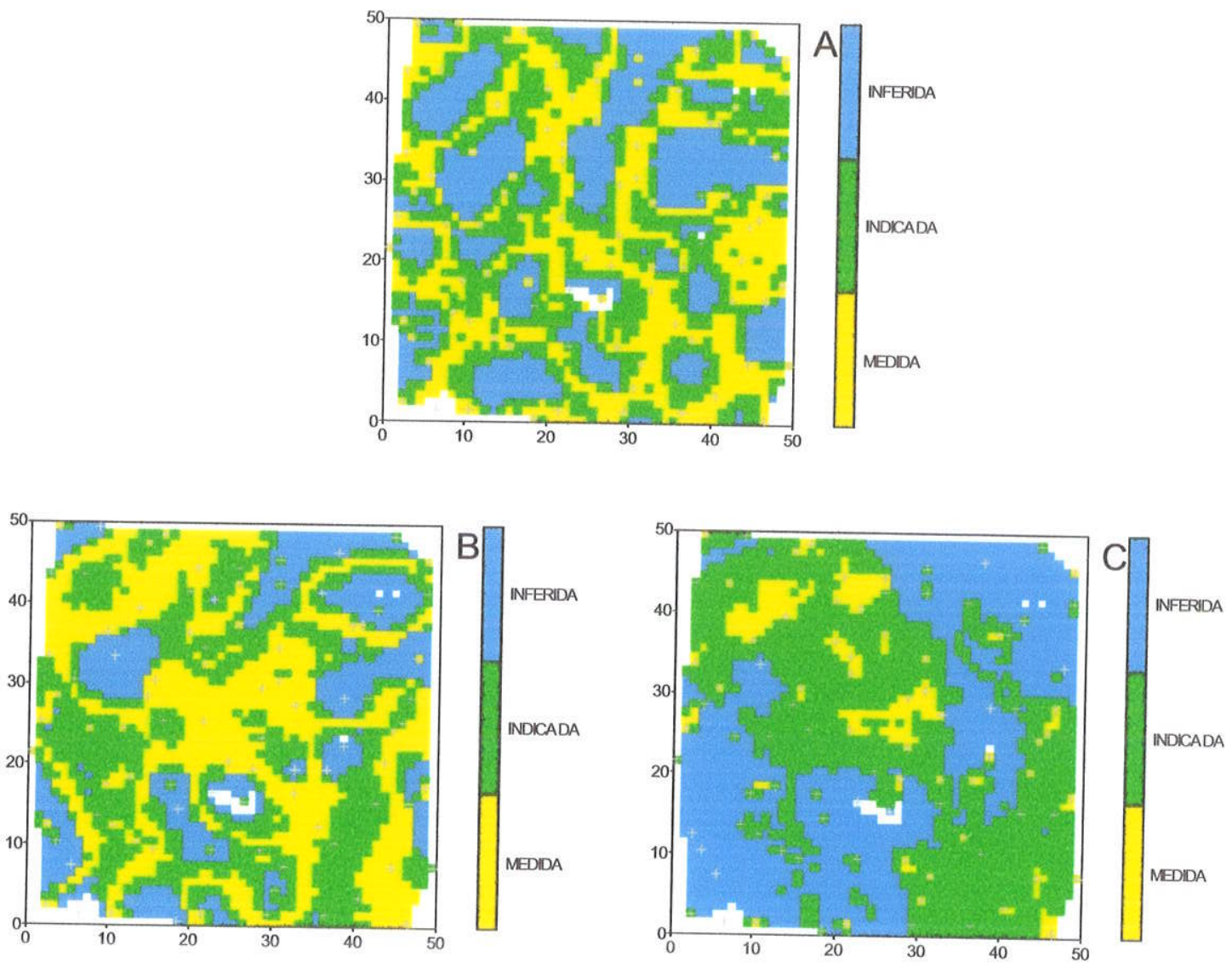

Figura 7.5 - Classificação dos recursos minerais dos blocos para os dados LOG10. A: erro relativo real; B: conforme erro de suavização e C: conforme o intervalo de confiança da média

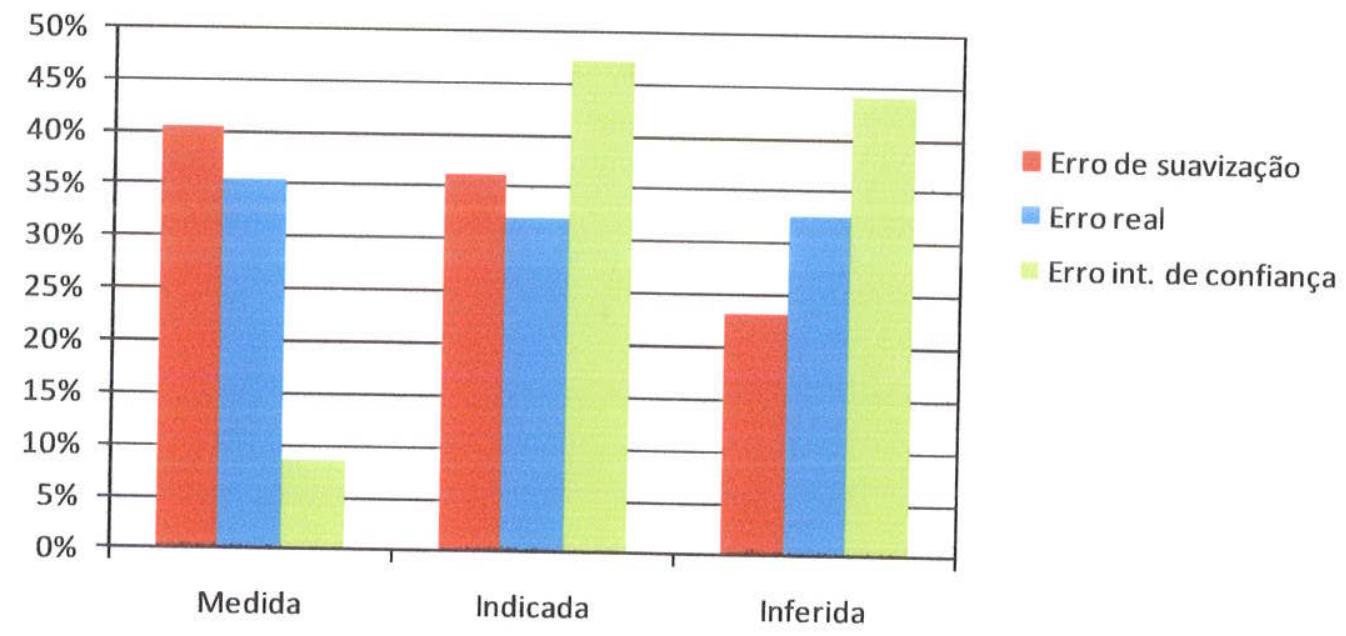

Figura 7.6 - Gráfico comparativo da definição das classes de recursos para os métodos aplicados no conjunto LOG10 

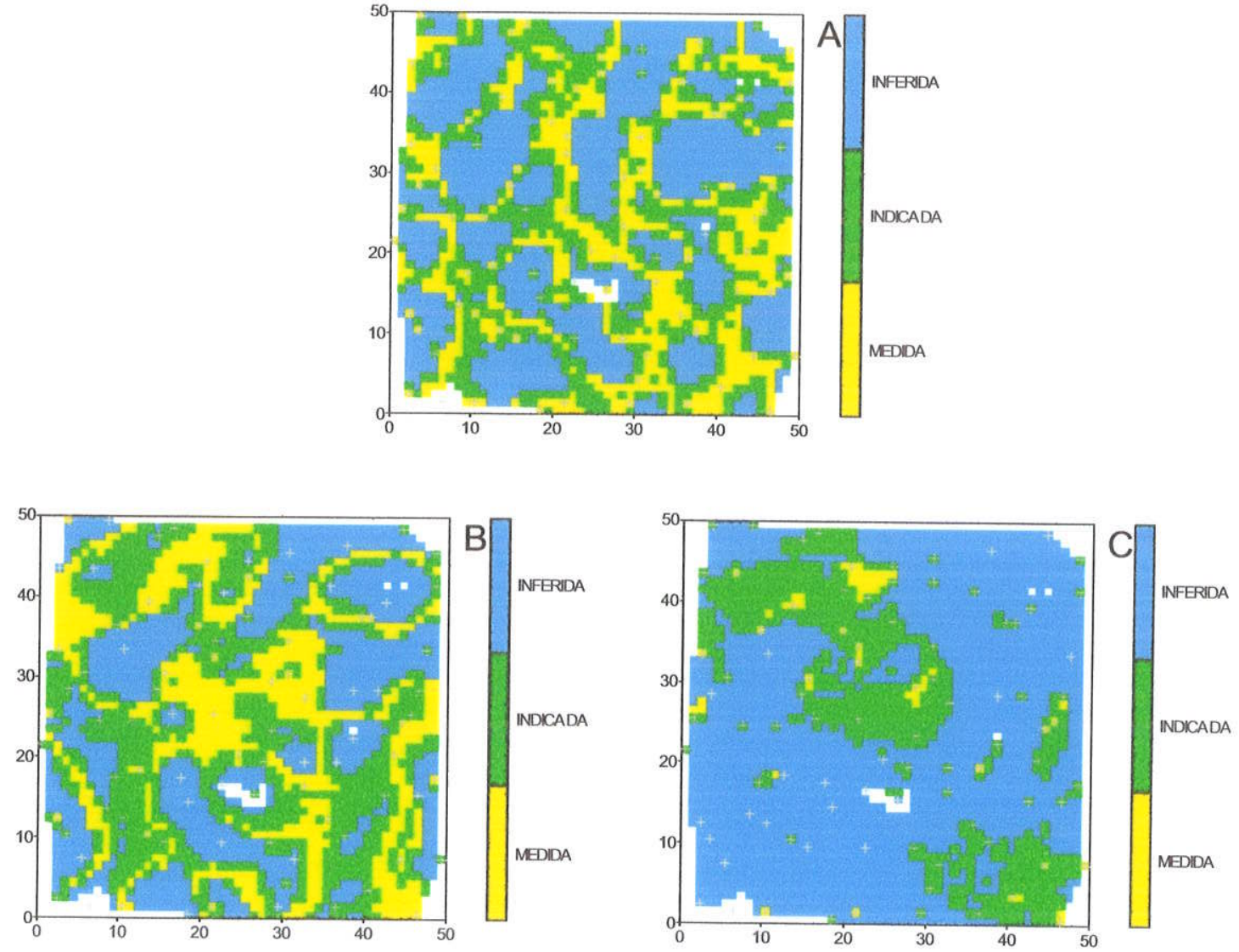

Figura 7.7 - Classificação dos recursos minerais dos blocos para os dados LOG15. A: erro relativo real; B: conforme erro de suavização e C: conforme o intervalo de confiança da média

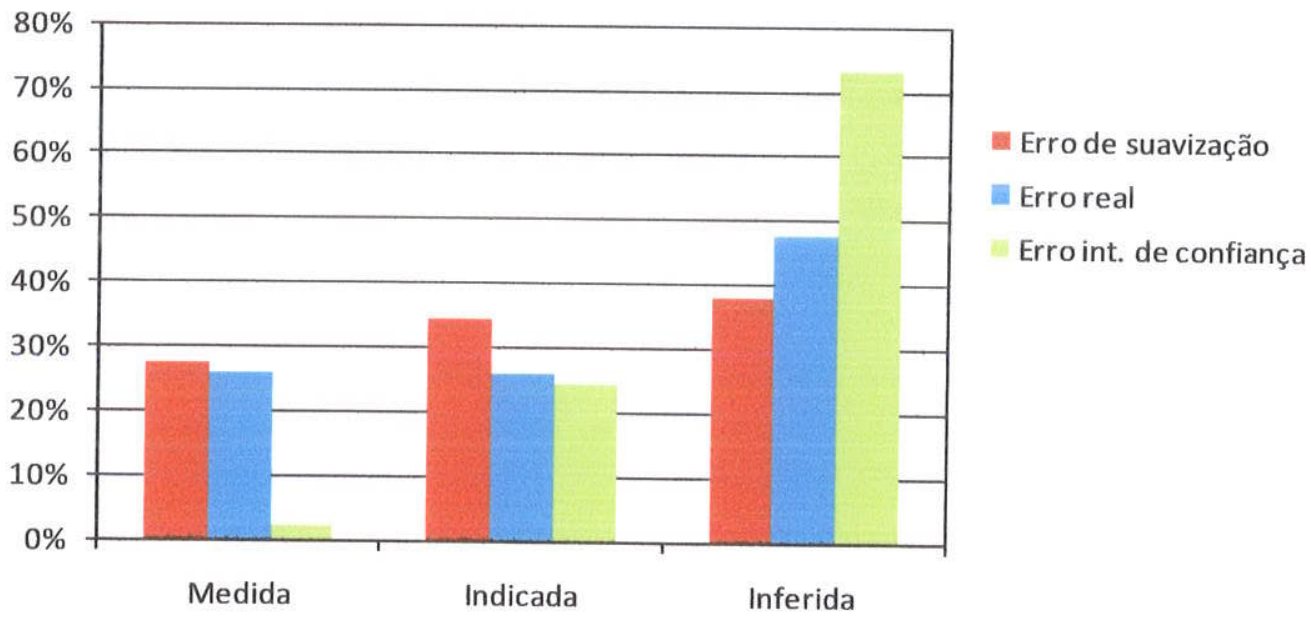

Figura 7.8 - Gráfico comparativo da definição das classes de recursos para os métodos aplicados no conjunto LOG15 

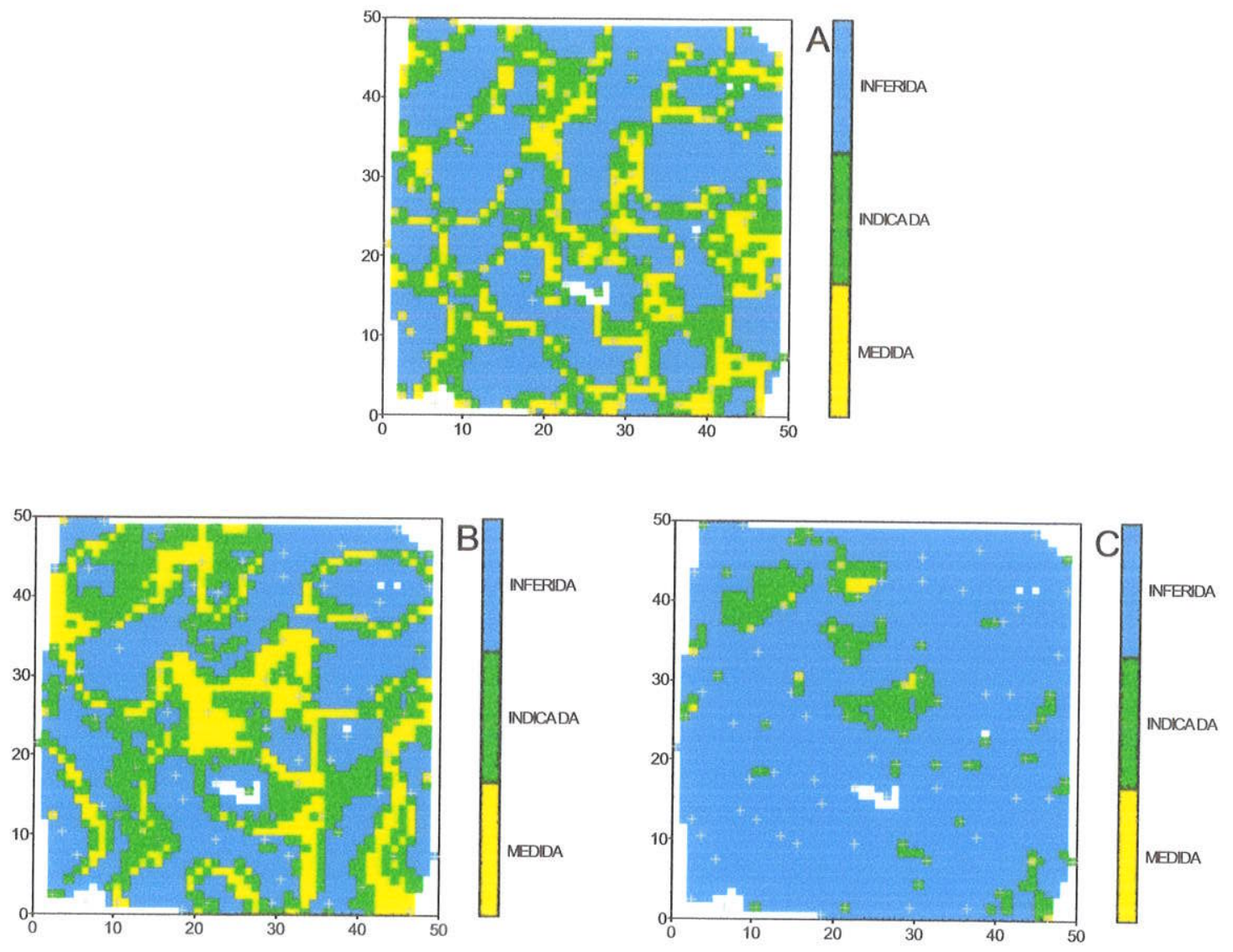

Figura 7.9 - Classificação dos recursos minerais dos blocos para os dados LOG20. A: erro relativo real; B: conforme erro de suavização e C: conforme o intervalo de confiança da média

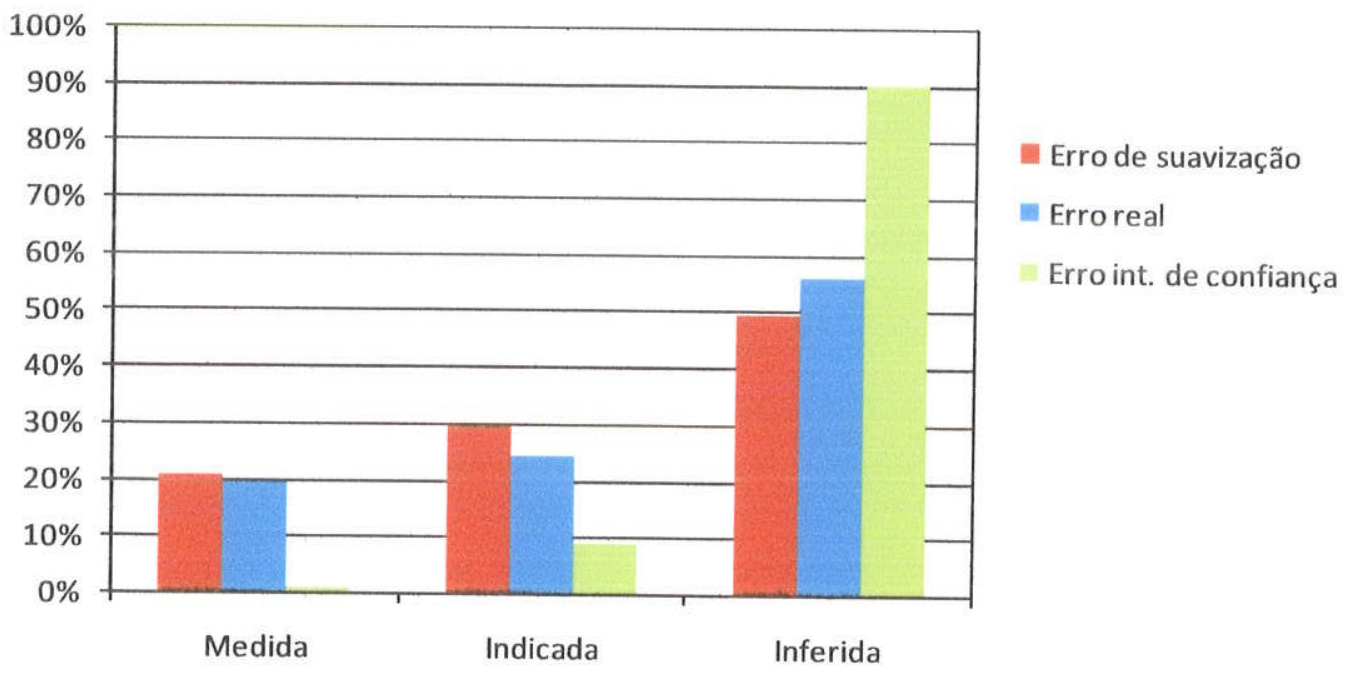

Figura 7.10 - Gráfico comparativo da definição das classes de recursos para os métodos aplicados no conjunto LOG20 
Os blocos com mesma categoria de recursos podem ser comparados entre si por meio de uma matriz, onde, nas linhas se colocam as categorias de recursos reais e em colunas as categorias de recursos estimados. Assim, recursos de mesma categoria estarão sobre a diagonal principal. Abaixo da diagonal os recursos subestimados e acima, os superestimados. Os resultados dessa comparação numérica, para cada conjunto de dados LOG5, LOG10, LOG15 e LOG20 encontramse respectivamente nas Tabelas $7.2,7.3,7.4$ e 7.5 .

Tabela 7.2 - Comparação dos blocos classificados com os erros experimentais em relação aos blocos reais para o conjunto LOG5

\begin{tabular}{|c|c|c|c|c|c|c|c|}
\hline \multirow{2}{*}{$\begin{array}{l}\text { DADO } \\
\text { REAL }\end{array}$} & \multicolumn{3}{|c|}{ ERRO DE SUAVIZAÇÃO } & \multirow{2}{*}{$\begin{array}{l}\text { DADO } \\
\text { REAL }\end{array}$} & \multicolumn{3}{|c|}{ ERRO INT. DE CONFIANCA } \\
\hline & Med. & Ind. & Inf. & & Med. & Ind. & Inf. \\
\hline Med. & 999 & 277 & 39 & Med. & 799 & 479 & 37 \\
\hline Ind. & 453 & 232 & 66 & Ind. & 328 & 391 & 32 \\
\hline Inf. & 77 & 80 & 45 & Inf. & 60 & 135 & 7 \\
\hline & $\begin{array}{l}\text { Sub. } \\
610 \\
\end{array}$ & $\begin{array}{c}\text { Mesma } \\
1276 \\
\end{array}$ & $\begin{array}{l}\text { Sup. } \\
382 \\
\end{array}$ & & $\begin{array}{l}\text { Sub. } \\
523 \\
\end{array}$ & $\begin{array}{c}\text { Mesma } \\
1197\end{array}$ & $\begin{array}{l}\text { Sup. } \\
548 \\
\end{array}$ \\
\hline
\end{tabular}

Tabela 7.3 - Comparação dos blocos classificados com os erros experimentais em relação aos blocos reais para o conjunto LOG10

\begin{tabular}{|c|c|c|c|c|c|c|c|}
\hline \multirow{2}{*}{$\begin{array}{l}\text { DADO } \\
\text { REAL }\end{array}$} & \multicolumn{3}{|c|}{ ERRO DE SUAVIZAÇÃO } & \multirow{2}{*}{$\begin{array}{l}\text { DADO } \\
\text { REAL }\end{array}$} & \multicolumn{3}{|c|}{ ERRO INT. DE CONWIANCA } \\
\hline & Med. & Ind. & Int: & & Med. & Ind. & Inf. \\
\hline Med. & 431 & 273 & 99 & Med. & 106 & 439 & 258 \\
\hline Ind. & 297 & 288 & 143 & Ind. & 55 & 348 & 325 \\
\hline Inf. & 190 & 261 & 286 & Inf. & 36 & 282 & 419 \\
\hline & $\begin{array}{l}\text { Sub. } \\
748\end{array}$ & $\begin{array}{c}\text { Mesma } \\
1005\end{array}$ & $\begin{array}{l}\text { Sup. } \\
515\end{array}$ & & $\begin{array}{l}\text { Sub. } \\
373\end{array}$ & $\begin{array}{c}\text { Mesma } \\
873\end{array}$ & $\begin{array}{l}\text { Sup. } \\
1022\end{array}$ \\
\hline
\end{tabular}

Tabela 7.4 - Comparação dos blocos classificados com os erros experimentais em relação aos blocos reais para o conjunto LOG15

\begin{tabular}{|c|c|c|c|c|c|c|c|}
\hline \multirow{2}{*}{$\begin{array}{l}\text { DADO } \\
\text { REAL }\end{array}$} & \multicolumn{3}{|c|}{ ERRO DE SUAVIZAÇÃO } & \multirow{2}{*}{$\begin{array}{l}\text { DADO } \\
\text { REAL }\end{array}$} & \multicolumn{3}{|c|}{ ERRO INT. DE CONFIANCA } \\
\hline & Med. & Ind. & Inf. & & Med. & Ind. & $\operatorname{lnf}$ \\
\hline Med. & 236 & 228 & 129 & Med. & 30 & 200 & 363 \\
\hline Ind. & 189 & 220 & 184 & Ind. & 21 & 164 & 408 \\
\hline Inf. & 197 & 335 & 550 & Inf. & 5 & 192 & 885 \\
\hline & $\begin{array}{l}\text { Sub. } \\
721\end{array}$ & $\begin{array}{c}\text { Mesma } \\
1006\end{array}$ & $\begin{array}{l}\text { Sup. } \\
541\end{array}$ & & $\begin{array}{l}\text { Sub. } \\
218\end{array}$ & $\begin{array}{c}\text { Mesma } \\
1079\end{array}$ & $\begin{array}{l}\text { Sup. } \\
971\end{array}$ \\
\hline
\end{tabular}


Tabela 7.5 - Comparação dos blocos classificados com os erros experimentais em relação aos blocos reais para o conjunto LOG20

\begin{tabular}{|c|c|c|c|c|c|c|c|}
\hline \multirow{2}{*}{$\begin{array}{l}\text { DADO } \\
\text { REAL }\end{array}$} & \multicolumn{3}{|c|}{ ERRO DE SUAVIZACÃO } & \multirow{2}{*}{$\begin{array}{l}\text { DADO } \\
\text { REAL }\end{array}$} & \multicolumn{3}{|c|}{ ERRO INT. DE CONFIANÇA } \\
\hline & Med. & Ind. & $\operatorname{lnf}$. & & Med. & lnd. & Inf. \\
\hline Med. & 135 & 156 & 153 & Med. & 10 & 72 & 362 \\
\hline Ind. & 160 & 178 & 217 & Ind. & 9 & 50 & 496 \\
\hline Inf: & 182 & 336 & 751 & Inf. & 1 & 83 & 1185 \\
\hline & $\begin{array}{l}\text { Sub. } \\
678\end{array}$ & $\begin{array}{c}\text { Mesma } \\
1064\end{array}$ & $\begin{array}{l}\text { Sup. } \\
526\end{array}$ & & $\begin{array}{c}\text { Sub. } \\
93\end{array}$ & $\begin{array}{c}\text { Mesma } \\
1245\end{array}$ & $\begin{array}{l}\text { Sup. } \\
930\end{array}$ \\
\hline
\end{tabular}

Como se pode verificar nas figuras acima, a classe de recurso medido diminui com o aumento da variabilidade dos dados, enquanto o recurso inferido aumenta no mesmo sentido. Além disso, observa-se que o erro derivado do intervalo de confiança da média tende a superestimar os erros e assim mover os recursos para classes com maiores incertezas. A definição das classes de recursos minerais a partir do erro de suavização mais se aproxima da classificação do erro relativo real em comparação da classificação baseada no intervalo de confiança. Nesse sentido, o erro de suavização proporciona melhores resultados e assim deve ser verificada exaustivamente para confirmar a sua viabilidade em aplicações reais.

A Tabela 7.6 ilustra a variação, em percentagem, da diferença de blocos definidos nas diferentes classes de recursos minerais de acordo com o método proposto nesse trabalho em comparação com a classificação baseada no erro real.

Tabela 7.6 - Diferença entre a quantidade de blocos definidos segundo a classificação de recursos minerais dos diferentes métodos utilizados nesse trabalho (Erro da suavização e Intervalo de confiança) pela classificação a partir do erro real

\begin{tabular}{lcccccc}
\hline \multirow{2}{*}{$\begin{array}{c}\text { Base de } \\
\text { dados }\end{array}$} & \multicolumn{2}{c}{ Medido } & \multicolumn{2}{c}{ Indicado } & \multicolumn{2}{c}{ Inferido } \\
\cline { 2 - 7 } & Erro de suav. & Inter. Conf. & Erro de suav. & Inter. Conf. & Erro de suav. & Inter. Conf. \\
\hline LOG5 & $16,3 \%$ & $-9,7 \%$ & $-21,6 \%$ & $33,8 \%$ & $-25,7 \%$ & $-62,4 \%$ \\
\hline LOG10 & $14,3 \%$ & $-75,5 \%$ & $12,9 \%$ & $46,8 \%$ & $-28,4 \%$ & $36,0 \%$ \\
\hline LOG15 & $4,9 \%$ & $-90,6 \%$ & $32,0 \%$ & $-6,2 \%$ & $-20,2 \%$ & $53,0 \%$ \\
\hline LOG20 & $7,4 \%$ & $-95,5 \%$ & $20,7 \%$ & $-61,3 \%$ & $-11,7 \%$ & $61,0 \%$ \\
\hline
\end{tabular}

Observando a Tabela 7.6 podemos dizer que na medida em que a variabilidade do depósito aumenta a classificação a partir do intervalo de confiança de $90 \%$, tornase inviável devido à enorme diferença entre as classes de recursos definidas por esse método em comparação com o erro real, principalmente na classe de recurso medido onde as diferenças ultrapassam os $90 \%$. Nesses casos, a utilização de um 
intervalo de confiança menos preciso poderia ser considerada, como por exemplo $80 \%$.

A classe de recurso inferido, a partir do erro calculado pelo intervalo de confiança também apresenta grandes discrepâncias em relação ao erro real e essa diferença aumenta consideravelmente à medida que a variabilidade do depósito é maior. Isso implica, em situações reais, que um projeto poderia necessitar de uma pesquisa mineral adicional no sentido de aumentar a confiabilidade dos recursos calculados ou poderia até ser inviabilizado por causa de uma classificação de recursos errônea e conseqüente avaliação de risco equivocada.

A classificação dos recursos a partir do erro de suavização proposto nesse trabalho apresentou, para os conjuntos de dados utilizados, uma melhor relação com o erro real calculado. Esse método, conforme ilustra a Tabela 7.6, apresenta uma variação de aproximadamente $10 \%$ a mais que a classificação do erro real para a classe de recurso medido e $20 \%$ a menos para o recurso inferido. Para a classe de recurso indicado, o método apresentou variação negativa de $21.6 \%$ para o conjunto LOG 5 e positiva para os demais conjuntos. Podemos dizer que o método proposto gerou resultados mais otimistas se comparado com o erro real em todos os conjuntos estudados.

Não se observa uma relação entre as diferenças do erro calculado para o erro real em função ao aumento da variabilidade do depósito, o que indica que o método proposto pode ser utilizado em qualquer nível de variabilidade. Entretanto podemos notar que na medida em que a variabilidade do depósito aumenta a quantidade de blocos nas classes de maior precisão (medido e indicado) caem significativamente para estimativas realizadas com o mesmo número de amostras e mesma configuração espacial. Isso demonstra que quanto maior a variabilidade da variável em estudo mais detalhada deve ser a amostragem para se ter acesso ao mesmo grau de incerteza.

A classificação dos recursos minerais a partir da proposta apresentada nesse trabalho mostra-se muito mais confiável no sentido de definir as classes de recursos de acordo com a confiabilidade da estimativa por krigagem ordinária. Esse trabalho foi desenvolvido a partir de dados sintéticos que nos possibilitou acesso ao erro verdadeiro da estimativa realizada e nos permitiu calcular a eficiência do método 
proposto. Entretanto, estudos adicionais devem ser realizados com dados reais de pesquisas e produção de um empreendimento mineiro a fim de se comprovar a eficiência do mesmo.

Para melhor ilustrar o método proposto selecionamos alguns blocos para demonstrar o comportamento dessa variável em distintas situações com relação à configuração espacial e variabilidade dos dados de amostragem.

A primeira situação apresentada corresponde a um exemplo onde o bloco estimado apresenta uma boa amostragem em sua vizinhança e os dados utilizados na estimativa apresentam baixa variabilidade como pode ser observado na Figura 7.11. A Tabela 7.7 demonstra os valores utilizados e o resultado dos cálculos dos erros que foram coloridos de acordo com a classe de recurso atribuída.

Tabela 7.7 - Parâmetros utilizados no cálculo dos erros e valores obtidos para as diferentes bases de dados. Bloco com centro em x: 25,5 e y: 22,5. (Legenda de classificação dos recursos em função do cálculo do erro: Verde - medido; amarelo -indicado e vermelho inferido)

\begin{tabular}{lcccccccc}
\hline Base de & \multicolumn{3}{c}{ Parametros } & \multicolumn{3}{c}{ Cálculo do erro } \\
\cline { 2 - 8 } dados & Z & Z*K $^{*}$ & So & CV & Z*Nso & Real & Erro Suaviz. & I.C. $90 \%$ \\
\hline LOG5 & 0,887 & 0,844 & 0,225 & 0,267 & 0,070 & $5 \%$ & $8 \%$ & $27 \%$ \\
LOG10 & 0,787 & 0,712 & 0,484 & 0,680 & 0,124 & $11 \%$ & $17 \%$ & $60 \%$ \\
LOG15 & 0,698 & 0,600 & 0,599 & 0,998 & 0,163 & $16 \%$ & $27 \%$ & $102 \%$ \\
LOG20 & 0,620 & 0,506 & 0,856 & 1,692 & 0,191 & $22 \%$ & $38 \%$ & $121 \%$ \\
\hline
\end{tabular}

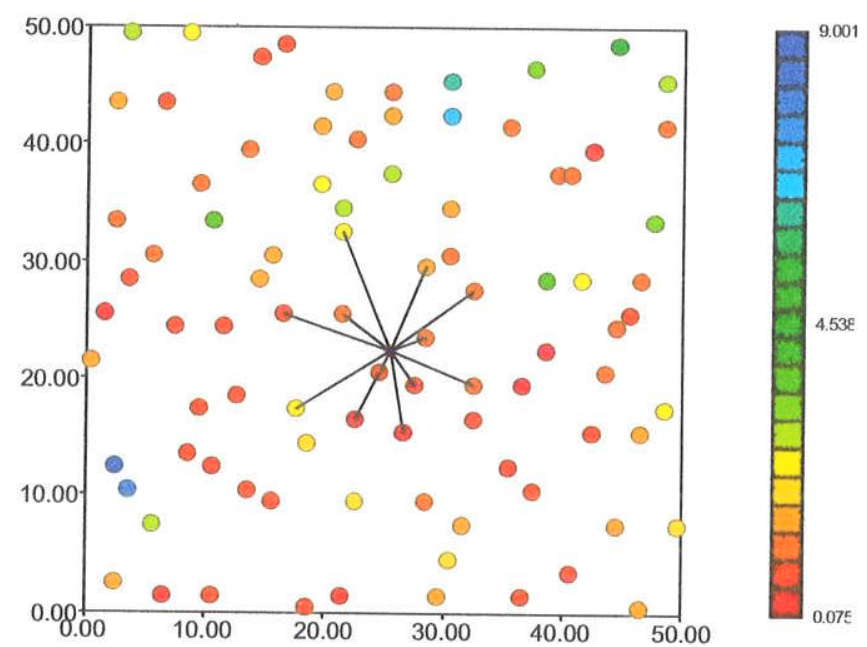

Figura 7.11 - Configuração espacial das amostras utilizadas para a estimativa do bloco. A escala de cores representa o teor da variável para a base de dados LOG10. (Bloco com centro em x: 25,5 e y: 22,5 ) 
Como demonstra a Tabela 7.7 esse bloco foi classificado segundo o erro real, ou seja, comparando o resultado da estimativa com o resultado da base de dados exaustivo, como recurso medido em LOG5, LOG10 e LOG15 e como indicado em LOG20. Isso nos permite afirmar que com o aumento da variabilidade dos dados, para uma mesma configuração espacial, a classe de recursos tente a cair para níveis com maiores incertezas. Para esse cenário, o erro de suavização classificou o bloco como recurso medido para LOG5 e LOG10 e como indicado em LOG15 e LOG20 demonstrando uma boa aproximação se comparado com o erro real. Já o erro calculado a partir do intervalo de confiança classificou esse bloco como recurso indicado em LOG5 e inferido em LOG10, LOG15 e LOG20; o que nos confirma que a utilização desse método não estima com exatidão o erro associado à estimativa, classificando os blocos em classes de maiores incertezas mesmo para baixas variabilidades e razoável configuração espacial entre as amostras utilizadas para a estimativa.

O cenário seguinte apresenta uma situação onde a disposição das amostras é parecida com a apresentada na situação anterior com a diferença que a variabilidade destas amostras é maior se comparado com a variabilidade das amostras apresentadas no cenário anterior conforme demonstra a Tabela 7.8 e a Figura 7.12.

Tabela 7.8 - Parâmetros utilizados no cálculo dos erros e valores obtidos para as diferentes bases de dados. Bloco com centro em x: 17,5 e y: 36,5. (Legenda de classificação dos recursos em função do cálculo do erro: Verde - medido; amarelo -indicado e vermelho inferido)

\begin{tabular}{lcccccccc}
\hline Base de & \multicolumn{5}{c}{ Parametros } & \multicolumn{3}{c}{ Cálculo do erro } \\
\cline { 2 - 8 } dados & Z & $Z^{*}$ oK & So & CV & $Z^{*}$ Nso & Real & Erro Suaviz. & I.C. 90\% \\
\hline LOG5 & 1,433 & 1,243 & 0,232 & 0,186 & 0,204 & $15 \%$ & $16 \%$ & $25 \%$ \\
LOG10 & 2,053 & 1,546 & 0,669 & 0,433 & 0,551 & $33 \%$ & $36 \%$ & $57 \%$ \\
LOG15 & 2,943 & 1,923 & 1,410 & 0,733 & 1,115 & $53 \%$ & $58 \%$ & $96 \%$ \\
LOG20 & 4,217 & 2,391 & 2,849 & 1,192 & 2,011 & $76 \%$ & $84 \%$ & $145 \%$ \\
\hline
\end{tabular}




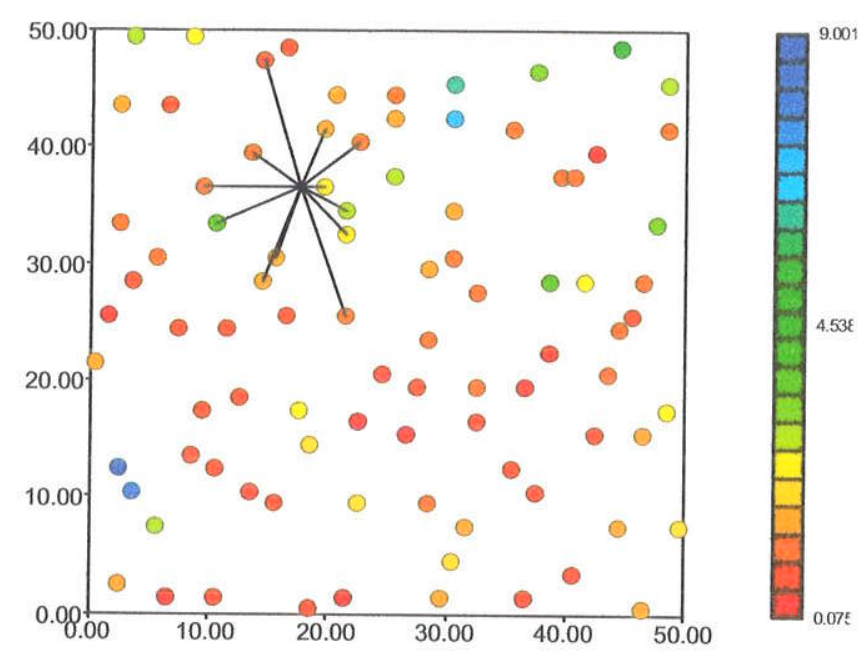

Figura 7.12 - Configuração espacial das amostras utilizadas para a estimativa do bloco. A escala de cores representa o teor da variável para a base de dados LOG10. (Bloco com centro em x: 17,5 e y: 36,5 )

Observando a Tabela 7.8 esse bloco classificado, segundo a diferença entre estimado e dado exaustivo, em recurso medido em LOG5, indicado em LOG10 e LOG15 e inferido para LOG20. Podemos observar que nesse cenário os valores estimados apresentaram valores abaixo do valor exaustivo e, com o aumento da variabilidade entre as amostras a diferença entre valor real e estimado foi aumentando, resultando em uma redução na classe de recurso.

O erro calculado a partir do erro de suavização apresentou boa correlação com o erro real sendo que para todas as bases de dados o bloco foi classificado na mesma categoria. Para o erro calculado a partir do intervalo de confiança o bloco foi classificado como recurso indicado em LOG5 e inferido em LOG10, LOG15 e LOG20, ou seja, essa classificação apresentou um cenário mais pessimista que o real para as bases de dados LOG5 e LOG10 e, apesar de classificar o bloco corretamente para as bases LOG15 e LOG20; o valor do erro calculado por esse método foi muito maior que o valor real do erro.

A situação apresentada corresponde a um bloco onde as amostras utilizadas para sua estimativa tem uma configuração semelhante a do primeiro cenário (Figura 7.11), com a diferença que essas amostras apresentam uma variabilidade maior se compararmos a mesma base. Observando esses dois cenários podemos afirmar que em um mesmo domínio a variabilidade também influência no cálculo do erro e o método proposto conseguiu identificar essa variação classificando o bloco estimado 
na categoria correta de recursos minerais. Esse efeito, onde a variância entre as amostras interfere de maneira significativa na incerteza do erro não é levado em consideração na avaliação dos recursos quanto utilizamos a variância de krigagem ou métodos qualitativos de classificação como o número e/ou distância entre as amostras utilizadas na estimativa. Essa relação entre variabilidade entre as amostras/incerteza não estaria sendo representada e os blocos desses dois cenários apresentados seriam classificados na mesma categoria de recurso, e como vimos, isso não ocorre.

O terceiro cenário representa uma situação onde as amostras utilizadas para a estimativa do bloco apresentam alta variabilidade sendo que duas amostras têm teores muito mais altos que as demais e o bloco analisado encontra-se próximo a essas amostras como pode ser observado na Figura 7.13. A Tabela 7.9 demonstra o cálculo dos erros.

Tabela 7.9 - Parâmetros utilizados no cálculo dos erros e valores obtidos para as diferentes bases de dados. Bloco com centro em x: 3,5 e y: 14,5. (Legenda de classificação dos recursos em função do cálculo do erro: Verde - medido; amarelo -indicado e vermelho inferido)

\begin{tabular}{lcccccccc}
\hline Base de & \multicolumn{5}{c}{ Parametros } & \multicolumn{3}{c}{ Cálculo do erro } \\
\cline { 2 - 9 } dados & Z & $Z^{*}$ oK & So & CV & $Z^{*}$ Nso & Real & Erro Suaviz. & I.C. $90 \%$ \\
\hline LOG5 & 1,779 & 1,393 & 1,088 & 0,781 & 0,631 & $28 \%$ & $45 \%$ & $119 \%$ \\
LOG10 & 3,163 & 1,941 & 3,915 & 2,017 & 2,187 & $63 \%$ & $113 \%$ & $368 \%$ \\
LOG15 & 5,626 & 2,703 & 12,917 & 4,779 & 5,772 & $108 \%$ & $214 \%$ & $892 \%$ \\
LOG20 & 10,005 & 3,766 & 39,314 & 10,439 & 13,765 & $166 \%$ & $366 \%$ & $1995 \%$ \\
\hline
\end{tabular}

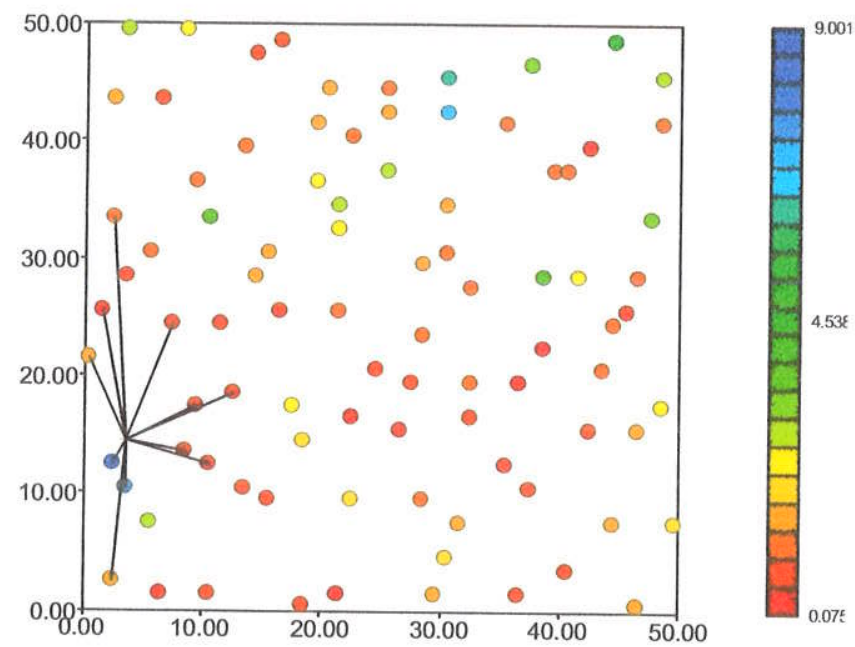

Figura 7.13 - Configuração espacial das amostras utilizadas para a estimativa do bloco. A escala de cores representa o teor da variável para a base de dados LOG10. (Bloco com centro em x: 3,5 e y: 14,5) 
Nessa situação apresentada onde a variabilidade é consideravelmente maior que no cenário anterior, o bloco foi classificado pela diferença do valor estimado com o real (erro real) como recurso indicado em LOG5 e recurso inferido em LOG10, LOG15 e LOG20, pois com o aumento da variabilidade os valores estimados são cada vez mais subestimados. O erro de suavização apresentou boa relação se comparado com a classificação a partir do erro real, pois classificou o bloco nas mesmas classes de recursos em todas as bases de dados estudadas e o erro pelo intervalo de confiança colocou o bloco na categoria de recurso indicado em todas as bases de dados. Já, o erro calculado pelo intervalo de confiança classificou o bloco como recurso inferido em todas as bases de dados. Vale ressaltar que, conforme demonstra a Tabela 7.9, o erro suavizado está muito mais próximo do erro real que o erro calculado para o intervalo de confiança em todas as populações.

Esse cenário ilustra uma situação onde o bloco está sendo estimado em uma área onde as amostras a seu redor apresentam alta variabilidade. O bloco está bem mais próximo de duas amostras de alto teor que das demais amostras e como podemos observar na Tabela 7.9 este bloco apresenta valores subestimados se comparado ao dado exaustivo. Novamente nesse caso, se utilizarmos os métodos qualitativos de classificação, certamente esse bloco estaria erroneamente classificado com grau de certeza da estimativa maior do que ele realmente pertence.

O próximo cenário apresenta uma situação de um bloco estimado sem amostras próximas. Tais amostras apresentam baixa variabilidade como pode ser observado na Figura 7.14. A Tabela 7.10 demonstra o resultado dos cálculos dos erros.

Tabela 7.10 - Parâmetros utilizados no cálculo dos erros e valores obtidos para as diferentes bases de dados. Bloco com centro em x: 16,5 e y: 4,5. (Legenda de classificação dos recursos em função do cálculo do erro: Verde - medido; amarelo -indicado e vermelho -inferido)

\begin{tabular}{lcccccccc}
\hline Base de & \multicolumn{3}{c}{ Parametros } & \multicolumn{3}{c}{ Cálculo do erro } \\
\cline { 2 - 8 } dados & Z & Z*oK & So & CV & Z*Nso & Real & Erro Suaviz. & I.C. $90 \%$ \\
\hline LOG5 & 0,333 & 0,730 & 0,264 & 0,362 & 0,191 & $-54 \%$ & $26 \%$ & $38 \%$ \\
LOG10 & 0,111 & 0,533 & 0,519 & 0,974 & 0,316 & $-79 \%$ & $59 \%$ & $90 \%$ \\
LOG15 & 0,037 & 0,389 & 0,702 & 1,806 & 0,393 & $-90 \%$ & $101 \%$ & $161 \%$ \\
LOG20 & 0,012 & 0,284 & 0,954 & 3,360 & 0,436 & $-96 \%$ & $154 \%$ & $258 \%$ \\
\hline
\end{tabular}




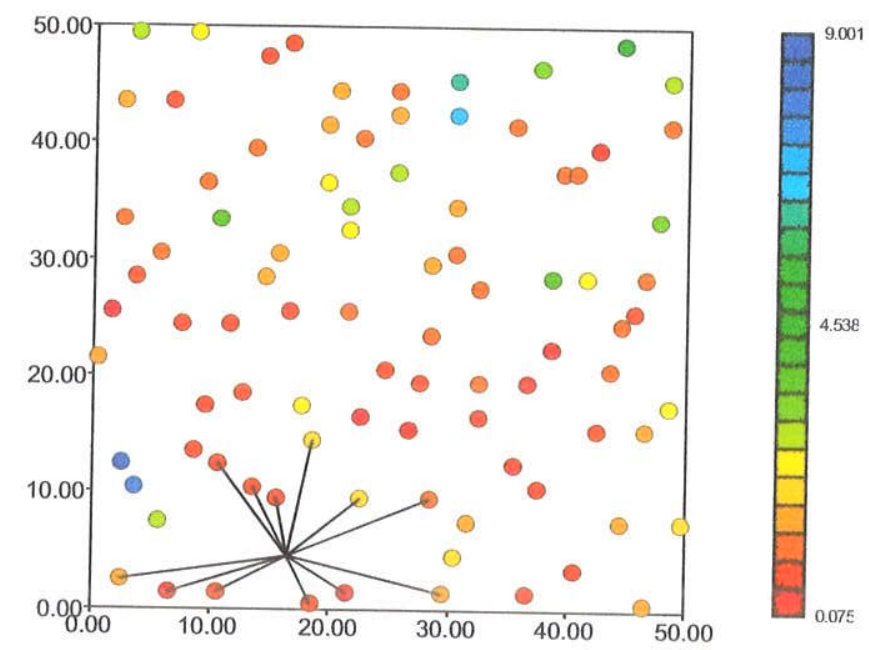

Figura 7.14 - Configuração espacial das amostras utilizadas para a estimativa do bloco. A escala de cores representa o teor da variável para a base de dados LOG10. (Bloco com centro em $x: 16,5$ e $y: 4,5)$

Podemos ver nessa situação que a falta de amostragem próxima ao bloco a ser estimado afeta, significamente o nível de incerteza da estimativa. Mesmo com as amostras mais próximas não apresentando grande variância o bloco foi classificado como reserva inferida para todas as bases de dados com relação ao erro real. A classificação de recursos a partir do erro de suavização e do intervalo de confiança colocou esse bloco na categoria de recursos indicado em LOG5 e inferido nas demais bases de dados. Esse foi o único caso estudado onde os recursos foram classificados em categorias inferiores ao real, pois apresentaram erro calculado, tanto utilizando o erro de suavização como o intervalo de confiança, menores que o real.

Para esse cenário podemos perceber que mesmo a baixa variabilidade entre as amostras utilizadas na estimativa o bloco foi superestimado em todas as bases de dados. Vale ressaltar que apesar das amostras estarem afastadas do bloco, estas se localizam dentro do limite espacial do variograma. Também podemos notar que com o aumento da variabilidade dos dados o erro torna-se maior.

Analisando os cenários apresentados fica clara a importância da utilização de um método quantitativo, com exceção da variância de krigagem, para o cálculo das incertezas associadas às estimativas realizadas por krigagem ordinária. A utilização dos métodos qualitativos, que usam apenas o número de amostras consideradas 
para realizar uma estimativa e/ou se as amostras estão dentro do raio de influência do variograma, mostram-se falhas em todas as situações discutidas.

A relação distância de amostragem x variância é a chave para uma correta classificação dos recursos minerais para qualquer tipo de depósito. Sabe-se que quanto maior a variância menor deve ser a malha de amostragem, mas por outro lado o custo para se ter uma amostragem detalhada pode inviabilizar o empreendimento. O ideal é buscar um meio termo que concilie um razoável investimento financeiro com uma correta avaliação dos recursos minerais minimizando assim os riscos que envolvem a abertura e operação de um empreendimento mineiro com lucratividade. O método proposto por esse trabalho pode ser uma boa alternativa a esse propósito. 


\section{CAPÍTULO 8 \\ CONSIDERAÇÕES FINAIS}

Diversas fontes de erros podem influenciar no resultado final de uma estimativa. Por isso, antes de se iniciar qualquer processo de classificação de recursos minerais, independente do método a ser aplicado, devemos conhecer as possiveis fontes de erros a fim de implementar técnicas que possam minimizá-los, tornando a base de dados mais confiável, gerando assim uma estimativa e conseqüente classificação precisa e segura.

Os códigos mundiais de classificação de recursos e reservas minerais vêm evoluindo ao longo dos anos no sentido de unificar a nomenclatura e suas definições criando assim um sistema universal de classificação ficando cada país a cargo de completar os códigos nacionais de acordo com as questões locais, culturais, governamentais e ambientais. Entretanto vimos que a tendência mundial desses códigos é o reconhecimento das particularidades de cada depósito mineral que impossibilita a regulamentação de uma técnica padrão para a classificação ou método de estimativa dos recursos minerais.

A geoestatística foi o primeiro método a proporcionar o cálculo da incerteza de estimativas por meio da variância de krigagem. Esta medida de incerteza foi intensivamente utilizada na indústria para diversos fins, inclusive para classificação de recursos ou reservas minerais. Mas, devido ao seu caráter homoscedástico, a variância de krigagem não deve ser utilizada exceto como um índice de configuração espacial dos pontos vizinhos empregados para interpolação. A variância de interpolação, por outro lado, é uma medida mais confiável e pode ser utilizada como medida de incerteza, bem como para derivar o erro de suavização.

A simulação estocástica tem sido utilizada para derivar cenários equiprováveis, os quais podem ser utilizados para calcular a incerteza associada a cada bloco de cubagem por meio da construção de histogramas. Outra possibilidade seria derivar o erro de simulação em cada realização e utilizá-lo para fins de classificação de recursos ou reservas minerais. Mas, deve-se tomar muito cuidado, pois embora os cenários sejam equiprováveis os erros em cada bloco podem variar muito, devido ao 
caráter aleatório do método da simulação, fazendo com que o mesmo bloco seja classificado em classes de reservas muito diferente, dependendo da realização.

A utilização do erro de suavização, derivado do processo de correção do efeito de suavização da krigagem ordinária, parece ser viável para aplicações práticas em classificação de recursos e reservas minerais. Nesta pesquisa foi considerada apenas a situação hipotética de uma bancada com informações de alguns blocos, as quais foram utilizadas para estimar os demais blocos e, portanto, não houve mudança de suporte amostral. Evidentemente, há a possibilidade de aplicação da metodologia em situações onde há mudança de suporte amostral, por exemplo, amostras de furos de sonda para avaliação de blocos de cubagem. Entretanto, isto requer a continuidade da pesquisa devendo ser uma meta para o futuro próximo. Esta pesquisa demonstrou como a incerteza afeta significativamente a classificação de recursos minerais. Na situação de pequena variabilidade, a grande maioria dos blocos que estava classificada como medida passa gradativamente para inferida com o aumento da variabilidade. Isto indica que a amostragem deve ser adensada em casos de grande variabilidade da mineralização, mas dentro do limite da viabilidade técnico-econômica do empreendimento mineiro.

Podemos concluir, através do estudo apresentado, que o método proposto é mais preciso se comparado aos métodos qualitativos de classificação de recursos e reservas minerais que ainda nos dias de hoje são bastante utilizados. Também, pode-se dizer que esse método é superior se comparado aos métodos que utilizam a Teorema do Limite Central para o cálculo da incerteza.

A solução definitiva para o problema da classificação de recursos ou reservas minerais ainda depende de pesquisas aplicadas, mas a alternativa proposta por meio do erro de suavização foi a que apresentou melhores resultados. Entretanto, esta alternativa necessita ser testada em aplicações de casos reais através de convênio universidade e empresa. Diversos cenários envolvendo dados reais de diferentes tipos de mineralização precisam ser testados.

Esta pesquisa demonstrou como a geoestatistica pode fazer o melhor uso da informação disponivel com otimização dos recursos financeiros, por meio de medidas de incerteza e erros derivados do simples processo da krigagem ordinária. 


\section{REFERÊNCIAS BIBLIOGRÁFICAS}

ANNELS, A. E. Mineral deposit evaluation: A practical approach. London: Chapman and Hall, 1991. 436 p.

ANNELS, A. E. Ore Reserves: Errors and classification. Transactions of the institution of mining and metallurgy, Section A, Mining Industry, v. 105, p. A150 - A156, 1996.

ARIK, A. An alternative approach to resource classification. In: INTERNATIONAL. SYMPOSIUM ON COPUTER APPLICATIONS IN THE MINERAL INDUSTRIES (APCOM'99), 28. 1999. Proceedings... EUA: Colorado School of Mines, Golden, 1999. p. $45-53$.

ARMSTRONG, M. Is research in mining geostats as dead as a dodo? in: DIMITRAKOULOS, R. Geostatistics for the next century. Holanda: Kluwer Academic, 1994. p. 303-312.

ARMSTRONG, M. Basic linear geostatistics. Berlim: Springer, 1998. 153 p.

AUSTRALASIAN INSTITUTE OF MINING AND METALLURGY (AusIMM). Australasian code for reporting of exploration results, mineral resources and ore reserves (The JORC Code). Austrália: The joint ore reserves committee of the Australasian institute of mining and metallurgy, Australian institute of geoscientists and minerals council of Australia (JORC), 2004. 32p. Disponivel em: $<$ http://www.jorc.org $>$. Acesso em março de 2010.

AUSTRALASIAN INSTITUTE OF MINING AND METALLURGY (AusIMM). Announcement of planned revision of the 2004 JORC Code. Austrália: JORC web site, 2009. $1 \mathrm{p}$. Disponivel em: <http://www.jorc.org/pdf/ announcement planned revision. pdf >. Acesso em julho de 2011.

BABAK, O. ; DEUTSCH, C. V. Uncertainty as the overlap of alternate conditional distributions. Computational geosciences, v.12, n. 4, p.503-512, 2008.

BIENIAWSKI, Z. T. Engineering rock mass classifications: A complete manual for engineers and geologists in mining, civil and petroleum engineering. Canadá: John Wiley \& Sons, 1989, 251 p.

BURMEISTER, B. From resource to reality: A critical review of the achievements of new australian gold mining projects during 1983-1987. Sidney: Macquarie University, 1988.

CAERS, J. Adding local accuracy to direct sequential simulation: Math. Geology, v. 32, n. 7 , p. 815-850, 2000.

CANADIAN INSTITUTE OF MINING, METALLURGY AND PETROLEUM (CIM). Resource and Reserve Definitions: CIM standards on mineral resources and reserves - definitions and guidelines. The Canadian Mining and Metallurgical Bulletin, v. 93, n. 1044, p. 53-61, 2000 .

CANADIAN SECURITIES ADMINISTRATORS (CSA). Standards of disclosure for mineral projects - National Instrument 43-101. Canadian Securities Administrators, 2001. 28 p. Disponivel em:<http://www.blakes.com/english /publications/bsra/v128/rule 43-101 sdmineral-projects.pdf>. Acesso em maio de 2010.

CHILES, J. P. ; DELFINER P. Geostatistics modeling spatial uncertainty. Canadá: John Wiley \& Sons, 1999, $695 \mathrm{p}$.

CLOW, G. Why gold mines fail? Canadá: Northern Miner Magazine, v. 6, n. 2, p. 31-34, 1991. 
COMMITTEE FOR MINERAL RESERVES INTERNATIONAL STANDARDS (CRIRSCO). International template for reporting of exploration results, mineral resources and mineral reserves. Committee for mineral reserves international standards. 2006. 36 p. Disponivel em: <http://www.crirsco.com/crirsco templatev2.pdfs. Acesso em março de 2010.

DAVID, M. Geostatistical ore reserve estimation. Developments in geomathematics 2. Amsterdam: Elsevier Scientific Publishing Company, 1977. 364 p.

DAVIS, S. B. Use and abuses of cross validation. Math. Geology, v.19, n. 3, p 249-258. 1997.

DEPARTAMENTO NACIONAL DA PRODUÇÃO MINERAL (DNPM). Código de mineração e legislação correlativa. Brasília: DNPM, 1987. 333p.

DEPARTAMENTO NACIONAL DA PRODUÇÃO MINERAL. (DNPM). Bases técnicas de um sistema de quantificação do patrimônio mineral brasileiro. Brasilia: DNPM, 1992. 28p.

DEUTSCH, C. V. ; JOURNEL, A. G. GSLIB: Geostatistical software library and user's guide. New York: Oxford University Press, 1992. 340 p.

DIATCHKOV, S. A. Principles of classification of reserves and resources in the CIS countries. Min. Eng., v. 46, n. 3, p. 214-217, 1994.

DIEHL, P. ; DAVID, M. Classification of ore reserves/resources based on geostatistical methods. The Canadian Mining and Metallurgical Bulletin, v. 75 , n. 838 , p. 127-136, 1982.

DOMINY, S. C. Fundamental sampling error and its relationship to the nugget effect in gold deposits. In: PROCEDINGS EGRU MINING AND RESOURCE GEOLOGY SYMPOSIUM, 62, 2004. EGRU Contribution 2004, p. 30-45.

DOMINY, S. C. ; ANNELS, A. E. ; NOPPÉ, M. Errors and uncertainty in mineral resource and ore reserve estimation: The importance of getting it right. Explor. Mining Geol., v. 11, p. $77-98,2002 a$.

DOMINY, S. C. ; ANNELS, A. E. ; NOPPÉ, M. Errors and uncertainty in ore reserve estimates - Operator beware. In: UNDERGROUD OPERATORS CONFERENCE, 2002b. p. 121-126. Disponivel em:<http://www.snowdenau.com/getBinary.aspx? documentid=784>. Acesso em setembro de 2009.

FROIDEVAUX, R. Geostatistics and ore reserve classification. The Canadian Mining and Metallurgical Bulletin, v. 75, n. 843, p. 77-83, 1982.

GOOVAERTS, P. Geostatistics for natural resources evaluation. New York: Oxford University Press, 1997. 483 p.

GUERTIN, K. Correcting conditional bias. In: VERLY, G.; DAVID, M.; JOURNEL, A. G.; MARECHAL, A. Geostatistics for natural resources characterization. Holanda: D. Reidel, Dordrecht, 1984. v.1, p. 245-160.

HENLEY, S. The Russian system of resource/reserves classification. Earth Science Computer Applications, v. 15, n. 12, p. 1-2, 2000.

HOHN, M. E. Petroleum and Geostatistics. Dordrecht: Kluwer Academic Publishers, 1999. $235 \mathrm{p}$. 
INSTITUTO DE INGENIEROS DE MINAS DE CHILE (IIMCh). Certification code for exploration prospects, mineral resources and ore reserves. Santiago do Chile: Instituto de ingenieros de minas de Chile, 2004. 43 p. Disponivel em: $<$ http://www.iimch.cl/index. php?option=com remository\&ltemid $=39 \&$ func $=$ fileinfo \&id $=46$ >. Acesso em maio de 2010.

ISAAKS, E. H. ; SRIVASTAVA, M. R. An Introduction to Applied Geostatistics. New York: Oxford University Press, 1989. $561 \mathrm{p}$.

JOINT COMMITEE FOR GUIDES IN METROLOGY (JCGM). International vocabulary in metrology: Basic and general concepts and associated terms (VIM). 1. ed. Sèvres: BIPM, 2008a. 90 p. Disponivel em <http:/www.bipm.org/en/publications/quides $>$. Acesso em julho 2010.

JOINT COMMITEE FOR GUIDES IN METROLOGY (JCGM). Evaluation of measurement data: Guide to the expression of uncertainty in measurement (GUM). 1. ed. Sèvres: BIPM, 2008b. 120 p. Disponivel em <http://www.bipm.org/en/publications/quides>. Acesso em julho 2010.

JOURNEL, A. G. The lognormal approach to predicting local distributions of selective mining unit grades. Math. Geolology, v.12, n. 4, p. 285-303. 1980.

JOURNEL, A. G ; KYRIAKIDIS, P. C.; MAO, S. Correcting the smoothing effect of estimators: A spectral postprocessor. Math. Geolology, v. 32, n. 7, p. 787-813, 2000.

JOURNEL, A. G. ; ROSSI, M. E. When do we need a trend model in kriging? Math. Geology, v. 21, n. 7, p. 715-739. 1989.

JOURNEL, A. ; Xu, W. Posterior identification of histograms conditional to local data. Math. Geol., v. 26, n. 3, p. 323-359, 1994.

LIPTON, I. T. A review of density determination methods for iron ore deposit evaluation. In: IRON MAKING RESOURCES AND RESERVES ESTIMATION CONFERENCE, 1997. Perth. Proceedings...Perph: Australasian Institute of Mining and Metallurgy, 1997. p. 5156.

MATHERON, G. Principles of Geostatistics. Economic Geology, v. 58, p. 1246-1266, 1963.

NEUSS, I. Outokumpu - Base Metals Best Practice. In: THE AUSTRALIAN INSTITUTE OF MINING AND METALLURGY (AusIMM). Mineral Resource and Ore Reserve Estimation - The AusIMM Guide to Good Practice. Melbourne: A C Edwards, 2001. p. 49-56.

OLEA, R. A. Geostatistics for Engineers and Earth Scientists. Massachusetts: Kluwer Academic Publishers, 1999. 303 p.

OLEA, R. A. ; PAWLOWSKY, V. Compensating for estimation smoothing in kriging. Math. Geology, v. 28, n. 4, p. 407-417, 1996.

ORTIZ, J. M. ; LEAUANGTHONG, O. ; DEUTSCH, C. V. A multi-Gaussian approach to assess block grade uncertainty. In: CIM CONFERENCE AND EXHIBITION, 2004. Edmonton. Proceedings... Edmonton: Canadian Institute of Mining, Metallurgy and Petroleum, 2004. p. 1-12. Disponivel em < http://www.uofaweb.ualberta.ca/ccg//pdfs/2004\%20311-Ucertainty\%20caling.pdf>. Acesso em maio 2010.

PALMER, K. J. ; PALMER, P. G. Mineral resource classification - Review of current pratices in NI 43-101 technical reports. In: CIM MEMO 2010, 2010. Sudbury. Proceedings... Sudbury: Canadian Institute of Mining, Metallurgy and Petroleum, 2010. p. 127-136. 
PAN, G. C. Smothing Effect, conditional bias and recoverable reserves. The Canadian Institute of Mining, Metallurgy and Petroleum Bulletin, v. 91, n. 1019, p. 81-86, 1998.

PHILLIPS, $R$. The liability of company directors and competent persons for resource/reserve disclosure. In THE CODES FORUM, 2000. Sydiney. Proceedings... Sydiney: Minerals Industry Consultants Association and The Australasian Institute of Mining and Metallurgy, 2000. p. 110-118. Disponivel em <http://www.jorc.org/pdf/phillips1.pdf>. Acesso em junho 2010.

SAHIN, A. Global estimates of ore reserves in a beach sand deposit. The Canadian Institute of Mining, Metallurgy and Petroleum Bulletin, v. 94, n. 1047, p. 43-47, 2001.

SAMAL, A. R. Calculation of confidence intervals of the block estimates using block-support anamorphosis and discrete Gaussian variogram. In: INTERNATIONAL SYMPOSIUM ON COPUTER APPLICATIONS IN THE MINERAL INDUSTRIES (APCOM'09), 34., 2009. Proceedings... Vancouver: CIM, 2009. p. 45-53. 2009.

SAUBOURIN, R. Geostatistics as a tool to define various categories of resources. Math. Geology, v.15, n. 1, p. $131-143,1983$.

SINCLAIR, A. J. Geological controls in Resource/Reserve estimation. Exploration and Mining Geology, v. 7, n. 2, p. 29-44, 1998.

SINCLAIR, A. J. ; BLACKWELL, G. H. Applied mineral inventory estimation. Cambridge: University Press, 2002. $381 \mathrm{p}$.

SOARES, A. Geoestatistica para as ciências da terra e do ambiente. 2. ed. Lisboa: IST Press, 2006. $214 \mathrm{p}$.

SOCIETY FOR MINING, METALLURGY AND EXPLORATION (SME). A Guide for Reporting Exploration Information, Mineral Resources, and Mineral Reserves. The Resources and Reserves Committee of The Society for Mining, Metallurgy and Exploration. EUA: The Society for Mining, Metallurgy and Exploration. 2007. 17 p.

SOUTH AFRICAN MINERAL RESOURCE COMMITTEE (SAMREC). South African Code for Reporting of Mineral Resources and Mineral Reserves (The SAMREC Code). África do Sul: South African Mineral Resource Committee and South African Institute of Mining and Metallurgy. 2007. 65. Disponivel em <http://www.samcode.co.za/ downloads/ SAMREC 2009.pdf>. Acesso em julho 2010.

SOUZA, A. L. Estudo do efeito de suavização da krigagem ordinária em diferentes distribuições estatísticas. 2007. 101 f. Dissertação (Mestrado) - Instituto de Geociências, Universidade de São Paulo, São Paulo, 2007.

SOUZA, L. E. Proposição geoestatística para quantificação do erro em estimativas de tonelagens e teores. 2007. $193 \mathrm{f}$. Tese (Doutorado) - Departamento de Engenharia de Minas da Escola de Engenharia da Universidade Federal do Rio Grande do Sul, Porto Alegre, 2007.

STEPHENSON, P. R. ; STOKER, P. T. Classification of mineral resources and ore reserves. In: INTERNACIONAL SYNPOSIUM ON COMPUTER IN THE MINERAL INDUSTRIES (APCOM'99), 28., 1999. Colorado. Proceedings... Colorado: Colorado School of Mines, 1999. p. 55-67. 
STEPHENSON, P. R. ; VANN, J. Common sense and good comunication in: AUSTRALIAN INSTITUTE OF MINING AND METALLURGY (AusIMM). Mineral resource and ore reserve estimation - The Aus/MM guide to good practice. Melbourne: The Australasian Institute of Mining and Metallurgy, 2001. p. 13-20.

STONE, J. G.; DUNN, P. G. Ore reserve estimates in the real world, 2.ed. Littleton: Society of Economic Geologists, 1996. 160 p.

VALLEEE, M. ; COTE, D. The guide to the evaluation of gold deposits: integrating deposit evaluation and reserve inventory practices. The Canadian Institute of Mining, Metallurgy and Petroleum Bulletin, v. 85, n. 957, p. 50-61, 1992.

VAUGHAN, W. S. ; FELDERHOF, S. International mineral resource and reserve classification and reporting systems. The Canadian Institute of Mining, Metallurgy and Petroleum Bulletin, v. 98, n. 1086, p. 1-13, 2005.

VUOLO, J. H. Fundamentos da Teoria de Erros. 2. ed. Rio de Janeiro: Edgard Blucher, 1996. $246 \mathrm{p}$.

WATANABE, J. Métodos geoestatisticos de co-estimativa: Estudo do efeito da correlação entre variáveis na precisão dos resultados. 2008. 79 f. Dissertação (Mestrado) Instituto de Geociências, Universidade de São Paulo, São Paulo, 2008.

WAWRUCH, T. M. ; BETZHOLD, J. F. Mineral resource classification through conditional simulation. In: INTERNACIONAL GEOSTATISTICS CONGRESS, 17., 2004. Baniff. Geostatistics Baniff 2004 - Series: Quantitative Geology and Geostatistics. v. 14. Bannif: Leuangthong, Oy; Deutsch, Clayton V., 2005.

WEATHERSTONE, N. International Standards for Reporting of Mineral Resources and Reserves - Status, Outlook and Important issues. In: WORLD MINING CONGRESS \& EXPO 2008), 21., 2008. Disponivel em < http://www.crirsco.com/isr mineral resources reserves0908.pdf>. Acesso em julho 2010.

WELLMER, F. W. Classification of ore reserves by geostatistical methods. Erzmetall, v. 36 , n. $7 / 8$, p. 315-321, 1983.

YAMAMOTO, J. K. Convex Hull - A pascal program for determining the convex hull for planar sets. Computers \& Geosciences, v. 23, n. 7, p. 725-738, 1997.

YAMAMOTO, J. K. Quantification of uncertainty in ore-reserve estimation: applications to Chapada Copper Deposit, State of Goias, Brazil. Natural Resources Research, New York, v. 8, n. 2, p. 153-163, 1999.

YAMAMOTO, J. K. An alternative measure of the reliability of ordinary kriging estimates, Math. Geology, v. 32, p. 489-509, 2000.

YAMAMOTO, J. K. Métodos convencionais. In: YAMAMOTO, J. K. Avaliação e classificação de reservas minerais. 1. ed. São Paulo: Editora da Universidade de São Paulo, 2001. $226 \mathrm{p}$.

YAMAMOTO, J. K. Correcting the smoothing effect of ordinary kriging estimates. Math. Geology, v. 37, n. 1, p. 69-94. 2005.

YAMAMOTO, J. K. On unbiased backtransform of lognormal kriging estimates. Computational Geosciences, v. 11, p. 219-234, 2007. 
YAMAMOTO, J. K. Estimation or simulation? That is the question. Computational Geosciences, v. 12, p. 573-591, 2008.

YAMAMOTO, J. K. ; BETTENCOURT, J. S. ; MONTANEIRO, T. J. Análise estatística. In: YAMAMOTO, J. K. Avaliação e classificação de reservas minerais. 1. ed. São Paulo: Editora da Universidade de São Paulo, 2001. 226 p.

YAMAMOTO, J. K. ; CHAO, L. Comparação de métodos para teste de bigaussianidade. Geociências (UNESP. Impresso), v. 28, p. 121-128, 2009.

YAMAMOTO, J. K. ; CONDE, R. P. Classificação de reservas minerais usando a variância de interpolação. Revista Brasileira de Geociências, Brasil, v. 29, n. 3, p. 349-356, 1999.

YAMAMOTO, J. K. ; FURUIE, R. A. A survey into estimation of lognormal data. Geociências (UNESP. Impresso), v. 29, p. 5-19, 2010.

YAMAMOTO, J. K. ; ROCHA, M. M. Revisão e recomendaçōes para o cálculo e classificação de reservas minerais. Revista Brasileira de Geociências, v. 26, n. 4, p. 243-254, 1996.

YAMAMOTO, J. K. ; ROCHA, M. M. Conceitos Básicos. In: YAMAMOTO, J. K. Avaliação e classificação de reservas minerais. 1. ed. São Paulo: Editora da Universidade de São Paulo, 2001. 226 p. 


\section{ANEXO 1}

Definição da terminologia utilizada nos sistemas de classificação de recursos e reservas minerais baseados no Boletim CRIRSCO (CRISCO, 2006)

Recurso Mineral é uma concentração ou depósito mineral com interesse econômico dentro ou sobre a crosta terrestre de tal forma que ocorra em qualidade e quantidade razoáveis para eventual extração econômica lucrativa. Suas características são conhecidas, estimadas e interpretadas a partir de evidências geológicas. Recursos Minerais são subdivididos, de acordo com o nível de confiança geológica nas categorias: Inferido, Indicado e Medido.

Recurso Mineral Inferido é a parte do Recurso Mineral para a qual a tonelagem, teor e/ou qualidade e conteúdo mineral pode ser estimado com baixo nível de confiança. É inferido através de informações geológicas, mas não pode ser comprovado. É baseado em informações obtidas através de técnicas de amostragem em afloramentos, trincheiras, poços e sondagens. As informações são limitadas a ponto de não poder confirmar sua continuidade geológica.

Recurso Mineral Indicado è a parte do Recurso Mineral para a qual a tonelagem, teor, qualidade, densidade, forma, características físicas, e conteúdo mineral podem ser estimados com um nivel razoável de confiança. É baseado em informações geológicas de amostragem em afloramentos, trincheiras, poços e sondagens. As informações são espaçadas a ponto de não confirmar a continuidade geológica e/ou teor, mas é espaçado o suficiente a ponto desta continuidade ser assumida.

Recurso Mineral Medido é a parte do Recurso Mineral para a qual a tonelagem, teor, qualidade, densidade, forma, caracteristicas físicas, e conteúdo mineral podem ser estimados com elevado nivel de confiança. $E$ baseado em informações geológicas detalhadas e confiáveis de amostragem em afloramentos, trincheiras, poços e sondagens. Existem informações suficientes para confirmar a continuidade geológica e/ou teor.

Reserva Mineral é a parte do Recurso Mineral para a qual se demonstra viabilidade técnica e econômica para produção. Devem ser incluídos fatores de diluição e perdas desse material que podem ocorrer durante sua extração e 
beneficiamento para sua determinação. Estudos apropriados devem ser realizados onde deverão ser considerados os denominado fatores modificadores, que são fatores que podem inviabilizar a explotação de um recurso mineral. Entre eles estão os fatores de mineração, metalúrgicos, econômicos, de mercado, legal, ambiental, social e governamental. As avaliações devem ser demonstradas para a época em que se reportam as reservas e razoavelmente justificadas. Reservas Minerais são subdivididas, de acordo com o nível de confiança geológica, nas categorias Provada e Provável.

Reserva Mineral Provável é a parcela economicamente lavrável do Recurso Mineral Indicado e, em alguns casos, do Recurso Mineral Medido incluindo fatores de diluição e perdas desse material que podem ocorrer durante sua extração e beneficiamento. Estudos apropriados devem ser realizados onde deverão ser considerados os denominado fatores modificadores, que são fatores que podem inviabilizar a explotação de um recurso mineral. Entre eles estão os fatores de mineração, metalúrgicos, econômicos, de mercado, legal, ambiental, social e governamental. As avaliações devem ser demonstradas para a época em que se reportam as reservas e razoavelmente justificadas.

Reserva Mineral Provada é a parcela economicamente lavrável do Recurso Mineral Medido incluindo fatores de diluição e perdas desse material que podem ocorrer durante sua extração e beneficiamento. Estudos apropriados devem ser realizados onde deverão ser considerados os denominado fatores modificadores, que são fatores que podem inviabilizar a explotação de um recurso mineral. Entre eles estão os fatores de mineração, metalúrgicos, econômicos, de mercado, legal, ambiental, social e governamental. As avaliações devem ser demonstradas para a época em que se reportam as reservas e razoavelmente justificadas. 


\section{ANEXO 2 \\ Definição da terminologia utilizada no sistema de classificação de recursos e reservas minerais russo (Henley, 2000)}

Categoria A: As reservas são explotáveis e conhecida em detalhe. Os limites do depósito foram delineados por trincheiras, sondagens ou escavaçōes subterrâneas. A qualidade e propriedades do minério são conhecidas em detalhes suficientes para garantir a viabilidade da exploração projetada.

Categoria B: As reservas são explotáveis, mas conhecidas com pouco detalhe. Os limites do depósito foram delineados por trincheiras, sondagens ou escavações subterrâneas. A qualidade e propriedades do minério são conhecidas em detalhes suficientes para garantir a viabilidade da exploração projetada.

Categoria $C_{1:}$ As reservas foram estimadas por uma rede espaçada de trincheiras, furos de sonda ou trabahos subterâneos. Esta categoria inclui também as reservas contiguas as fronteiras das categorias $A$ e $B$ bem como as reservas de depósitos minerais muito complexos em que a distribuiçäo não pode ser determinada até mesmo por uma rede de amostragem muito densa. A qualidade e as propriedades do depósito são conhecidas expermentamente por meio de análises por analogia com depósitos conhecidos do mesmo tipo.

Categoria $C_{2}$ : Essas reservas são baseadas em uma rede de exploração mutto espaçada, com pouca infomação. Os limites do compo de minério são definidos principalmente por extrapolação dentro de estruturas geológicas conhecidas, bem como por comparação com ottros depósitos similares nas proximidades. As propriedades minerais e de teor são deteminados a partir de amostragem e comparação com depósitos minerais similares na árex. As resenvas foram extrapoladas partr de dados limitados, nutas vezes, por apenas um furo.

Categoria $P_{1:}$ Os recursos podem se estender para fora dos limites reais das reservas de minério definidos na Categonia $C_{2}$. Os limites dos recursos da Categonia $P_{1}$ são deteminados indiretamente por extrapolação a partir de depósitos minerais semelhantes conhecidos na área. 
Categoria $\mathbf{P}_{2}$ : Esses recursos representam possiveis depósitos minerais ou regiões com potencial. Eles são estimados com base em dados geofísicos e geoquímicos. Morfologia, composição mineral e tamanho do corpo de minério são estimados por analogia a depósitos minerais similares.

Categoria $P_{3}$ : Qualquer potencial de depósito mineral é classificado como recursos na Categoria $P_{3}$. A presença desses recursos depende da definição teórica de um "ambiente favorável geológico".

As estimativas de prognóstico de Recursos (P1, P2 e P3) rotineiramente dependem de pressupostos e projeções sobre suas prováveis dimensões (comprimento, largura e profundidade). O teor não é estimado devido à insuficiência de dados e só será definido depois de elevado, pelo menos, a Categoria $\mathrm{C}_{2}$. 


\section{ANEXO 3 \\ Definição da terminologia utilizada no sistema de classificação de recursos e reservas minerais brasileiro (DNPM, 1992)}

Recursos Identificados: recursos cuja localização, teor, quantidade e qualidade são conhecido ou estimados a partir de evidência geológica específica. Subdividemse em: Econômicos, Subeconômicos e Interditados.

Recurso Econômico: concentração de materiais sólidos, líquidos ou gasosos identificada in situ, aflorante ou subterrânea, quantificada exclusivamente com base em dados geocientíficos e um teor de corte geológico, da qual podem ser recuperadas substâncias úteis e valiosas. Este conceito implica numa indicação preliminar de economicidade, ou seja, de perspectivas razoáveis de aproveitamento econômico, a ser comprovado posteriormente. Os recursos podem ser classificados como: Medido, Indicado e inferido.

Recurso Medido: recurso comprovado por sondagens, escavações subterrâneas e outras formas de amostragem em pontos poucos espaçados de modo a assegurar a sua continuidade e cujos dados geocientíficos (forma, dimensão, densidade, qualidade e teor) são conhecidos com confiabilidade ou, alternativamente, recurso calculado com confiabilidade de pelo menos $95 \%$, para o qual o erro de estimação é no máximo de $20 \%$.

Recurso Indicado: recurso amostrado por sondagens, escavações subterrâneas e outras formas de amostragem em pontos com espaçamento insuficiente para assegurar a continuidade, porém suficiente para uma indicação razoável da mesma e cujos dados geocientíficos (forma, dimensão, densidade, qualidade e teor) são conhecidos com razoável nível de confiabilidade, ou, alternativamente, recurso calculado com confiabilidade de pelo menos $95 \%$, para o qual o erro de estimação é superior a $20 \%$ e inferior a $50 \%$.

Recurso Inferido: recurso estimado com base em inferências a partir de evidências geológicas, sondagens, escavações subterrâneas e outras formas de amostragem, onde ainda faltam informações de testes e amostragem que venham a permitir uma estimativa sistemática mais confiável, ou, 
alternativamente, recurso calculado com confiabilidade de pelo menos $95 \%$, para o qual o erro de estimação é superior a $50 \%$.

Recursos Subeconômicos: parte dos recursos identificados que não atende aos critérios econômicos estabelecidos à época da avaliação. Subdivide-se em:

Marginal: parte dos recursos subeconômicos que, à época da determinação, está no limite de ser produzido economicamente. Sua característica principal é a incerteza econômica. Estão aí incluídos recursos que seriam passíveis de serem produzidos através de mudanças de caráter econômico ou tecnológico.

Submarginal: parte dos recursos subeconômicos que vai requerer um substancial aumento no preço do bem mineral ou grandes avanços tecnológicos que provoquem uma maior redução nos custos, para torná-lo econômica.

Recursos Interditados: parte dos recursos identificados que se encontra em áreas ou situações de impedimento temporário ou permanente devido restrições legais ou regulamentares.

Recursos Não Identificados: recursos cuja existência é apenas presumida. Correspondem a corpos não individualizados de minérios ou substância mineral, existindo supostamente com base em conhecimentos geológicos e teorias de caráter amplo. Para refletir os graus variados de conhecimento geológico, eles podem ser subdivididos em:

Hipotéticos: recursos não identificados cuja existência pode ser razoavelmente esperada em um distrito mineiro conhecido sob condições geológicas conhecidas.

Especulativos: recursos não identificados que podem ocorrer tanto em tipos conhecidos de depósitos sob condições geológicas favoráveis (onde nenhuma descoberta foi realizada anteriormente), como em tipos convencionais de depósitos ainda não conhecidos por seu valor econômico.

Os Recursos Hipotéticos e Especulativos podem ser reclassificados como identificado, caso prospecção ou pesquisa confirme a sua existência. 
Reserva: parte ou totalidade de um recurso medido ou indicado, que pode ser lavrada e da qual podem ser recuperadas economicamente substâncias minerais úteis e valiosas sob condições consideradas realistas à época de avaliação técnicoeconômica. $E$ oriunda das estimativas prévias dos recursos econômicos nas quais devem necessariamente ser considerados fatores econômicos, técnicos (da mineração e da metalurgia), mercadológicos, ambientais, sociais, governamentais e legais. As reservas são classificadas como: provada e Provável.

Reserva Provada: parte ou totalidade de um recurso medido economicamente lavrável comprovada por sondagens, escavações subterrâneas e outras formas de amostragem em pontos pouco espaçados de modo a assegurar a sua continuidade e cujos dados geocientíficos (forma, dimensão, densidade, qualidade e teor) são conhecidos com confiabilidade ou, alternativamente, reserva calculada por métodos geoestatísticos onde o bloco estimado tenha dimensões pertinentes à escala de produção e proporcionalidade com os alcances variográficos e tenha no mínimo uma amostra na sua auréola de influência, o que equivale a determinar as relações de covariância amostra(s)/bloco, bloco/bloco e amostra(s)/amostra(s).

Reserva Provável: parte ou totalidade de um recurso indicado economicamente lavrável amostrada por sondagens, escavações subterrâneas e outras formas de amostragem em pontos com espaçamento insuficiente para assegurar a continuidade, porém suficiente para uma indicação razoável da mesma e cujos dados geocientificos (forma, dimensão densidade, qualidade e teor) são conhecidos com razoável nível de confiabilidade, em condições tais que o minério provavelmente será confirmado, ou, alternativamente, reserva calculada por métodos geoestatísticos onde o bloco estimado tenha dimensões pertinentes à escala de produção e proporcionalidade com os alcances variográficos e nenhuma amostra em sua auréola de influência, o que equivale a atribuir à variância de krigagem do bloco o valor da variância a priori mais o valor do covariograma do bloco. 